\title{
Toxicology of perfluorinated compounds
}

\author{
Thorsten Stahl $1^{1 *}$, Daniela Mattern ${ }^{2}$ and Hubertus Brunn²
}

\begin{abstract}
Perfluorinated compounds [PFCS] have found a wide use in industrial products and processes and in a vast array of consumer products. PFCs are molecules made up of carbon chains to which fluorine atoms are bound. Due to the strength of the carbon/fluorine bond, the molecules are chemically very stable and are highly resistant to biological degradation; therefore, they belong to a class of compounds that tend to persist in the environment. These compounds can bioaccumulate and also undergo biomagnification. Within the class of PFC chemicals, perfluorooctanoic acid and perfluorosulphonic acid are generally considered reference substances. Meanwhile, PFCs can be detected almost ubiquitously, e.g., in water, plants, different kinds of foodstuffs, in animals such as fish, birds, in mammals, as well as in human breast milk and blood. PFCs are proposed as a new class of 'persistent organic pollutants'. Numerous publications allude to the negative effects of PFCs on human health. The following review describes both external and internal exposures to PFCs, the toxicokinetics (uptake, distribution, metabolism, excretion), and the toxicodynamics (acute toxicity, subacute and subchronic toxicities, chronic toxicity including carcinogenesis, genotoxicity and epigenetic effects, reproductive and developmental toxicities, neurotoxicity, effects on the endocrine system, immunotoxicity and potential modes of action, combinational effects, and epidemiological studies on perfluorinated compounds).
\end{abstract}

Keywords: PFCs, PFOA, PFOS, toxicology

\section{Introduction}

Perfluorinated compounds [PFCs] are organic substances in which all of the hydrogens of the hydrocarbon backbones are substituted with fluorine atoms. The fluorine-carbon bonds are extremely stabile conferring these substances with very high thermal and chemical stability. PFCs are persistent, and some of the substances bioaccumulate in the environment.

They can be divided into the groups of perfluorinated sulfonic acids, perfluorinated carboxylic acids [PFCA], fluorotelomer alcohols, high-molecular weight fluoropolymers and low-molecular weight perfluoroalkanamides. Perfluorooctanesulfonic acid [PFOS] and perfluorooctanoic acid [PFOA], often referred to as reference or key substances for the first two groups, have been most intensively studied from a toxicological standpoint.

PFCs have been synthesized for more than 50 years and are used in numerous industrial and consumer products. These compounds are intermediates or additives in the synthesis of certain fluorine compounds or their

\footnotetext{
* Correspondence: thorsten.stahl@lhl.hessen.de

${ }^{1}$ Hessian State Laboratory, Glarusstr. 6, Wiesbaden, D-65203, Germany
} Full list of author information is available at the end of the article decomposition products. These fluorine compounds are commonly used in consumer products as stain/water/ grease repellents in carpets and clothing or in cooking utensils as nonstick coatings [1,2].

The potentially toxic effects of these substances are presently being studied with increasing intensity. The relevance of this topic is also clearly reflected by the number of publications that have appeared in recent years. This increasing interest is the result of reports of toxic effects of PFCs in connection with the ubiquitous detection of this substance in the environment and in sundry matrices, i.e., bodies of water, wild animals, human blood, and breast milk samples, all of which have come to the attention of the public.

An estimate was published in 2008 by the German Federal Institute for Risk Assessment [BfR] and the European Food Safety Authority [EFSA] regarding the potential risks of PFCs in food stuffs for human health. In this document, it was reasoned that adverse effects for the general population were unlikely, based on the known PFC concentrations in food stuffs and serum samples and the present state of scientific knowledge. However, uncertainty was noted in the risk evaluation, and available data are inadequate in regard to the 
diversity of foodstuffs. In addition, only PFOS and PFOA were considered in the risk evaluation, but according to the Organisation for Economic Co-operation and Development [OECD], 853 different poly- and perfluorinated compounds exist $[3,4]$.

In a European Union [EU]-supported research project, which began in August 2009 and was called Perfluorinated Organic compounds in our Food [PERFOOD], efforts are being made to estimate the dietary exposure to PFCs. The present review summarizes current data on exposure and provides an overview of the present toxicological evaluation of PFOS and PFOA, as well as other PFCs.

\section{Exposure to polyfluorinated compounds Exposure via the food chain Dietary uptake}

One of the pathways by which PFCs can be taken up is through the ingestion of contaminated foodstuffs and/or drinking water. PFCs have been detected in fish, meat, milk products, and plants, e.g., grains. Plants can apparently take up PFCs from contaminated soil. This hypothesis was examined by Weinfurtner et al. [5], showing that the transfer of PFCs from the soil to the plants for potatoes, silage corn, and wheat was so marginal that no health danger for humans would be expected by this path of uptake.

Stahl et al. [6] described for the first time a significant, concentration-dependent transfer ('carry over') of PFCs from the soil to the plant. The higher the concentration of PFOA and PFOS in the soil, the higher the concentration that could be detected in the plants. The uptake and storage of these substances in the vegetative parts of the plants appear to be more significant than the transfer to the storage organs within the plants. In this study, the uptake, distribution, and storage of PFOA and PFOS were seen to be dependent upon the type of plant. The uptake of PFOA and PFOS from contaminated soil by plants enables the entrance of PFCs into the food chain of humans and may provide an explanation for the presence of these compounds in, for example, foodstuffs of animal origin, human blood samples, and human breast milk [6].

Trudel et al. [7] reported that oral ingestion of contaminated foodstuffs and drinking water accounts for the largest proportion of PFOA and PFOS exposures for adults. Tittlemier et al. [8] and Haug et al. [9,10] also expressed the opinion that foodstuffs are the most important uptake path. Within the framework of the 'Canadian Total Diet Study, ' the authors calculated that Canadians ingest on an average of $250 \mathrm{ng}$ of PFCA and PFOS per day. Scheringer et al. [11] also had come to the conclusion that $90 \%$ of all PFOS and PFOA exposures is derived from food. Similarly, Vestergren and
Cousins [12] are convinced that the main exposure of humans to PFOA is through dietary uptake.

Fromme et al. [13] quantified PFC dietary exposure in Germany. The authors collected and analyzed 214 duplicate meals and beverages from 31 volunteers aged 16 to 45 years old on 7 days in a row. The samples were tested for content of numerous PFCs. The results for PFOS and PFOA uptake of the general population are presented in Table 1.

Perfluorohexane sulfonate [PFHxS] and perfluorohexane acid [PFHxA] levels above the limit of detection [LOD] of 0.1 or $0.2 \mu \mathrm{g} / \mathrm{kg}$ fresh weight, respectively, were detected in only a few samples (3\% and $9 \%$ of the 214 samples, respectively), whereas perfluorooctane sulfonamide FOSA] was not detected (LOD $=0.2 \mu \mathrm{g} / \mathrm{kg}$ fresh weight). These authors also assume that dietary uptake represents the main source of PFC exposure for humans [13].

Numerous foodstuffs were tested for the presence of PFOS, PFOA, and other PFCs within the framework of the 'UK Total Diet Study' in 2004. PFOS concentrations above the $\mathrm{LOD}^{\mathrm{a}}$ were detected in potatoes, canned vegetables, eggs, sugar, and preserves. Particularly striking was the group of potato products, where in addition to PFOD, PFOA and 10 other PFCs were detected. The upper and lower bounds of total PFOS and PFOA uptake from foodstuffs are estimated in Table 2[14,15].

Inhabitants of reputedly remote regions are by no means exempt from the uptake of PFCs in their food. In a recent study, Ostertag et al. [16] examined the dietary exposure of Inuit in Nunavut (Canada) to these substances. The authors calculated an average daily exposure of 210 to $610 \mathrm{ng} /$ person. The traditional foods such as caribou meat contributed to a higher PFC exposure for this population group. Caribou meat contributed $43 \%$ to $75 \%$ of the daily exposure [16].

In 2008, an exposure assessment was made on dietary uptake of PFOS and PFOA in connection with possible health effects. The report was based on published data concerning concentrations of PFOS and PFOA in various foods in Europe and on the amount of the individual foods consumed according to the 'Concise European Food Consumption Database' [15]. Since the data for other foods were inadequate to make an exposure assessment, it was based solely on the presence of PFOS and PFOA in fish and drinking water. The results

Table 1 Dietary uptake of PFOS and PFOA (ng/kg BW/ day) by adults in Germany

\begin{tabular}{lcccc}
\hline Substance & Range & Mean & Average & 90th percentile \\
\hline PFOS & 0.6 to 4.4 & 1.4 & 1.8 & 3.8 \\
PFOA & 1.1 to 11.6 & 2.9 & 3.9 & 8.4 \\
\hline
\end{tabular}

Adapted from Fromme et al. [13]; $n=214$. 
Table 2 PFOS and PFOA uptake (ng/kg BW/day) from UK Total Diet Study of adults and children

\begin{tabular}{lcccc}
\hline Substance & \multicolumn{2}{c}{ Average consumption } & \multicolumn{2}{c}{ Heavy consumption } \\
& Adults & Children $^{\text {a }}$ & Adults & Children $^{\text {a }}$ \\
\hline PFOS & 10 to 100 & 50 to 300 & 30 to 200 & 100 to 500 \\
PFOA & 1 to 70 & 4 to 200 & 3 to 100 & 10 to 300 \\
\hline
\end{tabular}

${ }^{a}$ In each case, the age group with the highest estimated uptake is listed. Adapted from UK FSA [14]; EFSA [15].

of the exposure assessment for PFOS suggest a daily exposure of $60 \mathrm{ng} / \mathrm{kg}$ body weight [BW] for persons who consume average amounts of fish or $200 \mathrm{ng} / \mathrm{kg} \mathrm{BW}$ those who consume large amounts of fish. For PFOA, the daily uptake was estimated at $2 \mathrm{ng} / \mathrm{kg} \mathrm{BW/day,} \mathrm{and}$ for those who eat larger amounts of fish and fish products, the estimate was $6 \mathrm{ng} / \mathrm{kg} \mathrm{BW/day} \mathrm{[15].}$

The estimated consumption of drinking water was 2 $\mathrm{L} /$ person/day. The uptake from drinking water of PFOS and PFOA were ca. $0.5 \%$ and $18 \%$, respectively, of the average amount taken up by consumption of fish and fish products. For further details, see Table 3.

The German BfR [17] also undertook an assessment of dietary exposure of the general population to PFOS and PFOA. As a basis for the calculations, the Federal Office of Consumer Protection and Food Safety provided data on PFC concentrations in foods from 2006 to 2008. The data were, for the most part, derived from the Federal Control Plan (2007) 'Perfluorinated surfactants in specific foods' and encompassed 3, 983 test results on contents of PFOS (1993 data sets) and PFOA (1990 data sets) in foodstuffs. Concentrations of the substances were measured in chicken eggs, beef and poultry liver, pork, game and fish offal, poultry and game meat, salt water and fresh water fish, French fries, honey, and drinking water. In addition, the records contained data on the consumption of food and food products by the German population derived from a survey made in 1998. Since one must assume that for over a longer period of time, some foods that have a higher PFC concentration and others with a lower concentration will be consumed, the statistical calculations were made using an average ${ }^{b}$ value. In addition, the possibility had to be considered that foods that have exceptionally high concentrations may be consumed perhaps because of unusual local paths of entry. Therefore, exposure through particularly heavily contaminated foods was quantified for both average and above average consumers. The following scenarios were assumed for exposure assessment:

- Average concentration of PFOS and/or PFOA and average amounts consumed

- High concentration of PFOS and/or PFOA and average amounts consumed

- Average concentration of PFOS and/or PFOA and large amounts consumed

- High concentrations of PFOS and/or PFOA and large amounts consumed (worst case).

The PFOS and PFOA dietary uptake of the general population, divided into the four scenarios described above, can be seen in Table 4. In addition, the table shows the percentage of the EFSA-derived tolerable daily intake [TDI] calculated for PFOS and PFOA uptake.

In this exposure assessment, drinking water played a relatively small role in the total exposure to PFOS. The average PFOS uptake from drinking water by an average consumer amounted from 0.02 to $0.08 \mathrm{ng} / \mathrm{kg} \mathrm{BW} /$ day. The average PFOA uptake from drinking water, however, amounted from 0.32 to $0.40 \mathrm{ng} / \mathrm{kg} \mathrm{BW} /$ day. Thus, the total PFOA uptake, including drinking water, amounted from 1.03 to $1.34 \mathrm{ng} / \mathrm{kg} \mathrm{BW} /$ day for an average consumer [17]. If, however, the water is contaminated by an unusual source of PFCs, the role of drinking water in exposure to these substances may be considerable. This was the case, for example, in Arnsberg, Germany where the source of drinking water in 2006 was the PFC-contaminated river, Möhne [18]. Hölzer et al. [19] measured a PFOA concentration 4.5 to 8.3 times higher in the blood plasma of residents than in the plasma of a reference population from the neighboring towns, Siegen and Brilon. The mean concentrations of PFOA in the blood are shown in Table 5. The highest PFC concentration detected in the contaminated drinking water was for PFOA [19].

Table 3 PFOS and PFOA uptake through consumption of drinking water and fish and fish products

\begin{tabular}{lccc}
\hline $\begin{array}{l}\text { Substance and percentage of } \\
\text { uptake from drinking water }\end{array}$ & $\begin{array}{c}\text { Uptake from } \\
\text { drinking water }\end{array}$ & $\begin{array}{c}\text { Uptake from average consumption of fish } \\
\text { and fish products (ng/kg BW/day) }\end{array}$ & $\begin{array}{c}\text { Uptake from high consumption of fish } \\
\text { and fish products (ng/kg BW/day) }\end{array}$ \\
\hline PFOS & 0.24 & 45 to 58 & 140 to 230 \\
$\begin{array}{l}\text { Percentage of uptake from } \\
\text { drinking water }\end{array}$ & $0.4 \%$ to $0.5 \%$ & $0.1 \%$ to $0.2 \%$ \\
PFOA & 0.31 & 1.7 to 2.1 & 4.5 to 7.5 \\
$\begin{array}{l}\text { Percentage of uptake from } \\
\text { drinking water }\end{array}$ & $15 \%$ to $18 \%$ & $4 \%$ to $7 \%$ \\
\hline
\end{tabular}

Adapted from EFSA [15]. 
Table 4 PFOS and PFOA dietary exposure model (ng/kg BW/day) according to uptake scenarios and corresponding TDI

\begin{tabular}{|c|c|c|}
\hline Criterion & Average consumption & High consumption $^{\mathrm{b}}$ \\
\hline Average PFOS content & 2.30 to 3.69 & up to 8.92 \\
\hline Percentage of TDI ${ }^{\mathrm{a}}$ & $1.5 \%$ to $2.5 \%$ & $5.9 \%$ \\
\hline High PFOS content & 8.53 to 10.22 & up to 26.02 \\
\hline Percentage of TDI & $5.7 \%$ to $6.8 \%$ & $17.3 \%$ \\
\hline Average PFOA content & 0.71 to 0.95 & up to 2.07 \\
\hline Percentage of TDI & $0.05 \%$ to $0.06 \%$ & $0.14 \%$ \\
\hline High PFOA content & up to 5.7 & up to 13.11 \\
\hline Percentage of TDI & $0.38 \%$ & $0.87 \%$ \\
\hline
\end{tabular}

${ }^{\mathrm{a}}$ TDI for PFOS $=150 \mathrm{ng} / \mathrm{kg} \mathrm{BW/day,} \mathrm{TDI} \mathrm{for} \mathrm{PFOA} \mathrm{=} \mathrm{1,} 500 \mathrm{ng} / \mathrm{kg}$ BW/day (adapted from EFSA [15]); ${ }^{b}$ the 95 th percentile of the assumed amount of consumption was chosen for the calculation. The model calculation was adapted from BfR [17].

In a follow-up study, it was shown that elimination of PFCs from humans occurs slowly. The geometric mean of the PFOA concentrations in plasma decreased on an average of $10 \%$ per year for men, $17 \%$ per year for women, and $20 \%$ per year for children [20].

Another study showed that there was no increased PFC exposure in this region in 2006 before contamination of the drinking water. Samples of blood from 30 residents that had been drawn between 1997 and 2004 contained PFOS and PFOA concentrations comparable with those of the general population in Germany [21].

After concentrations as high as $0.64 \mu \mathrm{g} / \mathrm{L}$ were measured in drinking water in Arnsberg in 2006, the German Drinking Water Commission derived a critical limit of $0.3 \mu \mathrm{g} / \mathrm{L}$ for a health-based, lifelong exposure to PFOS and PFOA in drinking water. PFOS and PFOA concentrations in drinking water can be reduced by active charcoal filtration. Use and manufacture of PFOS are strictly limited by legal regulation, and a voluntary reduction of PFOA is being sought. Therefore, the focus of a study by Wilhelm et al. [22] was placed on shortchain C4-C7 compounds that are presently finding use as substitutes for PFOS and PFOA. In a new approach to evaluate short-chain PFCs, based on their half-life in humans, the following preliminary health-related indication values were considered safe for a lifelong exposure via drinking water: $7 \mu \mathrm{g} / \mathrm{L}$ for perfluorobutanoic acid [PFBA], $3 \mu \mathrm{g} / \mathrm{L}$ for perfluoro-n-pentanoic acid [PFPeA],

Table 5 Arithmetic/geometric mean of PFOS concentration in the blood $(\mu \mathrm{g} / \mathrm{L})$

\begin{tabular}{lcc}
\hline Test person & Resident of Arnsberg & Reference population \\
\hline Children & $24.6 / 22.1$ & $5.2 / 4.8$ \\
Women & $26.7 / 23.4$ & $3.2 / 2.8$ \\
Men & $28.5 / 25.3$ & $6.4 / 5.8$ \\
\hline
\end{tabular}

Residents of Arnsberg were compared with the reference population (adapted from Hölzer et al. [19]).
$1 \mu \mathrm{g} / \mathrm{L}$ for PFHxA, $0.3 \mu \mathrm{g} / \mathrm{L}$ for perfluoroheptanoic acid [PFHpA], $3 \mu \mathrm{g} / \mathrm{L}$ for perfluorobutanesulfonic acid [PFBS], $1 \mu \mathrm{g} / \mathrm{L}$ for perfluoropentane-1-sulfonic acid [PFPeS], $0.3 \mu \mathrm{g} / \mathrm{L}$ for PFHxS, and $0.3 \mu \mathrm{g} / \mathrm{L}$ for perfluoroheptane sulfonic acid [PFHpS]. A long-range minimum quality goal or general precautionary value for all PFCs in drinking water was set at $\leq 0.1 \mu \mathrm{g} / \mathrm{L}$ [22].

A study by Mak et al. [23] compared PFC concentrations in tap water from China with that from Japan, India, the USA, and Canada. Samples were collected between 2006 and 2008. Tap water from Shanghai, China contained the highest concentration of PFCs (arithmetic mean sum PFCs $0.13 \mu \mathrm{g} / \mathrm{L}$; PFOA $0.078 \mu \mathrm{g} /$ $\mathrm{L})$. The lowest values were obtained from Toyama, Japan $(0.00062 \mu \mathrm{g} / \mathrm{L})$. In addition to PFOS and PFOA, drinking water appears to also contain short-chain PFCs such as PFHxS, PFBS, PFHxA, and PFBA. In relation to the guidelines set down by the United States Environmental Protection Agency [US EPA] and the Minnesota Department of Health (PFOS $0.2 \mu \mathrm{g} / \mathrm{L}$, PFOA $0.4 \mu \mathrm{g} / \mathrm{L}$, PFBA $1.0 \mu \mathrm{g} / \mathrm{L}$, PFHxS $0.6 \mu \mathrm{g} / \mathrm{L}$, PFBS $0.6 \mu \mathrm{g} / \mathrm{L}$, PFHxA $1.0 \mu \mathrm{g} / \mathrm{L}$, PFPeA $1.0 \mu \mathrm{g} / \mathrm{L}$ ), tap water from these countries should not present a health risk for consumers, in respect to PFC contamination [23].

In a review article from Rumsby et al. [24] on PFOS and PFOA in drinking water and in diverse environmental bodies of water, the authors also conclude that PFOS and PFOA are detectable worldwide. Aside from situations in which there are unusual sources of contamination, the concentrations measured are, however, below existing health-based guidelines specified by various international bodies $(0.3$ to $0.5 \mu \mathrm{g} / \mathrm{L})$. Nonetheless, further studies of short-chain PFCs such as PFBS must be undertaken. This substance has a shorter half-life, is less toxic, and is not bioaccumulative, but it is nonetheless persistent, and its possible degradation products remain unknown [24].

D'Eon et al. [25] point out that perfluorinated phosphonic acids [PFPAs] should also be measured in future environmental monitoring studies. These substances were detected in $80 \%$ of all surface water samples and in six out of seven sewage treatment plant outflow samples in Canada. C8-PFPA was detected in concentrations from $0.088 \pm 0.033$ to $3.4 \pm 0.9 \mathrm{ng} / \mathrm{L}$ in surface water and from $0.76 \pm 0.27$ to $2.5 \pm 0.32 \mathrm{ng} / \mathrm{L}$ in sewage treatment plant outflow samples. Since they are structurally similar, one can assume that just like perfluorocarboxilic acids and perfluorosulfonic acids, PFPAs are also persistent [25].

\section{Human exposure via fish consumption}

In addition to drinking water, PFC accumulation in fish is also of particular importance for the internal contamination of humans. According to the exposure assessment of the German BfR consumption of salt water and 
fresh water, fish accounts for approximately $90 \%$ of the total dietary exposure to PFOS [17].

The fact that fish are often highly contaminated is a result of the pronounced biomagnification of these substances via the aquatic food chain. The role of fish consumption is apparent in a model calculation by Stahl et al. [26]. Based on the recommendation of the BfR of 0.1 $\mu \mathrm{g}$ PFOS/kg BW/day as a preliminary daily tolerable uptake, a $70-\mathrm{kg}$ adult should not exceed $7 \mu \mathrm{g}$ of PFOS [26]. Eating reasonable amounts of fish with high levels of contamination, i.e., from bodies of water with unusual sources of PFCs, may in itself result in reaching or exceeding this limit for the short term [26]. For example, eating $8 \mathrm{~g}$ of eel from Belgium with a concentration of $857 \mu \mathrm{g}$ PFOS $/ \mathrm{kg}$ fresh weight or eating $0.6 \mathrm{~g}$ of trout from the upper Sauerland region of Germany with a measured maximum level of $1,118 \mu \mathrm{g} / \mathrm{kg}$ fresh weight, is already adequate. Consumption of a normal portion (300 g) of these trout would result in exceeding the limit by a factor of 57 [26]. PFC contamination of fish was also dealt within the following studies:

As an example, analysis was made from a total of 51 eels, 44 bream, 5 herring, 5 mackerel, 3 carp, and 4 trout from various bodies of water in Germany (North Sea, Baltic Sea, Lake Storko in Brandenburg, rivers in Lower Saxony, rivers and lakes within the city limits of Berlin). None of the fish fillet samples had PFOA levels above the limit of detection $(0.27 \mu \mathrm{g} / \mathrm{kg})$; however, PFOS concentrations of 8.2 to $225 \mu \mathrm{g} / \mathrm{kg}$ fresh weight were measured in fish from densely populated regions. With regard to the TDI of $150 \mu \mathrm{g} / \mathrm{kg} \mathrm{BW/day} \mathrm{[15]} \mathrm{and}$ assuming the consumption of fish on a regular basis, the PFC concentrations in 33 of the 112 fish examined represent a potential health risk to heavy consumers of fish [27].

In a Swedish study, the authors also came to the conclusion that consumption of fish from fishing grounds with high concentrations of PFCs in the water can play an important role in dietary PFOS exposure [28]. Fish from Lake Vättern (mean 2.9 to $12 \mu \mathrm{g} / \mathrm{kg}$ fresh weight) had higher PFOS concentrations in the muscle tissue than fish from the brackish water of the Baltic Sea (mean 1.0 to $2.5 \mu \mathrm{g} / \mathrm{kg}$ fresh weight). A PFOS uptake of $0.15 \mathrm{ng} / \mathrm{kg} \mathrm{BW} /$ day was estimated for a moderate consumption (two portions of $125 \mathrm{~g} /$ month) and $0.62 \mathrm{ng} / \mathrm{kg}$ $\mathrm{BW} /$ day for a higher consumption (eight portions per month) of fish from the Baltic Sea. A PFOS uptake of $2.7 \mathrm{ng} / \mathrm{kg} \mathrm{BW} /$ day was calculated for people who eat large amounts of fish from Lake Vättern.

No foods that have been examined to date other than fish were found to have a level of contamination great enough to result in reaching the TDI for PFOS or PFOA, assuming realistic consumed amounts. By way of example, according to the model calculations shown above, an adult in the USA would have to consume 12 $\mathrm{kg}$ of beef $(0.587 \mu \mathrm{g}$ PFOS $/ \mathrm{kg})$ or $12 \mathrm{~L}$ of milk $(0.693 \mu \mathrm{g}$ PFOS/L) per day (at the measured levels of contamination in the USA) in order to reach the TDI [26].

Furthermore, offal from game contained the highest concentrations of PFOS and PFOA of all foods. The PFOS concentrations in offal from game were 100-fold higher than those in muscle tissues [17]. Data from a number of studies reporting PFC concentrations measured in diverse foods and tap water [7,14,17,29] are summarized in Table 6.

A detailed, up-to-date survey on the presence of PFCs in foods was also recently published by the EFSA [30] with the title 'Results of the monitoring of perfluoroalkylated substances in food in the period 2000 to 2009.'

When making an exposure assessment, it is important to take into account the fact that many different foods are generally consumed. Studies with the aim of representing the total dietary intake are both quantitatively and qualitatively inadequate. For example, in the various studies including those of the EFSA and the BfR, only a selection of foods were included. In addition, the number of samples was, in part, too small to provide a representative value. For these reasons, the exposure assessments presently available should be considered exploratory. Specific regional sources of contamination can increase PFC levels in foods and drinking water. Furthermore, individual dietary habits, i.e., a predilection for fish or offal from game, must be considered, and additionally, perfluorinated compounds other than PFOS and PFOA must be monitored. Since most studies have examined fresh and unpackaged foods, the effects of migration of PFCs from packaging and cooking utensils on the food products have not been taken into consideration.

\section{Exposure of food to food contact materials}

When coming into contact with foods, paper and cardboard packaging are protected from softening by treatment with, among other things, water- and oil-resistant perfluoro chemicals. Fluorotelomer alcohols [FTOH] may be present as contaminants in the coatings. About $1 \%$ of the FTOH can be converted to PFOA in the body $[31,32]$. Furthermore, PFOA is used in the production of polytetrafluoroethylene [PTFE] nonstick surface coatings for cooking utensils or paper coatings and may therefore be present in residual amounts [33]. A migration of $<6 \mu \mathrm{g} / \mathrm{kg}\left(<1 \mu \mathrm{g} / \mathrm{dm}^{2}\right)$ FTOH into food has been calculated as the sum of 6:2 FTOH, 8:2 FTOH, and 10:2 FTOH in an acetone extract of treated paper under the assumption of complete migration [15,33]. Powley et al. [34], using liquid chromatography coupled with tandem mass spectrometry were unable to detect a migration of PFOA from PFTE-coated cooking utensils (LOD $0.1 \mathrm{ng} / \mathrm{cm}^{2}$ ). 
Table 6 PFOS and/or PFOA concentrations of various foods $(\mu \mathrm{g} / \mathrm{kg})$

\begin{tabular}{|c|c|c|c|c|c|}
\hline Food product & Substance & $\begin{array}{c}\text { Germany } \\
{[17]}\end{array}$ & $\begin{array}{c}\text { Europe } \\
\text { [7] }\end{array}$ & $\begin{array}{c}\text { Spain } \\
\text { [29] }\end{array}$ & $\begin{array}{c}\text { UK } \\
{[14]}\end{array}$ \\
\hline \multirow[t]{2}{*}{ Grain products } & PFOS & n.r. & $<\mathrm{LOQ}$ & $<0.069$ & $<10 \pm<2$ \\
\hline & PFOA & n.r. & $<\mathrm{LOQ}$ to 0.5 & $<0.080$ & $<5 \pm<1$ \\
\hline \multirow[t]{2}{*}{ Milk } & PFOS & n.r. & $<\mathrm{LOQ}$ to 0.5 & $<0.014$ & $<0.5 \pm<0.1$ \\
\hline & PFOA & n.r. & $<\mathrm{LOQ}$ & 0.056 & $<0.5 \pm<0.1$ \\
\hline \multirow[t]{2}{*}{ Milk products } & PFOS & n.r. & 0.04 to 0.08 & 0.121 & $<5 \pm<1$ \\
\hline & PFOA & n.r. & $<\mathrm{LOQ}$ & $<0.040$ & $<5 \pm<1$ \\
\hline \multirow[t]{2}{*}{ Eggs } & PFOS & 0.51 & 0.08 to 0.5 & 0.082 & $1 \pm 0.2$ \\
\hline & PFOA & 1.6 & $<\mathrm{LOQ}$ & $<0.055$ & $<1 \pm<0.2$ \\
\hline \multirow[t]{2}{*}{ Fats and oils } & PFOS & n.r. & $<\mathrm{LOQ}$ & $<0.099$ & $<0.5 \pm<0.1$ \\
\hline & PFOA & n.r. & $<\mathrm{LOQ}$ & $<0.247$ & $<1 \pm<0.2$ \\
\hline \multirow[t]{2}{*}{ Fish } & PFOS & 9 to 67 & 0.2 to 60 & 0.407 & $<5 \pm<1$ \\
\hline & PFOA & 1.3 to 2 & $<$ LOQ to 2 & $<0.065^{a}$ & $<3 \pm<0.6$ \\
\hline \multirow[t]{2}{*}{ Meat } & PFOS & n.d. & 0.03 to 0.5 & 0.045 & $<10 \pm<2$ \\
\hline & PFOA & n.d. & $<$ LOQ to 1 & $<0.053^{\mathrm{b}}$ & $<2 \pm<0.4$ \\
\hline \multirow[t]{2}{*}{ Offal from game } & PFOS & 172 & n.r. & n.r. & n.r. \\
\hline & PFOA & 4.3 to 6.9 & n.r. & n.r. & n.r. \\
\hline \multirow[t]{2}{*}{ Fruits } & PFOS & n.r. & 0 & $<0.017$ & $<2 \pm<0.4$ \\
\hline & PFOA & n.r. & $<\mathrm{LOQ}$ to 0.3 & $<0.036$ & $<5 \pm<1$ \\
\hline \multirow[t]{2}{*}{ Vegetables } & PFOS & n.d. & $<\mathrm{LOQ}$ to 0.5 & 0.022 & $<3 \pm<0.6$ \\
\hline & PFOA & n.d. & $<\mathrm{LOQ}$ to 0.3 & $<0.027$ & $<10 \pm<2$ \\
\hline \multirow[t]{2}{*}{ Potatoes } & PFOS & 1.2 & 4 to 8 & n.r. & $10 \pm 2$ \\
\hline & PFOA & n.d. & 0.4 to 2 & n.r. & $1 \pm 0.2$ \\
\hline \multirow[t]{2}{*}{ Candies/Honey/Sugar } & PFOS & n.d. & 0.8 to 1.2 & n.r. & $1 \pm 0.2$ \\
\hline & PFOA & 0.5 & $<\mathrm{LOQ}$ & n.r. & $<1 \pm<0.2$ \\
\hline \multirow[t]{2}{*}{ Tap water } & PFOS & 0.004 to 0.008 & $<\mathrm{LOQ}$ to 0.01 & n.r. & n.r. \\
\hline & PFOA & 0.02 to 0.13 & $<$ LOQ to 0.2 & n.r. & n.r. \\
\hline
\end{tabular}

${ }^{\mathrm{a} F i s h}$; ${ }^{\mathrm{b}}$ pork; n.r., not reported; n.d., not detected; LOQ, limit of quantification.

Begley et al. [35] showed that nonstick cooking utensils contribute less to PFC exposure to food than coated papers or cardboard boxes. Residual amounts of PFOA in the range of a few micrograms per kilogram or nanograms per gram were all that could be detected in PTFE cooking utensils. Of the total amount of PFOA in a PTFE strip, $17 \%\left(30 \mathrm{ng} / \mathrm{dm}^{2}\right)$ migrated into the food simulant heated to $175^{\circ} \mathrm{C}$ for $2 \mathrm{~h}$. In contrast, some paper and cardboard surface coatings contained large amounts of PFCs. For example, microwave popcorn bags were found to contain 3 to $4 \mathrm{mg} / \mathrm{kg}\left(11 \mu \mathrm{g} / \mathrm{dm}^{2}\right)$.

After heating, the PFOA concentration in the popcorn itself was about $300 \mu \mathrm{g} / \mathrm{kg}$. PFOA migrated into the oil that coated the popcorn. Migration was enhanced by a temperature of $200^{\circ} \mathrm{C}$ [35].

Sinclair et al. [36] examined the emission of residual PFOA and FTOH from nonstick cooking utensils and microwave popcorn bags upon heating to normal cooking temperatures $\left(179^{\circ} \mathrm{C}\right.$ to $233^{\circ} \mathrm{C}$ surface temperature). Heating nonstick frying pans released $7 \mathrm{ng}$ to $337 \mathrm{ng}$ (0.11 to $5.03 \mathrm{ng} / \mathrm{dm}^{2}$ ) PFOA in the gas phase. Furthermore, concentrations of $6: 2 \mathrm{FTOH}$ and 8:2 FTOH of
$<0.15$ to $2.04 \mathrm{ng} / \mathrm{dm}^{2}$ and 0.42 to $6.25 \mathrm{ng} / \mathrm{dm}^{2}$ were detected. Repeated use of some frying pans was observed to result in a reduction in PFOA concentrations emitted in the gas phase. However, this was not the case for all frying pans from all of the manufacturers tested. In addition, 5 to $34 \mathrm{ng}$ PFOA and $223 \pm 37 \mathrm{ng}$ (6:2 FTOH) as well as $258 \pm 36 \mathrm{ng}(8: 2 \mathrm{FTOH})$ per bag were detected in the emitted vapor from microwave popcorn bags [36].

Tittlemier et al. [37], in the Canadian Total Diet Study, examined food samples between 1992 and 2004 for contamination with $\mathrm{N}$-ethylperfluorooctyl sulfonamide [ $N$-EtFOSA], FOSA, $N, N$-diethyl-perfluorooctanesulfonamide, $N$-methylperfluorooctyl sulfonamide, and $\mathrm{N}, \mathrm{N}$-dimethyl-perfluorooctanesulfonamide. FOSA, in ng/ $\mathrm{kg}$ and a few $\mu \mathrm{g} / \mathrm{kg}$ amounts, was detected in all food products tested (pastries, candies, milk products, eggs, fast-food products, fish, meat, and convenience foods). The highest concentrations (maximum $27.3 \mu \mathrm{g} / \mathrm{kg}$ ) were found in fast-food products (French fries, sandwiches, pizza), which are foods that are commonly packaged in grease-proof paper. Dietary FOSA uptake in Canada was 
estimated to be $73 \mathrm{ng} /$ person/day. The $N$-EtFOSA concentrations in the samples seem to drop throughout the time period of sampling. This is possibly the result of fact that manufacturing of perfluoro octylsulfonyl compounds was discontinued $[37,38]$.

In studies of packaged food products carried out by Ericson Jogsten et al. [39], PFHxS, PFOS, PFHxA, and PFOA were detected at levels above the LOD (PFHxS $0.001 \mu \mathrm{g} / \mathrm{kg}$, PFOS $0.008 \mu \mathrm{g} / \mathrm{kg}$, PFHxA $0.001 \mu \mathrm{g} / \mathrm{kg}$, PFOA $0.063 \mu \mathrm{g} / \mathrm{kg}$ ) in at least one mixed-food sample. Among the packaged foods tested were goose liver paté, deep-fried chicken nuggets, frankfurters, marinated salmon, and head lettuce [39].

Similar to the results of Begley et al. [35], the US Food and Drug Administration [FDA] named coated paper as the largest possible source of fluorochemicals. According to the FDA, nonstick frying pans are, by comparison, an insignificant source of PFCs [15]. In the ninth list of substances for food contact materials, the EFSA Panel on food additives, flavourings, processing aids and materials in contact with food [AFC] recommends limiting the use of ammonium perfluorooctanoate [APFO] for articles with repeated use to those on which the coating is baked at a high temperature. According to the analytical data, APFO, as auxiliary material in the production of PTFE, could not be detected at levels above the LOD of $20 \mu \mathrm{g} / \mathrm{kg}$ in the finished product. In the worst case, the AFC determined an APFO migration of $17 \mu \mathrm{g} / \mathrm{kg}$ food [15]. As a result of advances in food technology, contamination of foodstuffs during manufacturing, packaging, or cooking only plays a minor role in the total exposure of humans to PFCs [15].

The German Federal Environment Agency has rated the uptake of PFCs through the use of nonstick pots and pans as low. The available data are, however, not yet adequate for a reliable assessment of PFC exposure through food contact materials [4].

Several studies point out the possibility of underestimation of PFC exposure through food contact materials. Mixtures of perfluorooctanesulfonamide esters are often used in the manufacture of water-and greaseproof papers and cardboards. These perfluorooctylsulfonyl compounds have yet to be studied. They may remain as residues in the coatings and migrate into the food.

D'Eon and Mabury [40] examined the formation of PFCA through the biotransformation of polyfluoroalkyl phosphate surfactants [PAPS]. The authors showed that, in spite of their large molecular size, these substances are bioavailable and that PFOA and other PFCs may be formed by their biotransformation. PAPS can probably be degraded by dephosphorylating enzymes in organisms because of the phosphate-ester bond between the fluorinated part and the acidic head group. However, it should be noted that the rats in this study were fed high oral doses of $200 \mathrm{mg} / \mathrm{kg}$ PAPS. Renner raises concerns of the fact that PAPS may migrate much more effectively into emulsions such as butter, margarine, or lecithin additives than into food simulants such as oil or water $[40,41]$.

The fact that studies using conventional food simulants do not accurately reflect the actual migration of fluorochemicals into food was confirmed by Begley et al. [42]. They recommend an emulsion containing oil as simulant for greasy food products. The authors measured the migration of three PAPS from the paper packing material, finding $3.2 \mathrm{mg} / \mathrm{kg}$ in popcorn after preparation and $0.1 \mathrm{mg} / \mathrm{kg}$ in packaged butter after a 40-day storage by $4^{\circ} \mathrm{C}[42]$.

$\mathrm{Lv}$ et al. [43] determined the contents of PFOA and PFOS in packing materials and textiles by means of liquid extraction under pressure and subsequent gas chromatography coupled with mass spectroscopy analysis. PFOA concentrations of 17.5 to $45.9 \mu \mathrm{g} / \mathrm{kg}$ and PFOS concentrations of 17.5 to $45.9 \mu \mathrm{g} / \mathrm{kg}$ were found in the packing materials and textiles tested [43].

Given the present state of knowledge, it is not possible to say whether the use of nonstick-coated cooking utensils or packaging materials with PFC-based coating lead to a significant increase in dietary internal PFC contamination of humans.

\section{Additional potential pathways of exposure leading to internal polyfluorinated compound contamination of humans}

PFCs may also enter the body by ingestion of dust and dirt particles and by contact with products that have been treated with substances that contain PFCs or its precursor compounds $[9,44]$. These may include carpets, upholstered furniture, or textiles. These routes of entry may be of particular importance in regard to children because contact can occur indirectly by hand-to-mouth transfer or directly if an infant sucks on the product. Another route that must be considered is inhalation of PFCs in indoor or outdoor air $[10,45,46]$ as well as the inhalation of waterproofing sprays. Dermal exposure may also occur by skin contact with PFC-treated products [17].

\section{Exposure via non-food personal items}

An estimate of exposure via non-food products is difficult because of the large number of possible applications of PFCs such as for jackets, trousers, shoes, carpets, upholstered furniture, and as cleaning agents. In addition, only data are available concerning possible PFCs exposure via non-food products. In order to make an estimation of exposure, research groups such as Washburn et al. [47] have resorted to the use of models.

In this study, the concentrations of deprotonated PFOA [PFO] (the anion of PFOA) were determined by 
Table 7 PFO concentrations in consumer articles (from Washburn et al. [47])

\begin{tabular}{lccc}
\hline Product group & $\begin{array}{c}\text { Concentration according to } \\
\text { information on product composition } \\
\text { (mg PFO/L) }\end{array}$ & $\begin{array}{c}\text { Calculated total concentration in the } \\
\text { end product (mg PFO/kg end } \\
\text { product) }\end{array}$ & $\begin{array}{c}\text { Results of the extraction tests from } \\
\text { the end product (ng PFO/cm }\end{array}$ \\
product)
\end{tabular}

extraction tests and information about the composition of the products. Values from the study by Washburn et al. [47] are shown in Table 7.

Age-specific behavior was taken into account in order to assess the PFO exposure of consumers through contact with these products. A one-compartment model was chosen to determine the contribution of PFC-treated non-food products to the concentration of PFO in serum, and a dermal absorption coefficient of $1.0 \times 10^{-5}$ per hour was adopted. The values obtained are hypothetical and are categorized as more typical exposure [MTE] or reasonable maximum exposure [RME] scenarios. An assumable daily total PFOA exposure via nonfood articles for adults was estimated at $0.09 \mathrm{ng} / \mathrm{kg} \mathrm{BW}$ (MTE). The maximum uptake of PFOA was estimated at $3.1 \mathrm{ng} / \mathrm{kg} \mathrm{BW}$ (RME). According to this assessment, the exposure would drop by one or two orders of magnitude upon reaching adulthood because of the low frequency of hand-to-mouth transfer [15,47].

\section{Exposure via indoor and outdoor air}

Based on studies in Japan [48] and Canada [49], the EFSA determined the lifetime average daily dose [LADD] via ingestion, inhalation, and skin contact with contaminated house dust in interior rooms. The corresponding data are presented in Table 8. These calculations by the EFSA are based on mean PFC concentrations of $0.440 \mathrm{ng}$ PFOS $/ \mathrm{kg}$ and $0.380 \mathrm{ng}$ $\mathrm{PFOA} / \mathrm{kg}$ in house dust. The exposure to PFOS and

Table 8 PFOS and PFOA uptake via inside air (ng/kg BW/ day; from EFSA [15])

\begin{tabular}{lcc}
\hline Exposure source & PFOS uptake & PFOA uptake \\
\hline Ingestion of house dust & 0.57 & 0.49 \\
Skin contact with house dust & 0.36 & 0.31 \\
Inhalation of house dust & 0.006 & 0.005 \\
$\rightarrow$ LADD $^{a}$ & 0.93 & 0.81 \\
\hline
\end{tabular}

${ }^{a}$ LADD, lifetime average daily dose.
PFOA through inhalation was estimated at $0.022 \mathrm{ng} / \mathrm{m}^{3}$ and $0.019 \mathrm{ng} / \mathrm{m}^{3}$, respectively [15].

In a recent study by Kato et al. [50], 39 samples of house dust that had been collected in diverse countries worldwide in 2004 were tested for concentrations of 17 PFCs. Six of the compounds were detected in $70 \%$ of the samples tested. The highest mean values measured were for PFOS, PFBS, PFHxS, perfluorooctanesulfonamide ethanol [FOSE], 2-(N-ethyl-perfluorooctanesulfonamido) acetic acid (Et-PFOSA-AcOH), and 2-(NMethyl-perfluorooctanesulfonamide) ethanol [Me-FOSE] [50]. The values are shown in Table 9.

Data have been published on the inhalation exposure to PFOS and PFOA for Norway, the UK, Japan, and North America. As a result of the large variability of the PFC concentrations in outdoor air, the EFSA calculated LADD values for 'high' and for 'low' PFC exposures via inhalation of outdoor air. The PFOS and PFOA concentrations of air and dust that were used as basis for calculation, as well as the LADD values, are shown in Table 10.

Consequently, the uptake of PFOS and/or PFOA from outdoor air, even assuming a high concentration of PFCs, amounts to less than $0.5 \%$ or $17 \%$, respectively, of the contamination via indoor air and, in comparison to dietary uptake, would therefore appear to be negligible [15].

Table 9 PFC concentrations in 39 samples of house dust (from Kato et al. [50])

\begin{tabular}{lc}
\hline Substance & Mean value $(\boldsymbol{\mu g} / \mathbf{k g})$ \\
\hline PFOS & 480 \\
PFBS & 359 \\
Et-FOSA-AcOH & 244 \\
Me-FOSE & 219 \\
FOSE & 208 \\
PFHxS & 186 \\
\hline
\end{tabular}


Table 10 PFOS and PFOA uptake via ingestion and inhalation of outdoor air (from EFSA [15])

\begin{tabular}{lcccc}
\hline Outdoor air contamination & \multicolumn{2}{c}{ Low uptake } & \multicolumn{2}{c}{ High uptake } \\
& PFOS & PFOA & PFOS & PFOA \\
\hline In dust $(\mu \mathrm{g} / \mathrm{kg})$ & 30 & 400 & 100 & 4000 \\
In air $\left(\mathrm{ng} / \mathrm{m}^{3}\right)$ & 0.001 & 0.003 & 0.01 & 0.3 \\
$\rightarrow$ LADD $(\mathrm{ng} / \mathrm{kg} \mathrm{BW/day)}$ & 0.00069 & 0.0063 & 0.0041 & 0.14 \\
\hline
\end{tabular}

Fromme et al. [38] summarized human exposure to PFCs via outdoor and indoor air in western countries. A comparison of the various PFCs in outdoor air shows that the levels of FOSE or FOSA, PFOS, and PFOA concentrations decrease according to the sequence city, country, and outlying regions. Furthermore, there appears to be a north-south gradient since the maximum 8:2 FTOH concentrations were $0.19 \mathrm{ng} / \mathrm{m}^{3}$ in the northern hemisphere and $0.014 \mathrm{ng} / \mathrm{m}^{3}$ in the southern hemisphere. In addition, it must be assumed that there are seasonal variations in PFOS and PFOA concentrations in outdoor air. Samples taken in the spring contained higher concentrations of PFCs than samples from the winter. [38].

\section{Total exposure}

The individual pathways of exposure according to EFSA [15] and Fromme et al. [38] are summarized, and the resulting total exposure to PFCs is calculated in Table 11. The calculated total exposure according to the data of the EFSA [15] and Fromme et al. [38] are of the same order of magnitude for PFOA. For PFOS, the total exposure derived from the data of the EFSA [15] is significantly higher than the result obtained using the data from Fromme et al. [38]. This resulted from the higher values for dietary exposure according to the EFSA [15]. According to this assessment, exposure via drinking water and outdoor air appear to be insignificant, barring special sources of contamination.

Fromme et al. [51] initiated a study, the Integrated Exposure Assessment Survey [INES] in which PFC concentrations in foods, indoor air, and house dust were correlated with concentrations in blood. The blood concentrations of the 48 INES participants varied between 4.9 to $55.0 \mu \mathrm{g} / \mathrm{L}$ for PFOS and 2.7 to $19.1 \mu \mathrm{g} / \mathrm{L}$ for PFOA. Further details have not yet been published since the study is ongoing.

Zhang et al. [52] took a different approach. The daily uptake, calculated from blood concentrations using a one-compartment model, was found to agree closely with the daily PFOS uptake via food and house dust (0.74 vs. $1.19 \mathrm{ng} / \mathrm{kg} \mathrm{BW}$ for men and $1.2 \mathrm{vs.} 1.15 \mathrm{ng} / \mathrm{kg}$ BW for women) [52].

\section{Pre- and postnatal exposures}

PFC exposure of the fetus (prenatal) and nursing infants (postnatal) has also been shown in studies of motherchild pairs.

\section{Prenatal exposure}

PFOS was detected in cord blood samples in studies from Northern Canada, Germany, Japan, the USA, Canada, and Denmark [37,53-57]. This also applies to PFOA, with the exception of the Japanese study [54]. Thus, PFCs are considered to cross the placental barrier. This was also shown in animal studies [58].

In the northern Canadian study, the mean PFOS- and PFOA-cord blood concentrations in humans were 17 $\mu \mathrm{g} / \mathrm{L}$ and $3.4 \mu \mathrm{g} / \mathrm{L}$, respectively. In the other studies, the values were from 3 to $7 \mu \mathrm{g} / \mathrm{L}$ for PFOS and 1.6 to 3.4 $\mu \mathrm{g} / \mathrm{L}$ for PFOA. In the German study, PFOS concentrations in cord blood were reported to be lower than the mother's blood by a factor of $0.6(7.3 \mu \mathrm{g} / \mathrm{L}$ vs. $13 \mu \mathrm{g} / \mathrm{L})$. By contrast, however, the PFOA concentrations were a factor of 1.26 higher in cord blood than in the mother's blood (3.4 $\mu \mathrm{g} / \mathrm{L}$ vs. $2.6 \mu \mathrm{g} / \mathrm{L})$ [53].

Inoue et al. [54] also compared PFOS concentrations in the mother's blood with the cord blood of the fetus. The concentration in the maternal blood varied from 4.9 to $17.6 \mu \mathrm{g} / \mathrm{L}$, whereas the cord blood concentration had a PFOS level of 1.6 to $5.3 \mu \mathrm{g} / \mathrm{L}$. A strong correlation

Table 11 Estimate of total PFC uptake for adults (ng/kg BW/day)

\begin{tabular}{|c|c|c|c|c|c|c|}
\hline \multirow[t]{2}{*}{$\begin{array}{l}\text { Source of } \\
\text { contamination }\end{array}$} & EFSA [15] & $\begin{array}{l}\text { Fromme et al. } \\
\qquad[38]\end{array}$ & EFSA [15] & $\begin{array}{l}\text { Fromme et al. } \\
\qquad[38]\end{array}$ & Fromme et al. [38] & Fromme et al. [38] \\
\hline & PFOS & PFOS & PFOA & PFOA & FTOH & FOSE/FOSA \\
\hline Diet & 60 to 200 & 1.5 to 4.48 & 2 to 6 & 2.82 to 11.5 & n.r. & $0.217-6.87$ \\
\hline Fish & 45 to 58 & n.r. & 1.7 to 2.1 & n.r. & n.r. & n.r. \\
\hline Drinking water & 0.24 & 0.023 to 0.130 & 0.31 & 0.022 to 0.087 & n.r. & n.r. \\
\hline $\begin{array}{l}\text { Indoor air + house } \\
\text { dust }\end{array}$ & 0.93 & $\begin{array}{c}0.0047+0.032 \text { to } \\
4.22\end{array}$ & 0.81 & $\begin{array}{c}0.0009+0.016 \text { to } \\
1.03\end{array}$ & $\begin{array}{c}0.038 \text { to } 0.105+0.103 \text { to } \\
1.02\end{array}$ & $\begin{array}{c}0.460 \text { to } 2.05+0.983 \text { to } \\
2.03\end{array}$ \\
\hline Outdoor air & $\begin{array}{l}0.001 \text { to } \\
0.004\end{array}$ & 0.0001 to 0.001 & $\begin{array}{l}0.006 \text { to } \\
0.14\end{array}$ & 0.001 to 0.012 & 0.003 & 0.001 to 0.012 \\
\hline Total uptake & 60.9 to 200 & 1.56 to 8.84 & $\begin{array}{l}2.82 \text { to } \\
6.95\end{array}$ & 2.86 to 12.6 & 0.144 to 1.13 & 1.66 to 10.9 \\
\hline
\end{tabular}

n.r, Not reported. 
was found between the PFOS concentration in the mother's blood and in cord blood $\left(r^{2}=0.876\right)$. In this study, PFOA was only found in the mother's blood [54].

Monroy et al. [56] also made comparative measurements of PFC concentrations in mother's blood ( $n=$ 101 ) in the 24th to 28th week of gestation and at the time of birth as well as in cord blood $(n=105)$. These authors established higher PFOS concentrations in the mother's blood during pregnancy than at the time of birth. PFOS concentrations in cord blood were lower than those in the mother's blood samples.

Fei et al. [57] also examined PFOS and PFOA concentrations in the blood of women during the first trimester $(n=1,400)$ and during the second trimester $(n=200)$ of pregnancy. They also analyzed cord blood $(n=50)$ after birth. The values from these last two studies are shown in Figure 1.

\section{Postnatal exposure}

The presence of PFOS and PFOA in human breast milk was demonstrated in studies from Sweden [59] and China [60], among others. The PFC concentrations measured in these studies were similar. In another study by Völkel et al. [61], PFOS and PFOA concentrations were also determined in 57 human milk samples from Germany and 13 samples from Hungary. The PFOA concentrations measured in this study $(0.201$ to $0.46 \mu \mathrm{g} / \mathrm{L})$ were similar to those reported by So et al. [60] and Kärrman et al. [59]. Only 11 PFOA values were greater than the LOD of $0.2 \mu \mathrm{g} / \mathrm{L}$. In the Swedish study, the same problem emerged, whereby only one sample contained concentrations greater than the blank level of $0.209 \mu \mathrm{g} / \mathrm{L}$.

In 24 pooled samples of human milk (1, 237 individual samples) obtained in the year 2007 from 12 provinces of China, Liu et al. [62] measured PFOS concentrations of $0.049 \mu \mathrm{g} / \mathrm{L}$ (mean) and for PFOA, $0.035 \mu \mathrm{g} / \mathrm{L}$. The concentrations of PFCs varied greatly between different geographic regions. High concentrations of PFOA were measured in Shanghai $(0.814 \mu \mathrm{g} / \mathrm{L}$ in rural areas and $0.616 \mu \mathrm{g} / \mathrm{L}$ in urban areas) [62].

PFOS and/or PFOA concentrations measured in human milk samples by Kärrman et al. [59], So et al. [60], Völkel et al. [61] and Liu et al. [62] are shown in Table 12.

Using the data from the Swedish study, for example, an infant who weighs $5 \mathrm{~kg}$ and drinks $800 \mathrm{~mL}$ human milk per day would have a daily uptake of 0.048 to 0.38 $\mu \mathrm{g}$ PFOS and 0.17 to $0.39 \mu \mathrm{g}$ PFOA [15]. If the data from Shanghai are used, the infant would ingest more PFOA (consumed volume $=742 \mathrm{~mL} /$ day, $\mathrm{BW}=6 \mathrm{~kg}$ ) amounting to $0.088 \mu \mathrm{g} / \mathrm{kg} \mathrm{BW}$ [62], thereby nearly reaching the TDI of $0.1 \mu \mathrm{g} / \mathrm{kg} \mathrm{BW} /$ day recommended by the German Drinking Water Commission.

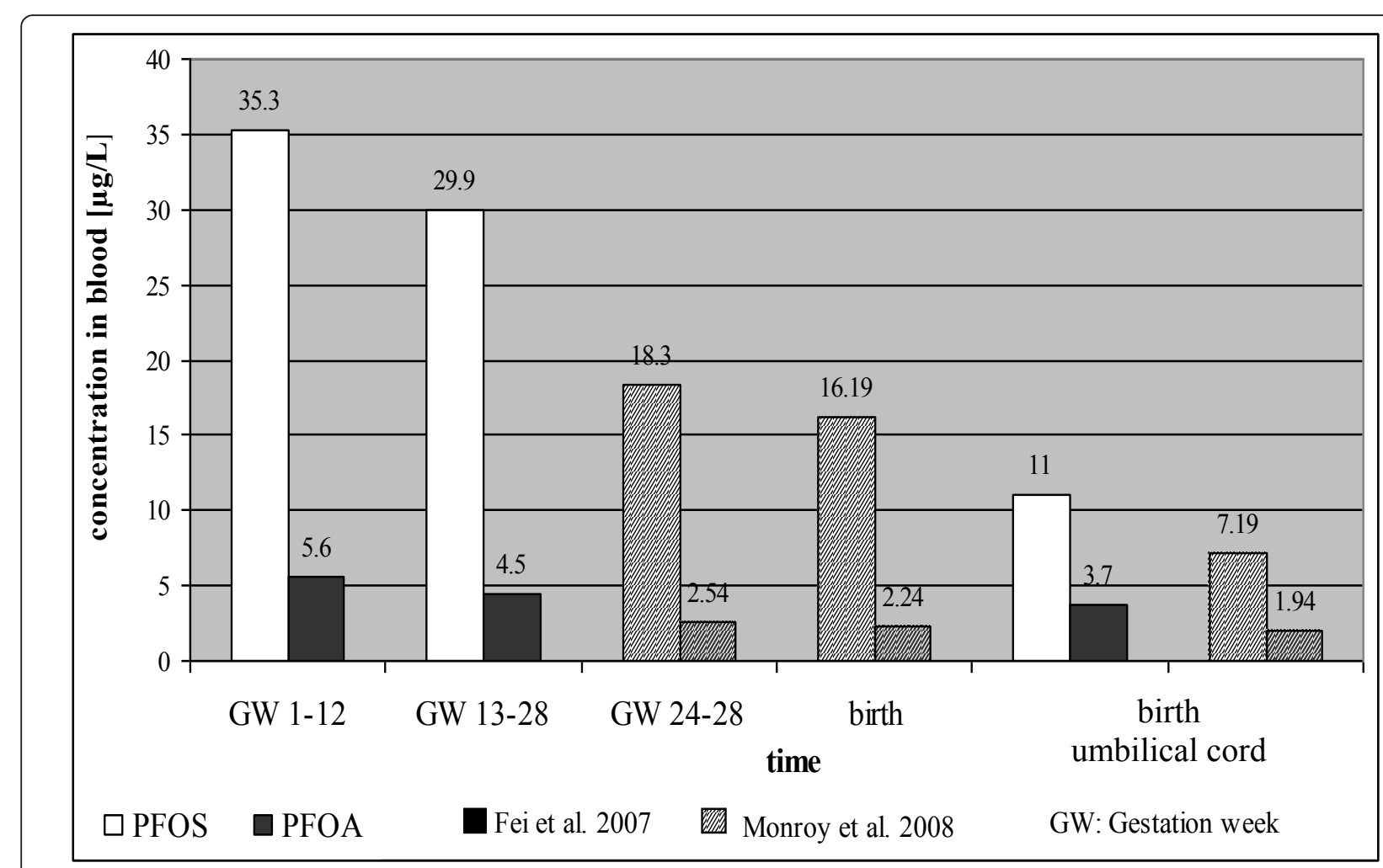

Figure 1 PFOS and PFOA blood concentrations in maternal blood and in cord blood. (By Fei et al. [57]; Monroy et al. [56]). 
Table 12 PFOS and PFOA concentrations ( $\mu \mathrm{g} / \mathrm{L}$ ) of human breast milk

\begin{tabular}{lcccc}
\hline Substance & Sweden & China & Germany \\
& Kärrman et al. [59] & So et al. [60] & Liu et al. [62] & Völkel et al. [61] \\
\hline PFOS & 0.06 to 0.47 & 0.045 to 0.36 & 0.049 (median) & 0.028 to 0.309 German samples \\
& 0.201 (arithmetic mean) & 0.121 (arithmetic mean) & & 0.096 to 0.639 Hungarian samples \\
PFOA & $<0.209$ to 0.492 & 0.047 to 0.21 & 0.035 (median) & 0.201 to 0.46 \\
& & 0.106 (arithmetic mean) & \\
\hline
\end{tabular}

It can be seen in the study by Kärrman et al. [59] that the mean PFOS concentration of $0.201 \mu \mathrm{g} / \mathrm{L}$ in human milk is correlated with the serum PFOS concentration of $20.7 \mu \mathrm{g} / \mathrm{L}\left(r^{2}=0.7\right)$, reaching a level of about $1 \%$ of the serum concentration. A similar and even stronger correlation $\left(r^{2}=0.8\right)$ was also determined for PFHxS (milk $0.085 \mu \mathrm{g} / \mathrm{L}$, serum $4.7 \mu \mathrm{g} / \mathrm{L}$ ). The total concentration of PFCs was $32 \mu \mathrm{g} / \mathrm{L}$ in serum and $0.34 \mu \mathrm{g} / \mathrm{L}$ in milk. The authors calculated a PFC uptake of about 0.2 $\mu \mathrm{g} /$ day for infants. The PFOS and/or PFHxS concentrations in human milk samples that had been obtained between 1996 and 2004 showed little variation throughout that time period, providing no evidence of a possible temporal trend [59].

Tao et al. [63] analyzed PFC concentrations in human milk samples from various Asian countries. The PFOS concentration varied between $0.039 \mu \mathrm{g} / \mathrm{L}$ in India and $0.196 \mu \mathrm{g} / \mathrm{L}$ in Japan. The mean PFHxS concentrations ranged from $0.006 \mu \mathrm{g} / \mathrm{L}$ (Malaysia) to $0.016 \mu \mathrm{g} / \mathrm{L}$ (Philippines). The mean PFOA concentration in Japan was $0.078 \mu \mathrm{g} / \mathrm{L}$. In addition, the average PFC uptake of nursing infants from seven Asian countries was compared to the dietary uptake values from adults in Germany, Canada, and Spain. The PFOS uptake of nursing infants $(11.8 \pm 10.6 \mathrm{ng} / \mathrm{kg} \mathrm{BW} /$ day $)$ was 7 to 12 times higher, and the PFOA uptake $(9.6 \pm 4.9 \mathrm{ng} / \mathrm{kg} \mathrm{BW} /$ day $)$ was 3 to 10 time higher than the dietary exposure of adults to these substances [63].

Llorca et al. [64] also analyzed human milk samples for PFC contamination. The milk samples, from donors living in Barcelona, Spain, were all from at least 40 days after birth. PFOS and perfluoro-7-methyloctanoic acid were detected in $95 \%$ of all samples. Concentrations of 0.021 to $0.907 \mu \mathrm{g} / \mathrm{L}$ PFOA were measured in 8 out of 20 human milk samples. According to this study, infants ingest $0.3 \mu \mathrm{g}$ PFCs/day while nursing [64].

According to the results of these studies, nursing contributes to PFC exposure of infants. The mechanism by which these compounds pass from the mother's blood to the milk is not fully understood. Bonding to proteins would appear likely $[38,65]$.

PFC contaminations of infant formulas were examined in two studies. Tao et al. [63] detected PFC concentrations above the LOD in only a few cases ${ }^{\mathrm{a}}$. Llorca et al. [64] found six PFCs in all baby formulas of various brands as well as in baby cereals. Elevated concentrations (as high as $1.29 \mu \mathrm{g} / \mathrm{kg}$ ) of perfluorodecanoic acid [PFDA], PFOS, PFOA, and perfluor-7-methyloctanoic acid were detected. Contamination of baby food is likely the result of migration of the compounds from the packaging or containers used during production [64].

\section{Human internal contamination}

Taves [66] and Shen and Taves [67] were the first to show the presence of organic fluorides in human blood. Until the 1990s, however, the presence of these compounds was not considered of importance. Only since 1993 have PFC concentrations in the serum of exposed workers been the subject of study. The PFOS concentrations in the serum were found to be between 1, 000 and $2,000 \mu \mathrm{g} / \mathrm{L}$. Data on serum concentrations in the general population have only been available since 1998 . These values were approximately 100 times lower than in occupationally exposed workers $[15,68,69]$.

The plasma to serum ratio for PFHxS, PFOS, and PFOA is 1:1, independent of the concentration, whereas the ratio of serum or plasma to whole blood was stated to be $2: 1$. This indicates that the PFC concentration in whole blood is only $50 \%$ of the concentration in plasma and/or serum. The difference is the result of the distribution volume of red blood cells in the samples since fluorochemicals are neither found intracellularly nor bound to the red blood cells [70].

Kannan et al. [71] examined $473 \mathrm{blood} /$ serum/plasma samples from people of various countries. Of the four PFCs measured (PFOS, PFHxS, PFOA, FOSA), PFOS was quantitatively the dominant component in blood. The highest PFOS concentrations were detected in samples from the USA and Poland (>30 $\mu \mathrm{g} / \mathrm{L}$ ). In Korea, Belgium, Malaysia, Brazil, Italy, and Colombia, blood PFOS concentrations were in the range of 3 to $29 \mu \mathrm{g} / \mathrm{L}$. The lowest PFOS concentrations were measured in samples from India $(<3 \mu \mathrm{g} / \mathrm{L})$. In this study, the PFOA concentrations were lower than the values for PFOS, except in India and Korea. The joint occurrence of the four PFCs varied according to the country of origin of the samples. This suggests differences in the exposure pattern in the individual countries [71].

Kärrman et al. [72] measured plasma PFOS concentrations from residents of Australia, Sweden, and the UK 
with levels of $23.4 \mu \mathrm{g} / \mathrm{L}, 33.4 \mu \mathrm{g} / \mathrm{L}$, and $14.2 \mu \mathrm{g} / \mathrm{L}$, respectively. Ericson et al. [73] determined average values of $7.64 \mu \mathrm{g}$ PFOS/L and $1.8 \mu \mathrm{g}$ PFOA/L in blood samples from the Spanish population [15].

Calafat et al. [74], within the framework of the National Health and Nutrition Examination Surveys [NHANES] from 1999 to 2000, also examined serum samples from the US population for concentrations of 11 different PFCs. The group of 1, 562 participants in the study was made up of male and female subjects, three ethnic groups, and four age categories (12 to 19 years, 20 to 39 years, 40 to 59 years, 60 years and older). Consequently, these data are representative of the exposure of the US population to PFCs. PFOS, PFOA, PFHxS, and FOSA were detected in all serum samples [74]. The values are presented in Table 13.

Wilhelm et al. [75] took three biomonitoring studies as a basis to arrive at a reference value for PFOA and PFOS in the blood plasma of the general population in Germany. Two studies were carried out in southern Germany $[76,77]$ and one in North Rhine Westphalia [19]. Although these studies are not representative of the general population of Germany, they present the best basis for deriving a reference value for internal contamination with PFOS and PFOA. Based on the 95th percentile, the following reference values were suggested: for PFOA, $10 \mu \mathrm{g} / \mathrm{L}$ for all groups and for PFOS, $10 \mu \mathrm{g} / \mathrm{L}$ for children of school age, $15 \mu \mathrm{g} / \mathrm{L}$ for adult women, and $25 \mu \mathrm{g} / \mathrm{L}$ for men [75].

The mean PFOA concentration in the blood for the European population is within the region of 4 to $20 \mu \mathrm{g} /$ $\mathrm{L}$; their mean PFOS serum concentration is within the range of $4 \mu \mathrm{g} / \mathrm{L}$ (Italy) and $55 \mu \mathrm{g} / \mathrm{L}$ (Poland). PFOS is the quantitatively dominant component of PFCs in all of the blood samples measured worldwide. In general, PFOA concentrations in serum are lower than concentrations of PFOS [15].

Olsen et al. [69] determined the PFOS concentrations in serum to be 6.1 to $58.3 \mu \mathrm{g} / \mathrm{L}$ and in human liver, 4.5$57 \mu \mathrm{g} / \mathrm{kg}(n=31)$. The mean liver to serum ratio for PFOS concentration was 1.3:1. Liver to serum ratios could not be established for PFOA, PFHxS, and FOSA because $90 \%$ of the concentrations of these substances were below the $\mathrm{LOD}^{\mathrm{a}}[69]$.

Table 13 PFOS and PFOA serum concentrations ( $\mu \mathrm{g} / \mathrm{L}$ ) of the US population (from Calafat et al. [74])

\begin{tabular}{lccc}
\hline Substance & 10th Percentile & 50th Percentile & 95th Percentile \\
\hline PFOS & 15.1 & 30.2 & 75.6 \\
PFOA & 2.8 & 5.1 & 11.9 \\
PFHxS & 0.8 & 2.1 & 8.7 \\
FOSA & $<0.1$ & 0.3 & 1.4 \\
\hline
\end{tabular}

Kärmann et al. [78] analyzed blood samples from 66 Swedish study participants. Concentrations of 12 PFCs were determined (PFBS, PFHxS, PFOS, perfluorooctanesulfonamido acid, FOSA, PFHxA, PFOA, perfluorononanoic acid [PFNA], PFDA, perfluoroundecanoic acid [PFUnA], perfluorododecanoic acid [PFDoA], perfluorotetradecanoic acid [PFTDA]) along with the concentrations of other 'traditional' persistent organic pollutants [POPs]. The mean concentrations of PFCs in whole blood were 20 to 50 times higher than the total concentrations of polychlorinated biphenyls $[\mathrm{PCB}]$ and p, p'dichlorodiphenyldichloroethylene. Similarly, the PFC concentrations were 300 to 450 times greater than for hexachlorbenzene and the sum of the six chlordanes and the three polybrominated diphenyl ethers. However, the PFCs and the POP that were measured behaved differently in regard to their distribution in the body, making an additional comparison of total body contamination necessary. PFCs are mainly found in the blood and the liver, whereas polychlorinated and polybrominated POPs are chiefly present in the fat tissue and blood lipids. The reason for these differences appears to be related to the different basic structures and the binding behavior in blood of these substances $[40,79,80]$. Whole blood contains about $0.5 \%$ blood lipids, and thus represents only a small part of the total body contamination of PCB for example. The total body contamination was calculated using the proportionate weights of the main distribution tissues. This analysis showed a similar total body contamination for PFCs and for the POP that had been analyzed to be about $1.6 \mathrm{mg}$ PFOS and $1.7 \mathrm{mg}$ for PCB153, one of the most abundant individual PCB congeners [72].

\section{Gender and age-dependent differences}

No correlation between the PFOS concentration and age or gender were found in studies by Olsen et al. [69] on US citizens or in the studies by Kannan et al. [71]. Data of Calafat et al. [74,81] show significantly higher PFOS and PFOA concentrations in men than in women; however, an age-related difference was not found. Harada et al. [82] reported higher PFC serum concentrations in Japanese men than in women, and in addition, they also reported a rise in PFC serum concentrations in women with increasing age so that by age 60 , the concentrations in women were comparable to those in men. The situation was similar for PFOA [82].

Kärrman et al. [83] determined a rise in PFOS serum concentrations with increasing age. PFOS, PFOA, and PFHxS concentrations in blood were also higher in men than in women. Ericson et al. [73] confirmed higher PFHxS and PFOA concentrations in blood of male subjects. Concentrations were significantly different between age groups $25 \pm 5$ years (18 participants) and $55 \pm 5$ years ( 30 participants) only for PFHxS and FOSA 
( $p<0.05$ and $p<0.001$, respectively). The group of younger participants ( $25 \pm 5$ years) presented higher PFHxS values and lower FOSA values than did the older participants [73].

Rylander et al. [84] also registered higher concentrations of PFOS, PFOA, PFHxS, and PFHpS in male Norwegian participants than in women. Here, also increasing concentrations of PFOS, PFHxS, and PFHpS were observed with increasing age.

A study of 245 blood samples of donors from China showed that lower concentrations of PFOS were detected in infants, young children, children, and adolescents $(2.52$ to $5.55 \mu \mathrm{g} / \mathrm{L})$ than in adults $(8.07 \mu \mathrm{g} / \mathrm{L})$, and correlations of PFOS $(r=0.468)$ and PFHxS $(r=0.357)$ with age were reported. In contrast, PFOA concentrations in blood of the children and adolescents were higher $(1.23$ to $2.42 \mu \mathrm{g} / \mathrm{L})$ than in adults $(1.01 \mu \mathrm{g} / \mathrm{L})$, showing a negative correlation with age $(r=-0.344)$. The composition of the PFC concentration profiles also varied between age groups, suggesting different sources of exposure. Gender specific differences in PFC concentration could not be determined in any of the groups [52].

Fromme et al. [77] carried out a study of PFC concentrations in blood of participants in Germany. Concentrations of PFOA and PFOS were measured in 356 blood plasma samples. The mean values of $10.9 \mu \mathrm{g} / \mathrm{L}$ PFOS and $4.8 \mu \mathrm{g} / \mathrm{L}$ PFOA were determined for women. The values for men were higher $(13.7 \mu \mathrm{g} / \mathrm{L}$ PFOS and 5.7 $\mu \mathrm{g} / \mathrm{L}$ PFOA). Higher blood PFC concentrations correlated with increasing age in students; however, this correlation was only statistically significant for female students [77]. A second German study also confirmed age as having an effect on PFC concentrations is plasma. The age of men correlated positively with the plasma concentrations of PFOS, PFOA, and PFHxS. In the case of women, this was only true for PFOA [19]. In a US American study, the mean PFOS and PFHxS concentrations were significantly lower in participants who were younger than 40 years than in the group over 40 years [85]. The values from this study are shown in Table 14.

According to the EFSA [15], none of the studies included show a clear difference in relationship to PFOS and/or PFOA serum concentrations in relation to age or gender of the participants. Fromme et al. [38] had come

Table 14 PFOS, PFOA, and PFHxS concentrations in blood $(\mu \mathrm{g} / \mathrm{L})$ according to age group

\begin{tabular}{lccc}
\hline Substance & $<\mathbf{4 0}$ years & $\mathbf{4 0}$ to $\mathbf{6 0}$ years & $>\mathbf{6 0}$ years \\
\hline PFOS & $24.8 / 33.3$ & $31.7 / 33.6$ & $35.3 / 35.1$ \\
PFOA & $2.2 / 5.3$ & $2.4 / 5.5$ & $2.4 / 6.0$ \\
PFHxS & $0.7 / 1.8$ & $1.9 / 2.5$ & $2.2 / 3.0$ \\
\hline
\end{tabular}

Values from 1974/1989 of Olsen et al. [85]. to the conclusion, however, that the majority of the studies show gender-specific differences in serum concentrations of PFOS and PFOA. In regard to age dependency, however, they agree with the EFSA [15] that there is no significant correlation between age and PFC blood concentrations although it must be assumed that these compounds accumulate in the body over time.

Since human biomonitoring studies showed higher PFOS blood concentrations for men than for women, Liu et al. $[62,86,87]$ investigated the effect of pregnancy, menstruation, and periodic exposure to PFOS concentration in the blood of mice. The animals received 50 $\mu \mathrm{g} / \mathrm{L}$ PFOS in their drinking water. Pregnancy or menstruation led to lower PFOS concentrations in the blood. Every additional individual exposure to PFOS increased the concentration of the substance in blood.

\section{Geographic and ethnic differences}

Geographical differences have been detected in the PFOS and PFOA concentrations in serum of blood donors in diverse countries. Kannan et al. [71] reported differences in the occurrence of PFOS and PFOA among blood donors in nine different countries. Harada et al. [82] detected differences in the PFOS and PFOA serum concentrations for both genders in Japan. The concentrations of PFOS and PFOA in blood measured in Germany were lower than the values from a study in the USA and Canada [77].

Fromme et al. [38] came to the conclusion that serum concentrations of the US population are higher than those of inhabitants of Europe, Asia, or Australia. The same is true of PFHxS [38] (Table 15).

Concentrations of $29 \mu \mathrm{g} / \mathrm{L}$ PFOS, $3.9 \mu \mathrm{g} / \mathrm{L}$ PFOA, 0.5 $\mu \mathrm{g} / \mathrm{L}$ PFHxS, $0.8 \mu \mathrm{g} / \mathrm{L}$ PFNA, and $1.1 \mu \mathrm{g} / \mathrm{L}$ PFHpS (mean values) were detected in $95 \%$ of all blood samples from Norwegians [84]. In another Norwegian study of 315 women, concentrations of $20 \mu \mathrm{g} / \mathrm{L}$ PFOS, $4.4 \mu \mathrm{g} / \mathrm{L}$ PFOA, $1.0 \mu \mathrm{g} / \mathrm{L}$ PFHxS, and $0.81 \mu \mathrm{g} / \mathrm{L}$ PFNA were found in $90 \%$ of the plasma samples [88].

Kärrman et al. [83] did not find a difference in PFC serum concentrations for participants from rural or urban regions of Australia. Mean values for PFOS (20.8 $\mu \mathrm{g} / \mathrm{L})$, PFOA $(7.6 \mu \mathrm{g} / \mathrm{L})$, and PFHxS $(6.2 \mu \mathrm{g} / \mathrm{L})$ measured in this study were similar to the values determined for

Table 15 Serum and plasma PFC concentrations ( $\mu \mathrm{g} / \mathrm{L}$ ) according to geographical origin of participants

\begin{tabular}{lccc}
\hline Substance & US population & EU population & Asian population \\
\hline PFOS & 656 & 1 to 116 & n.r. \\
PFOA & 88 & 0.5 to 40 & n.r. \\
PFHXS & $<0.4$ to 712 & $<0.4$ to 40 & 0.1 to 20.9 \\
\hline
\end{tabular}

Adapted from Fromme et al. [38]; n.r., not reported. 
serum concentrations in Europe and Asia, or higher, but lower than in the USA.

In an African study, concentrations of $1.6 \mu \mathrm{g} / \mathrm{L}$ PFOS, $1.3 \mu \mathrm{g} / \mathrm{L}$ PFOA, and $0.5 \mu \mathrm{g} / \mathrm{L}$ PFHxS were measured in the blood of mothers who were tested. Fifty eight percent of the PFOS molecules present were in the linear form. The highest PFC concentrations were detected in the blood of people from urban and semi-urban regions, which are areas with the highest quality of living conditions [89].

Hemat et al. [90] determined a lower internal PFC contamination of people in Afghanistan. PFOS concentrations of 0.21 to $11.8 \mu \mathrm{g} / \mathrm{L}$ were detected in blood, and PFOA and PFHxS concentrations were below the LOD of $0.5 \mu \mathrm{g} / \mathrm{L}$. In drinking water, as well, PFOA or PFOS concentrations were not detected at levels above the LOD $(0.03$ and $0.015 \mu \mathrm{g} / \mathrm{L})$. The studies cited here are shown in Figure 2.

The study of Kannan et al. [71] in which samples were obtained from nine different countries showed differences in levels of PFOS in relation to the country of the donors. The US study [91] showed that non-Hispanic whites had statistically significantly higher concentrations of PFOS than both non-Hispanic blacks and Mexican Americans; Mexican Americans had statistically significantly lower concentrations than non-Hispanic blacks. Genetic variability, diet, lifestyle, or a combination of all these factors may contribute to the different patterns of human exposure to PFOS observed among the population groups [15].

\section{Dietary influences}

A Swedish study in which samples of blood from 108 women were analyzed showed a correlation between increased consumption of predatory fish (pike, perch, zander) and PFOS concentration in the blood. This correlation could not, however, be shown for total fish consumption or for other groups of foodstuffs ([92] cited in EFSA [15]). A Polish study established a correlation between increased fish consumption and the highest serum concentrations measured in 45 test candidates for 10 fluorochemicals (including PFOS and PFOA) [93].

In a study of 60 participants in Norway, Rylander et al.[84] determined significantly lower concentrations of PFOS and PFOA in the blood of candidates who stated that they had consumed $150 \mathrm{~g}$ of vegetables and fruits per week over the past year. In contrast, an increase consumption of oily fish (150 g/week) led to significantly higher concentrations of these substances in the blood.

In another study, Rylander et al. [88] examined blood from 315 Norwegian women between the ages of 48 and 62 years. Participants who consumed larger

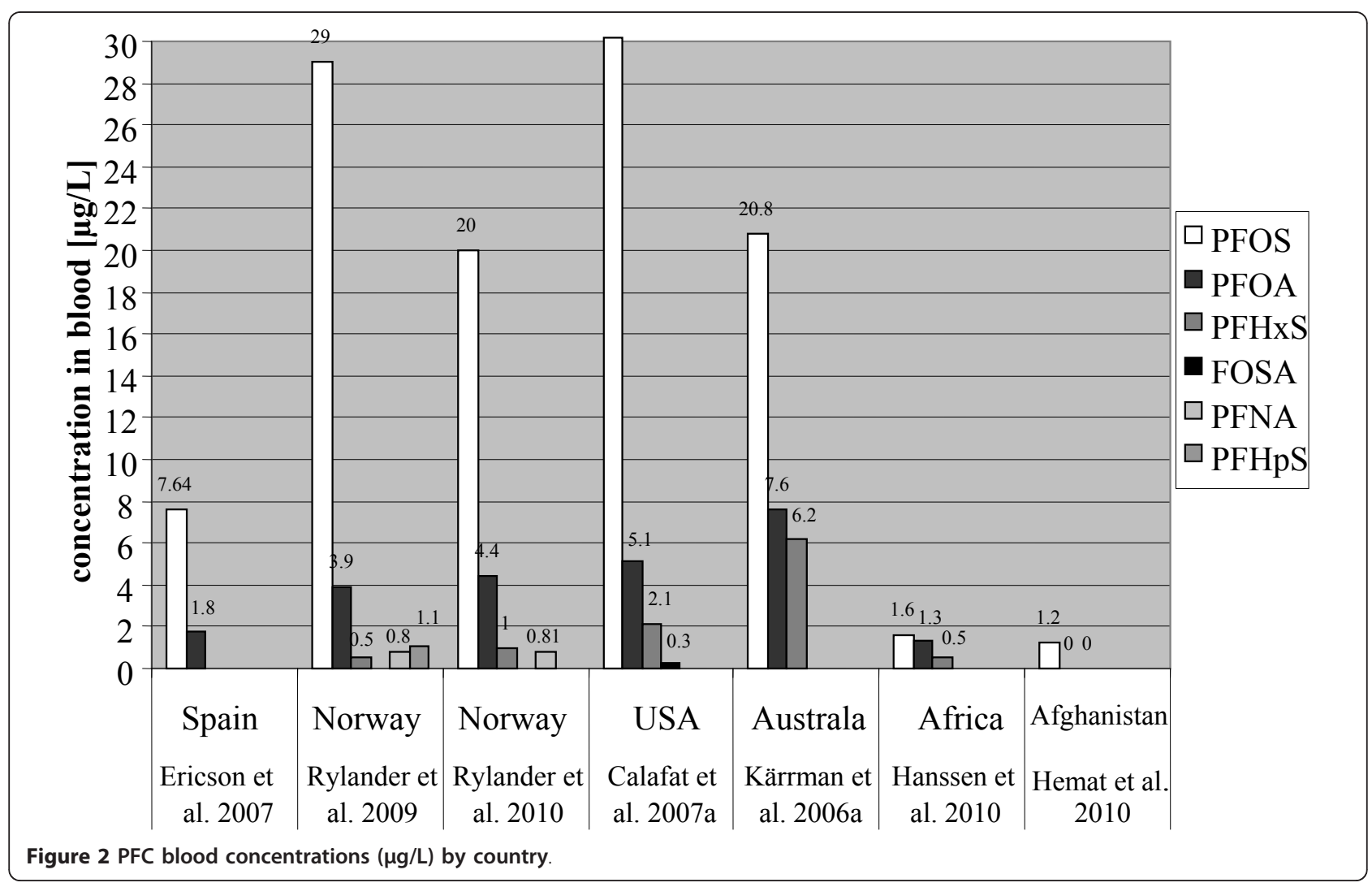


amounts of fish had higher PFOS, PFNA, and PFHxS concentrations in their blood than did younger women with larger households and a more western diet of rice, pasta, water, white and red meat, chocolate, snacks, and pastry. No specific cluster of foods could be correlated with higher PFOA blood concentrations [88].

\section{Time trends}

A study of 178 US serum samples shows an increase in PFOS and PFOA concentrations between 1974 and 1989. The mean values of serum concentrations of PFOS, PFOA, and PFHxS from 1974 and 1989 are shown in Table 16. Serum samples collected in 2001 did not show any further increase in PFC concentrations $[69,85]$.

A Japanese study established an increase in PFOS and PFOA concentrations in serum samples over the last 25 years. PFOS concentrations increased by a factor of 3 , and PFOA concentrations by as much as a factor of 14 [82].

A continual increase in PFOA and PFOS over time was also shown in a Chinese study in which serum samples from 1987, 1990, 1999, and 2002 were analyzed [94]. The changes in serum concentrations over time as shown in this study are presented in Figure 3.

On the other hand, another study showed the decline of serum concentrations of PFOS by $32 \%$, of PFOA by $25 \%$, and of PFHxS by $10 \%$ (data from the NHANES from 1999 to 2000). These changes can probably be attributed to the change in production of PFOS and perfluorooctane sulfonylfluoride compounds. The PFNA concentrations increased by $100 \%$ [95]. These values are also shown in Table 16. The concentrations listed by Olsen $[69,85]$ are mean values, while those from Calafat et al. [95] are geometric mean values, making a comparison of the results difficult or impossible.

Studies from the Sauerland region of Germany show constant PFOS and PFOA concentrations between 1997 and 2004; however, the plasma concentrations of PFHxS have risen continuously since 1977 [21].

Differences dependent upon the isomery of the compounds Studies have shown that the linear form of PFOS [LPFOS] is more plentiful than the branched isomers in the human serum and plasma samples. L-PFOS was seen to account for $58 \%$ to $70 \%$ of the total PFOS in samples from Australia, 68\% from Sweden, and 59\% from the UK. The disparities are presumably the result

Table 16 PFC concentration in blood ( $\mu \mathrm{g} / \mathrm{L})$ by year

\begin{tabular}{lccccc}
\hline Substance & \multicolumn{3}{c}{ Olsen et al. [69,85] } & \multicolumn{2}{c}{ Calafat et al. [95] } \\
& $\mathbf{1 9 7 4}$ & $\mathbf{1 9 8 9}$ & $\mathbf{2 0 0 1}$ & $\mathbf{1 9 9 9}$ to $\mathbf{2 0 0 0}$ & 2003 to 2004 \\
\hline PFOS & 29.5 & 34.7 & 35.8 & 30.4 & 20.7 \\
PFOA & 2.3 & 5.6 & 4.7 & 5.2 & 3.9 \\
PFHxS & 1.6 & 2.4 & 1.5 & 2.1 & 1.9 \\
\hline
\end{tabular}

of different sources of exposure in the various countries. For example, a standard PFOS product produced by electrochemical fluoridation [ECF] consists of $76 \%$ to 79\% L-PFOS [72].

A study by De Silva and Mabury [96] showed that $98 \%$ of the PFOA in the serum of the participants was linear PFOA [L-PFOA], so only $2 \%$ was present in the branched form. The same is true of PFNA and PFUnA. A standard PFOA product produced by ECF consists of $80 \%$ L-PFOA. The high proportion of L-PFOA in serum can probably be attributed to the exposure and metabolism of FTOH and alkanes [38].

\section{Toxicology of perfluorinated compounds Toxicokinetics of perfluorinated compounds Uptake}

Data from animal experiments show that PFC uptake can occur by oral, inhalation, or dermal exposure [97-102].

Oral uptake of PFOS and PFOA results in rapid and almost complete assimilation. Ninety five percent of the radioactively labeled PFOS dose $(4.3 \mathrm{mg} / \mathrm{kg} \mathrm{BW})$ and $93 \%$ of the labeled PFOA-dose $(11 \mathrm{mg} / \mathrm{kg} \mathrm{BW})$ were resorbed by male rats within $24 \mathrm{~h}$. The authors found $5 \%$ and $7 \%$ of the total radioactivity in feces and in the digestive tract and concluded that the remainder is the resorbed portion. These resorption data are from Gibson and Johnson [97] and were determined using ${ }^{14} \mathrm{C}$ labeled PFOS and PFOA [17].

After 10 inhalations of $84 \mathrm{mg} / \mathrm{m}^{3}$ APFO, a mean concentration of $108 \mathrm{mg} / \mathrm{L}$ was measured in the blood of male rats. The APFO blood concentration declined to $0.84 \mathrm{mg} / \mathrm{L} 84$ days after the treatment [100].

Uptake via dermal exposition appears to be somewhat weaker [101]. A study by Kennedy [99] showed a dosedependent increase in blood concentration of organofluoro compounds in rats after dermal application of APFO. The subchronic dermal treatment with 2, 000 $\mathrm{mg} \mathrm{APFO} / \mathrm{kg}$ resulted in blood concentrations of 118 $\mathrm{mg} / \mathrm{L}$.

In rats, an uptake of 8:2 FTOH via the skin was relatively low. After $6 \mathrm{~h}$ of exposure, 37\% of the substance evaporated or was removed by washing. The evaporated portion was trapped by a device attached to the skin and was consequently analyzed. The treated area of skin was washed with a soap-ethanol mixture, and the 8:2 FTOH concentration in the solvent was measured. In these experiments, a single 8:2 FTOH dose of $125 \mathrm{mg} /$ $\mathrm{kg}^{\mathrm{c}}$ in $0.5 \%$ methyl cellulose was applied. The $8: 2 \mathrm{FTOH}$ was labeled with ${ }^{14} \mathrm{C}\left(3-{ }^{14} \mathrm{C}\right.$ 8:2 FTOH $)$ and applied to the shaved area of skin $\left(10 \mu \mathrm{L} / \mathrm{cm}^{2}\right)$ [102].

\section{Distribution}

PFOS and PFOA are weakly lipophilic, very water soluble, and bind preferentially to proteins. The principle 


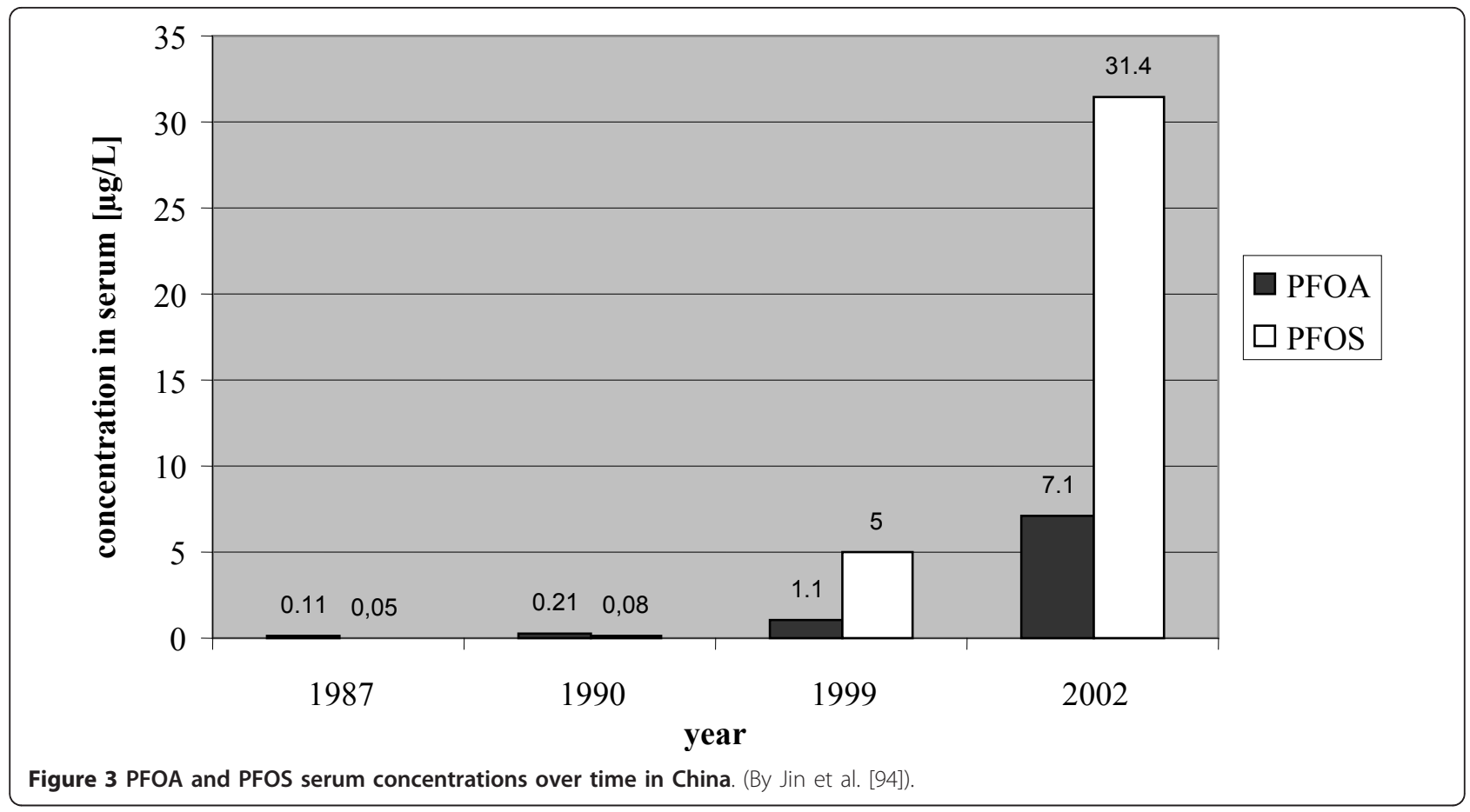

binding partner is albumin $[61,103]$; however, it also binds to $\beta$-lipoproteins or fatty acid binding proteins in the liver [L-FABP] [104].

Approximately $90 \%$ to $99 \%$ of the perfluoridated carboxylic acids in the blood are bound to serum albumin $[103,105]$. The chain length and the functional group of the PFCs have an influence on the preferential binding site and binding affinity [80]. PFCs have the same binding site and a similar affinity to serum albumin as fatty acids [80].

Qin et al. [106] used spectrometry to determine the influence of the length of the carbon chain of perfluorinated carboxylic acids on the binding to bovine serum albumin. They determined that the binding strength increased with the increasing chain length of the perfluorinated compound. The changes in enthalpy and entropy indicate that Van-der-Waals' forces and hydrogen bonds are the dominant intermolecular forces [106]. Bischel et al. [79] also confirmed the high affinity interactions between perfluorinated compounds and serum albumin, in particular at low molar ratios. PFOS and PFOA are primarily extracellular and accumulate primarily in the liver, blood serum, and kidneys. Small amounts of the substances are found in other tissues as well. According to studies by Austin et al. [107] and Seacat et al. [108], the liver to serum ratio for PFOS is about 2.5. PFOS and PFOA were also found primarily in the liver and kidneys of chickens [109] and Han et al. [110] found an active uptake mechanism for PFO (the anion of PFOA) in rat hepatocytes.
In addition, differences in distribution patterns may be dose dependent. In experiments with rats, Kudo et al. [111] found that $2 \mathrm{~h}$ after a single intravenous injection of low-dosage PFOA $(0.041 \mathrm{mg} / \mathrm{kg} \mathrm{BW})$, a larger proportion of the substance is found in the liver (52\%) than with a higher dosage (27\% for a dosage of $16.56 \mathrm{mg} / \mathrm{kg} \mathrm{BW}$ ). Apparently, PFOA is distributed to the blood or other tissues as soon as the level in the liver reaches $4 \mathrm{mg} / \mathrm{kg}$. The study does not provide an immediate explanation of these results; however, a dose-dependent difference in intracellular distribution between the membrane fraction and the cytosol was observed for the two different dosages of $0.041 \mathrm{mg} / \mathrm{kg} \mathrm{BW}$ and $4 \mathrm{mg} / \mathrm{kg} \mathrm{BW}$. Injection of the higher dosage resulted in PFOA primarily in the cytosolic fraction. If the liver concentration remained under $4 \mathrm{mg} / \mathrm{kg}$, PFOA was found almost completely in the membrane fraction with a remainder of $3 \%$ in the cytosol. Kudo et al. [111] concluded that this indicates a preferred bond of PFOA to membrane components that are not unlimitedly available. As a consequence, higher dosages of PFOA are distributed in the blood or other tissues. Elimination via the bile rose with higher doses were administered, suggesting transport of unbound PFOA from the cytosolic fraction of the cell to the bile. A biliary elimination rate of $0.07 \mathrm{~mL} / \mathrm{hr} / \mathrm{kg} \mathrm{BW}$ was determined $^{\mathrm{d}}$. The rate of elimination rose in a dose-dependent manner; however, the differences of the rates between the administered doses were not significant [111].

Tan et al. [112] discovered differences in distribution patterns dependent upon the perfluorinated compound, 
species (rat or monkey), and gender. PFOS, probably because of its higher liver to blood distribution coefficient, seemed to remain in the tissue longer than PFOA. The maximal transport capacity of renal resorption in monkeys was 1, 500 times greater than that of rats, and the clearance of renal filtrate in the central compartment was about 10 times greater. Male rats showed a slower renal elimination of PFOA than female animals; however, low PFOA concentrations $(<0.1 \mu \mathrm{g} / \mathrm{mL})$ were eliminated at a similarly slow rate by females [112].

In addition, Liu et al. [113] studied age-dependent differences in the toxicokinetics of PFOS in mice. The concentrations and distribution ratios of PFOS in the blood, brain, and liver of mice after a single subcutaneous application of $50 \mathrm{mg}$ PFOS $/ \mathrm{kg}$ BW differed significantly between the individual postnatal developmental stages. With increasing age, the differences became more evident. Gender-specific differences were greater in older mice. A study demonstrated the following distribution pattern of FTOH:

Four to seven percent of the ${ }^{14} \mathrm{C}$-labeled 8:2 FTOH was recovered in the tissue of rats 7 days after oral applications $(125 \mathrm{mg} / \mathrm{kg})$, principally in the fat, liver, thyroid, and adrenal tissues [102]. PFCs are also distributed in the milk and via the placenta, as described in the 'Pre- and postnatal exposures' section.

PFOS could also be detected in the livers of rat fetuses [114]. Additionally, on the basis of studies of rats, it was possible to estimate that the PFOA plasma concentration of the fetus amounts to half the steady state concentration in the plasma of the mother animal. In the transition of PFOA to the milk of the mother animal, the steady state concentration in the milk was $1 / 10$ lower than the level in plasma ([58] cited in EFSA $[15,115])$. Peng et al. [116] determined that the ratio of concentrations in the eggs of sturgeons to the concentration in the liver of the mother sturgeon was 0.79 for PFOA and 5.5 for perfluorotridecanoic acid.

Contamination with PFOA may have also resulted from corresponding precursor substances. It has, for example, been demonstrated that PFOA can be formed from FTOH [31,32]. Following a single dose of $30 \mathrm{mg} /$ $\mathrm{kg} \mathrm{BW} 8: 2 \mathrm{FTOH}$ on the eighth gestational day [GD] (GD 8) in mice, the PFOA concentrations in the fetus rose from $45 \pm 9 \mu \mathrm{g} / \mathrm{kg}$ (GD 10) to $140 \pm 32 \mu \mathrm{g} / \mathrm{kg}$ (GD 18). Furthermore, PFNA was also detected at a concentration of $31 \pm 4 \mu \mathrm{g} / \mathrm{kg}$ (GD 18). For the mice that were not contaminated with 8:2 FTOH in utero, but rather through nursing, concentrations of $57 \pm 11$ $\mu \mathrm{g}$ PFOA/L were detected on the third and $58 \pm 3 \mu \mathrm{g}$ $\mathrm{PFOA} / \mathrm{L}$ on the 15 th day after birth. This indicates that the progeny became contaminated with PFOA by nursing from the mother animal that had been exposed to FTOH [117].

\section{Metabolism}

As far as it is known, PFOS and PFOA are not metabolized in mammals. Thus, PFOA is not subject to defluorination nor to phase-II metabolism of biotransformation [101]. According to Fromme et al. [2], only FTOH comes into question regarding metabolism.

For example, Fasano et al. [102] could detect glucuronide and glutathione conjugates in the bile as well as perfluorooctanoate and perfluorhexanoate in excrements and in the plasma of male and female rats that had received a single oral dose of 5 and $125 \mathrm{mg} / \mathrm{kg}{ }^{14} \mathrm{C}$ labeled 8:2 FTOH. This implies that FTOH is metabolized and that a removal of $\mathrm{CF}_{2}$ groups takes place.

Other studies have also shown possible formation of PFCA from FTOH $[31,32,117]$. It is generally assumed that oxidation of the alcohol group takes place to form fluorotelomer aldehyde, followed by oxidation to saturated fluorotelomer compounds (fluorotelomer saturated carboxylate [FTCA]). Butt et al. [118] examined in greater detail the biotransformation pathway for $8: 2$ FTOH in rainbow trout, in particular, from the metabolic intermediates 8:2 FTOH unsaturated carboxylate [FTUCA] and 7:3 FTOH saturated carboxylate [FTCA]. The authors administered these intermediates as well as 8:2 FTCA to the trout for 7 days and then identified the compound in the blood and liver for a further 10 days. Exposure to 7:3 FTCA resulted in lower concentrations of 7:3 FTUCA and perfluorohepatanoate (PFHpA) and did not result in an accumulation of PFOA. Furthermore, 8:2 FTCA and 8:2 FTUCA were generated. PFOA was formed when 8:2 FTCA and 8:2 FTUCA were administered. These results suggest a $\beta$-oxidation beginning with 8:2 FTUCA to 7:3 keto acid and 7:2 ketone for the PFOA formation [118].

The emerging metabolic products are often more toxic than the original substance itself. This was also shown for FTOH in a study by Martin et al. [119]. In tests in which isolated rat hepatocytes were incubated with FTOH of various chain lengths, the shortest (4:2 FTOH) and longest (8:2 FTOH) lengths showed a greater toxicity, in terms of the $\mathrm{LC}_{50}$ than did, e.g., 6:2 FTOH.

Treatment with 8:2 FTOH led to a decline in glutathione [GSH] levels and an increase in protein carbonylation and lipid peroxidation. The addition of aminobenzotriazol, an inhibitor of cytochrome P450, diminished the cytotoxicity of all tested FTOH and decreased protein carbonylation and lipid peroxidation of 8:2 FTOH. Preincubating the hepatocytes with hydralazine or aminoguanidine (a carbonyl trap with nucleophilic amino groups that form adducts with aldehydes) also reduced the cytotoxicity of 8:2 FTOH. Likewise, a GSH-reactive $\alpha / \beta$-unsaturated acid which is a result from the metabolism proved more toxic than the corresponding FTOH compound. It can be concluded from 
this that the toxicity of FTOH is the result of electrophonic aldehydes or acids, GSH decrease, and protein carbonylation [119].

\section{Excretion}

Since PFOS and PFOA cannot be metabolized by mammals, excretion is the only means by which the toxic activity of these compounds can be eliminated once they have been taken up by the body [17].

Measurements of PFC concentrations in urine and feces yielded an elimination half-life of more than 90 days for PFOS in rats. The half-life of PFOA is markedly shorter and exhibits gender-dependent differences, 2 to $4 \mathrm{~h}$ for female rats and 4 to 6 days for male rats [115].

Because of albumin binding of a large portion of PFCs in the blood, the glomerular filtration rate is low. However, an active excretory mechanism via transport proteins has been described in rats. This so-called organic anion transporter [OAT] (OATs 2 and 3 ) enables the uptake of PFOA from the blood by the proximal tubule cells in the kidneys [120]. The expression of OAT 2 and 3 in the kidneys correlates with the excretion of PFOA by rats and is presumably regulated by sex hormones. This may explain why female rats have excreted $91 \%$ of the applied dose of ${ }^{14} \mathrm{C}$-labeled PFOA after $24 \mathrm{~h}$ via urine, while only $6 \%$ of the administered ${ }^{14} \mathrm{C}$-labeled PFOA can be detected in the urine of male rats. An active excretory mechanism has not yet been described for PFOS ([121] cited in EFSA [15]).

Weaver et al. [122] confirmed the involvement of the basolateral OATs 1 and 3 in renal secretion of C7-C9 PFCA in rats. On the other hand, the apical organic anion transport polypeptide [OATP] 1a1 contributes to the reabsorption of C8-C10 PFCA in the proximal tubule cells of the rat, with the highest affinity to $\mathrm{C} 9$ and C10. The OATP 1a1 expression is heightened in the kidneys of male rats and might therefore also help explain the gender-specific differences in renal PFCA excretion.

Experiments by Johnson et al. [123] show the presence of an enterohepatic circulation of PFCs. Increased fecal excretion of ${ }^{14} \mathrm{C}$-labeled PFOA and PFOS in rats was observed after multi-day administration cholestyramine per os, accompanied by a concurrent reduction in concentrations of the substances in the liver and plasma. Cholestyramine is an anion-exchange resin; it is not resorbed and carries PFOA and PFOS to the intestines to be excreted. The rates of excretion for PFOA and/or PFOS in rats that had received APFO $(13.3 \mathrm{mg} / \mathrm{kg})$ or the potassium salt of PFOS $(3.4 \mathrm{mg} / \mathrm{kg})$ intravenously were increased by 9.8 times and 9.5 times, respectively, after a 14- or 21-day administration of a $4 \%$ cholestyramine mixture in their feed [123].

Cui et al. [124] examined PFOS and PFOA excretions in male rats during a 28-day consecutive administration of PFOS and PFOA. Urine was confirmed as the primary path of excretion of PFOS and PFOA in rats in this study. In particular, PFOA excretion rates were greater in urine than in feces. Within the first $24 \mathrm{~h}$ after the start of oral application of PFOA or PFOS, $24.7 \%$ to $29.6 \%$ PFOA and $2.6 \%$ to $2.8 \%$ PFOS of the oral dosage (5 and $20 \mathrm{mg} / \mathrm{kg} \mathrm{BW} /$ day) were excreted in the urine and feces. The rate of excretion over this period of time increased with the increasing dosage. The higher rate of elimination indicates a lower accumulation capacity. The rapid, almost total uptake and relatively weak elimination of PFOA and PFOS facilitate the bioaccumulation in the body [124].

In experiments on chickens, Yoo et al. [109] determined a rate of elimination for PFOA six times higher than for PFOS. The authors administered 0.1 or $0.5 \mathrm{~g} / \mathrm{L}$ PFOA or 0.2 or $0.1 \mathrm{~g} / \mathrm{L}$ PFOS to the 6-week-old male chickens for 4 weeks. A 4-week excretion phase for PFOA and PFOS followed. The data from the study can be seen in Table 17[109].

In primates, the half-life of PFCs is longer than in other experimental animals such as mice and rats. The elimination half-life is 14 to 42 days in male or female cynomolgus monkeys after oral and intravenous applications. The PFOA concentrations after a 4-week oral application are shown in Table 18. Urine was the principle path of excretion for PFOA in monkeys [125].

In contrast, the half-life of PFOA in Japanese macaques is notably shorter (2.7 to 5.6 days) ([101] as cited by Harada et al. [126]). A half-life of 110 to 130 days was determined for nonhuman primates after a single, intravenous application [127].

The elimination half-time for PFOS in male cynomolgus monkeys was found to be about 200 days [128]. In addition to species-specific differences, the structure of the PFCs can also influence excretion.

Benskin et al. [129] administered a single dose of 500 $\mu \mathrm{g} / \mathrm{kg}$ BW PFOS, PFOA, and PFNA or $30 \mu \mathrm{g} / \mathrm{kg} \mathrm{BW}$ PFHxS to seven male Sprague-Dawley rats. Urine, feces, blood, and tissue samples were taken over the following 38 days, and PFC concentrations were determined by high performance liquid chromatography coupled with tandem mass spectroscopy. It was found that all PFC branch-chained isomers had a lower half-time in the blood than the corresponding linear isomers. The only exception was the PFOS isomer that had an $\alpha$-perfluoro methyl chain (1m-PFOS). This was probably less readily excreted than the linear isomer of PFOS due to spatial shielding of the hydrophilic sulfonate moiety. The authors therefore reasoned that the property of PFOS, PFOA, PFNA and PFHxS chain branching, in general, lowers the half-life in the blood and increases excretion rates. However, different kinetic data may arise depending upon gender, dosage, and species [129]. 
Table 17 Excretion of PFOS and PFOA by young chickens

\begin{tabular}{lcc}
\hline Parameter & PFOS & PFOA \\
\hline Excretion half-life & 125 days & 4.6 days \\
Residual blood concentration at the end of the 4-week excretion phase & $48 \%$ to $52 \%$ & $2 \%$ to $3 \%$ \\
Excretion rate constant & $0.023 \% \pm 0.004 \%$ per day & $0.150 \% \pm 0.010 \%$ per day \\
\hline
\end{tabular}

Excretion was after a 4-week exposure and a 4-week excretion phase (from Yu et al. [171]).

Part two of this study examined the same circumstances under the more realistic conditions of a subchronic exposure. PFCs were mixed with the feed and administered to male and female rats over a period of 12 weeks, followed by a 12-week excretion phase. The feed contained $0.5 \mu \mathrm{g} / \mathrm{g}$ of the ECF products PFOA (approximately $80 \%$ linear), PFOS (approximately 70\% linear), and PFNA (linear form and isopropyl-PFNA). Blood samples that were collected during the exposure phase showed a preferential accumulation of the linear form of PFOA and PFNA over the branched chain isomers. Thus, most of the branched chain PFCA isomers were more quickly eliminated than were the linear forms. No statistically significant differences in rate of elimination of branched chain or linear isomers of PFOS were found. Additional exceptions for two small ECF PFOA isomers and $1 \mathrm{~m}$-PFOS exist. In general, female rats excrete PFCs more rapidly than male rats [130].

Olsen et al. [131] studied the pharmacokinetic behavior of PFBS in rats, monkeys, and humans. Rats received an intravenous PFBS dose of $30 \mathrm{mg} / \mathrm{kg} \mathrm{BW}$ and monkeys, a dose of $10 \mathrm{mg} / \mathrm{kg}$ BW. Serum and urine samples were collected from the animals following application of the substance. Human participants in the study were workers who were occupationally exposed to PFBS. The elimination half-life of PFBS can be seen in Table 19. PFBS is apparently excreted more rapidly than PFHxS and PFOS by rats, monkeys, and humans, whereby species specific differences were observed. This indicates, also for humans, that the capacity for accumulation of PFBS in serum is lower than for long-chain homologues. PFBS excretion for humans was shown to be via the urine [131].

Additional human PFC half-life values were calculated on the basis of serum concentrations from 26 workers

\begin{tabular}{|c|c|c|c|}
\hline \multirow[t]{2}{*}{ Sample matrix } & \multicolumn{3}{|c|}{ Dose } \\
\hline & $3 \mathrm{mg} / \mathrm{kg}$ & $10 \mathrm{mg} / \mathrm{kg}$ & $20 \mathrm{mg} / \mathrm{kg}$ \\
\hline Serum & $81 \mathrm{mg} / \mathrm{L}$ & 99 mg/L & $156 \mathrm{mg} / \mathrm{L}$ \\
\hline Urine & 53 mg/L & 166 mg/L & $181 \mathrm{mg} / \mathrm{L}$ \\
\hline Feces & 7 mg/kg & 28 mg/kg & $50 \mathrm{mg} / \mathrm{kg}$ \\
\hline Liver & $16 \mathrm{mg} / \mathrm{kg}$ & 14 mg/kg & $50 \mathrm{mg} / \mathrm{kg}$ \\
\hline
\end{tabular}

from Butenhoff et al. [283] in the fluorochemical industry. The mean time was 5.4 years for PFOS, 3.8 years for PFOA, and 8.5 years for PFHxS [132].

The renal clearance values for PFOS are $0.012 \mathrm{~mL} / \mathrm{kg} /$ day for men and $0.019 \mathrm{~mL} / \mathrm{kg} /$ day for women, which are low in comparison with the values for the animals studied. The values for renal clearance of PFOA are somewhat higher [126]. The corresponding data are summarized in Table 20.

Renal clearance of PFOS and PFOA is therefore weak, and the compounds have a markedly long half-life in the human body when compared with those in other species. This hinders the translation of results from animal experiments to humans. A gender-dependent excretion of PFOS and PFOA via a hormone-regulated mechanism seems unlikely in humans [126]. This mechanism would also not be expected in mice or rabbits. In the animal model, excretion is mainly through urine and, to a smaller extent, through feces [133,134]. Protein binding and the formation of transporters are decisive factors in the distribution and excretion of PFCs $[15,115]$. Table 19 presents a summary of the elimination half-life values for various species of PFCs.

\section{Toxicodynamics of perfluorinated compounds Acute toxicity}

In animal models, PFOS and PFOA demonstrate a moderate acute toxicity. The lethal dose with $50 \%$ lethality [LD ${ }_{50}$ ] for PFOS is $251 \mathrm{mg} / \mathrm{kg} \mathrm{BW}$ for a single oral dose in rats. $\mathrm{LD}_{50}$ values for PFOA range from 430 to 680 $\mathrm{mg} / \mathrm{kg}$ BW with an average of $540 \mathrm{mg} / \mathrm{kg}$ BW per day $[15,17]$. The lethal concentration with $50 \%$ lethality $\left[\mathrm{LC}_{50}\right]$ for $1 \mathrm{~h}$ inhalation of airborne dust contaminated with PFOS was $5.2 \mathrm{mg} / \mathrm{L}$ for rats. Kennedy et al. [100] determined an $\mathrm{LC}_{50}$ of $0.98 \mathrm{mg} / \mathrm{L}$ for inhalation of PFOA. Inhalation of this concentration over one 4-hour period resulted in enlargement of the liver and corneal opacity in rats.

Glaza et al. [135] determined a dermal $\mathrm{LC}_{50}$ of 2, 000 $\mathrm{mg} \mathrm{PFOA} / \mathrm{kg} \mathrm{BW}$ in rabbits [15]. Rats and rabbits were tested in another study on the dermal toxicity of APFO by Kennedy [99]. Dermal application of $0.5 \mathrm{~g}$ APFO for $24 \mathrm{~h}$ caused light skin irritation in rabbits.

Skin irritation was less pronounced in rats than in rabbits. Irritation of the skin and eyes by PFOS was not observed in albino New Zealand rabbits. ([136] cited in 
Table 19 Elimination half-lives by various species according to perfluorinated compound and gender

\begin{tabular}{|c|c|c|c|c|c|c|c|c|c|}
\hline \multirow[t]{2}{*}{ Species } & \multirow{2}{*}{$\begin{array}{l}\text { PFOS } \\
\text { M/F }\end{array}$} & \multicolumn{2}{|c|}{ PFOA } & \multicolumn{2}{|c|}{ PFHxS } & \multicolumn{2}{|c|}{ PFBA } & \multirow{2}{*}{$\begin{array}{c}\text { PFBS } \\
M / F\end{array}$} & \multirow[t]{2}{*}{ References } \\
\hline & & $\mathbf{F}$ & M & $\mathbf{F}$ & M & $\mathbf{F}$ & M & & \\
\hline $\begin{array}{l}\text { Chicken } \\
\text { Chick }\end{array}$ & $\begin{array}{c}125 \\
\text { days } \\
16 \\
\text { days }\end{array}$ & - & $\begin{array}{l}4.6 \text { days } \\
3.9 \text { days }\end{array}$ & - & - & - & - & - & Yoo et al. [109]; Yeung et al. [284] \\
\hline Rat & $\begin{array}{l}100 \\
\text { days }\end{array}$ & $\begin{array}{c}2 \text { to } 4 \\
h\end{array}$ & $\begin{array}{l}4 \text { to } 6 \\
\text { days }\end{array}$ & - & - & $\begin{array}{l}1.6 \text { to } \\
1.8 \mathrm{~h}\end{array}$ & $\begin{array}{l}7 \text { to } \\
9 \mathrm{~h}\end{array}$ & $\begin{array}{c}4.5 \mathrm{~h} \\
(\mathrm{M}) \\
4 \mathrm{~h}(\mathrm{~F})\end{array}$ & Chang et al. [285]; Johnson et al. [98]; Olsen et al. [131] \\
\hline Mouse & - & 17 days & 19 days & - & - & $3 \mathrm{~h}$ & $7 \mathrm{~h}$ & - & Chang et al. [285]; Lau et al. [161] \\
\hline Rabbit & - & $7 \mathrm{~h}$ & $5.5 \mathrm{~h}$ & - & - & - & - & - & Hundley et al. [133] \\
\hline Dog & - & $\begin{array}{l}8 \text { to } 13 \\
\text { days }\end{array}$ & $\begin{array}{l}20 \text { to } 30 \\
\text { days }\end{array}$ & - & - & - & - & - & Hanhijarvi et al. [286] \\
\hline Monkey & $\begin{array}{l}150 \\
\text { days }\end{array}$ & 30 days & 21 days & $\begin{array}{l}87 \\
\text { days }\end{array}$ & $\begin{array}{l}141 \\
\text { days }\end{array}$ & $\begin{array}{l}1.7 \\
\text { days }\end{array}$ & - & $\begin{array}{c}3.5 \text { to } 4 \\
\text { days } \\
4 \text { days } \\
\text { (M) } \\
3.5 \text { days } \\
\text { (M) }\end{array}$ & $\begin{array}{l}\text { Butenhoff et al. [125]; Chang et al. [285]; Buttenhoff et al. [283]; Olsen et } \\
\text { al. [85]; Seacat et al. [128]; Olsen et al. [131] }\end{array}$ \\
\hline Human & $\begin{array}{c}5.4 \\
\text { years }\end{array}$ & - & $\begin{array}{c}3.8 \\
\text { years }\end{array}$ & - & $\begin{array}{c}8.5 \\
\text { years }\end{array}$ & - & - & $\begin{array}{c}30 \text { days } \\
25.8 \\
\text { days }\end{array}$ & Olsen et al. $[85,131,132]$ \\
\hline
\end{tabular}

F, female; M, male; PFBA, perfluorobutane acid; (from Lau et al. [115] amended and expanded).

EFSA [15]). PFOS was shown to be more toxic than PFOA in studies of fresh water organisms such as water flea, water snails, shrimp, and planaria. Ji et al. [137] even alluded to a toxicity of PFOS 10 times higher than PFOA in such organisms. The lowest $\mathrm{LC}_{50}$ for fish is a 96-h $\mathrm{LC}_{50}$ of $4.7 \mathrm{mg} / \mathrm{L}$ to the fathead minnow Pimephales promelas for the lithium salt [134]. Table 21 summarizes the various $\mathrm{LD}_{50}$ and $\mathrm{LC}_{50}$ values.

\section{Subacute and subchronic toxicities}

Studies have shown that the primary effects of subacute and/or subchronic toxicities induced by repetitive applications of PFOS and PFOA varied according to species: hypertrophy and vacuolization of the liver, reduction of serum cholesterol, reduction of triglycerides in serum, reduction in body weight gain or body weight, and increased mortality.

The most sensitive target organs for repetitive oral application of PFOS over a period of 4 weeks to 2 years in rats and cynomolgus monkeys were the liver and thyroid. The liver was also the most sensitive target organ for repetitive applications of PFOA in mice, rats, and primates. The effects observed include increased weight of liver, increases in enzymatic activity of transaminases in serum (alanine aminotransferase [ALT], aspartate aminotransferase [AST]), hepaticellular hypertrophy, vacuolization, and liver necrosis (17, [127] cited in EFSA [15]). A 28-day study on the oral toxicity of PFOA showed increased mortality, dose-dependent reduction in weight gain and increase in liver weight in rats and mice that had received $30 \mathrm{mg} / \mathrm{kg}$ in their feed or $50 \mathrm{mg} / \mathrm{L}$ in their drinking water ([138,139]; [140] cited in EFSA [15]).

No evidence of disease or increase in mortality rate was observed in a 90-day study (13 weeks) on male rats. An increase in weight loss was observed in the group which received the highest dosage of APFO $(6.5 \mathrm{mg} / \mathrm{kg}$

Table 20 PFOS and PFOA renal clearance and serum half-life in humans compared with monkeys and rats

\begin{tabular}{|c|c|c|c|c|}
\hline Substance & Species & Gender & Renal clearance $(\mathrm{mL} / \mathrm{day} / \mathrm{kg})$ & Serum half-life in days \\
\hline \multirow[t]{3}{*}{ PFOS } & Human & Female (48 kg) & 0.019 & n.r. \\
\hline & & Male $(61 \mathrm{~kg})$ & 0.012 & 3,165 \\
\hline & Cynomolgus monkey & Male & n.r. & 200 \\
\hline \multirow[t]{6}{*}{ PFOA } & Human & Female (48 kg) & 0.027 & n.r. \\
\hline & & Male $(61 \mathrm{~kg})$ & 0.033 & 1,573 \\
\hline & Japanese macaque & Female & 32 & 2.7 \\
\hline & & Male & 15 & 5.6 \\
\hline & Wistar rat & Female & 1,054 & 0.08 \\
\hline & & Male & 46.1 & 5.63 \\
\hline
\end{tabular}


Table $21 \mathrm{LD}_{50}$ and $\mathrm{LC}_{50}$ values for PFOS and PFOA (from [15]; BfR [17] enhanced)

\begin{tabular}{|c|c|c|c|c|}
\hline Criterion & PFOS & PFOA & Animal species & Reference \\
\hline $\mathrm{LD}_{50}$ & 251 mg/kg BW & 430 to 680 mg/kg BW & Rat & $\begin{array}{l}\text { Dean and Jessup } \\
{[287]}\end{array}$ \\
\hline $\mathrm{LC}_{50}$ & $\begin{array}{l}5.2 \mathrm{mg} / \mathrm{L} \\
\text { inhalative }\end{array}$ & $0.98 \mathrm{mg} / \mathrm{L}$, inhalation & Rat & Kennedy [100] \\
\hline $\mathrm{LD}_{50}$ & n.r. & $\begin{array}{l}\text { 4, } 300 \mathrm{mg} / \mathrm{kg} \text { APFO, } \\
\text { dermal }\end{array}$ & Rabbit & Kennedy [99] \\
\hline $\mathrm{LD}_{50}$ & n.r. & $\begin{array}{l}7,000 \mathrm{mg} / \mathrm{kg} \\
7,500 \mathrm{mg} / \mathrm{kg} \text {, dermal }\end{array}$ & $\begin{array}{l}\text { Male rats } \\
\text { Female rats }\end{array}$ & Kennedy [99] \\
\hline $\mathrm{LC}_{50}$ & n.r. & $2,000 \mathrm{mg} / \mathrm{kg}$, dermal & Rabbit & Glaza et al. [135] \\
\hline $\begin{array}{l}48 \mathrm{~h}- \\
L C_{50} \\
96 \mathrm{~h}- \\
L C_{50}\end{array}$ & $\begin{array}{l}27 \text { to } 233 \mathrm{mg} / \mathrm{L} \\
10 \text { to } 178 \mathrm{mg} / \mathrm{L}\end{array}$ & $\begin{array}{l}181 \text { to } 732 \mathrm{mg} / \mathrm{L} \\
337 \text { to } 672 \mathrm{mg} / \mathrm{L}\end{array}$ & $\begin{array}{l}\text { Four fresh water species (water flea, water snail, shrimp, } \\
\text { planarian) }\end{array}$ & Li [288] \\
\hline $\mathrm{LC}_{50}$ & $18 \mathrm{mg} / \mathrm{L}$ & 200 mg/L & Japanese water flea & Ji et al. [137] \\
\hline
\end{tabular}

n.r., Not reported.

$\mathrm{BW} /$ day), at a dosage of $0.64 \mathrm{mg} / \mathrm{kg} \mathrm{BW} /$ day, and increased levels of palmitoyl-CoA-oxidase activity, a marker for peroxisome proliferation.

In addition, liver weight increased. Histopathological changes included hypertrophy and necrosis of the liver cells. Levels of estradiol, testosterone, and luteinizing hormone $[\mathrm{LH}]$ remained unchanged. The PFOA concentrations in serum, measured after treatment with various APFO doses, are shown in Table 22. The "no observed adverse effect level' [NOAEL] determined in this study was $0.06 \mathrm{mg} / \mathrm{kg}$ since a dose of $0.64 \mathrm{mg} / \mathrm{kg} \mathrm{BW} /$ day and above resulted in reversible changes to the liver [141].

Liver toxicity was also described in rats after inhalation and dermal uptake of PFCs. An increase in mortality rates was observed after inhalation exposure to PFOA. Based on non-neoplastic effects in the liver at the next higher dosage, the NOAEL was noted as 0.14 to $0.16 \mathrm{mg} / \mathrm{kg} \mathrm{BW/day} \mathrm{[127].}$

Further studies show that the toxicity profiles of LPFOA, $80 \%$ linear and 20\% branched chain PFOA, as well as $100 \%$ branched chain PFOA are similar. However, the branched chain form is less effective than the pure linear form. The 'lowest observed adverse effect level' [LOAEL] in rats was higher for linear and branched chain isomers ( $1 \mathrm{mg} / \mathrm{kg} \mathrm{BW/day)} \mathrm{than} \mathrm{the}$ LOAEL for the purely linear application form of PFOA

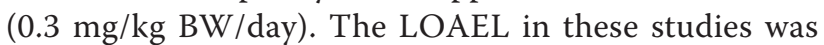

Table 22 PFOA serum concentrations of male rats after a 90-day exposure to various dosages of APFO

\begin{tabular}{cc}
\hline $\begin{array}{c}\text { Dosage (mg APFO/kg feed/ } \\
\text { day) }\end{array}$ & $\begin{array}{c}\text { PFOA serum concentration }(\mathbf{m g} / \\
\text { L) }\end{array}$ \\
\hline 0.06 & 7.1 \\
0.64 & 41 \\
1.94 & 70 \\
6.5 & 138 \\
\hline
\end{tabular}

Adapted from Perkins et al. [141]. based on the reduction of cholesterol and triglyceride levels in the blood of rats. This LOAEL was equivalent to a PFOA serum concentration of 20 to $51 \mathrm{mg} / \mathrm{L}$ in rats ([142] cited in EFSA [15]). These observations are in agreement with the conclusion drawn above that branched chain isomers are generally excreted more rapidly than the linear forms $[129,130]$.

Seacat et al. [108] assumed a NOAEL for PFOS of 0.34 to $0.4 \mathrm{mg} / \mathrm{kg} \mathrm{BW} /$ day when ingested by rats with their food. This was the lowest dose for which an effect could be observed over a time period of 14 weeks in male rats. Nonetheless, this dose was denoted as NOAEL, whereby the observed hepatocellular hypertrophy and vacuolization were marginal [108].

Curran et al. [143] undertook a detailed and extensive study of subacute toxicity of PFOS in rats. The authors exposed Sprague-Dawley rats to doses of 2, 20, 50, or $100 \mathrm{mg}$ PFOS $/ \mathrm{kg}$ in the feed over a period of 28 days. At low dosages, PFOS accumulated primarily in the liver and at lower concentrations, in other organs such as the spleen and heart, as well as in the serum. The PFOS concentrations in the serum and other organs were seen to rise at higher dosages $(50$ and $100 \mathrm{mg} / \mathrm{kg}$ food). The results of this study confirm that the liver is the target organ for PFOS. Hepatomegaly, reduced triglyceride and cholesterol levels in serum, increased the expression of the gene for acyl-coenzyme A-oxidase 1 (ACOX1) and of cytochrome P450 4A22 (CYP4A22) are all indications of exposure to a peroxisome proliferator. Changes in fatty acid profiles in the liver encompass an increase in the total amount of simple unsaturated fatty acids, a loss in the total amount of polyunsaturated fatty acids as well as an increase in linoleic acid concentration and a reduction of long-chain fatty acids. These changes also portend to a weak peroxisome proliferator. The authors suggest that the fatty acid dysfunctions in the liver may possibly be the cause of changes in the 
cell membranes in red blood cells, seen as an increase in lysis and cell fragility. Concentrations of the thyroid hormones tri-iodo thyronine $\left[\mathrm{T}_{3}\right]$ and thyroxine $\left[\mathrm{T}_{4}\right]$ were lowered in PFOS-exposed rats. The kidneys and the cardiovascular system do not seem to be influenced by PFOS. The LOAEL in this study was $20 \mathrm{mg}$ PFOS/ kg feed for male rats and $2 \mathrm{mg}$ PFOS/ $\mathrm{kg}$ feed for female rats based on increased liver weight and reduced body weight. At these dosages, the animals had serum concentrations of 13.5 or $1.5 \mathrm{mg}$ PFOS $/ \mathrm{kg}$, respectively [143].

In a study on the subacute toxicity of PFCs in rats, Cui et al. [144] determined that the liver, the lungs, and the kidneys were the main target organs for these substances. They exposed Sprague-Dawley rats to PFOS or PFOA at concentrations of 5 and $20 \mathrm{mg} / \mathrm{kg} \mathrm{BW} /$ day, respectively, for 28 days. Changes were observed in the group with the highest PFOS dose $(20 \mathrm{mg} / \mathrm{kg} /$ day $)$ including reduced activity, lethargy, reduced food uptake, and an apparent loss of body weight. Hypertrophy and cytoplasmic vacuolization of the liver and epithelial cells induced pleural thickening. The highest PFOA concentrations after a 28-day exposure were measured in the kidneys $(228 \pm 37 \mathrm{mg} / \mathrm{kg}$ at a dosage of 5 $\mathrm{mg} / \mathrm{kg} /$ day). The highest PFOS concentrations were 648 $\pm 17 \mathrm{mg} / \mathrm{kg}$ in the liver following an exposure of $20 \mathrm{mg} /$ $\mathrm{kg} /$ day for 28 days. The increased accumulation of PFOS may explain the higher toxicity of this substance [144].

In a 90-day study on the oral toxicity of PFOA in rhesus monkeys, all four of the animals in the group that received $100 \mathrm{mg} / \mathrm{kg} \mathrm{BW/day} \mathrm{died} \mathrm{within} 5$ weeks, and three monkeys of the group that received $30 \mathrm{mg} / \mathrm{kg}$ $\mathrm{BW} /$ day died in the 13th week. Loss of heart and brain masses was detected in female animals that received 10 $\mathrm{mg} / \mathrm{kg} \mathrm{BW/day.} \mathrm{PFOA-induced} \mathrm{organ} \mathrm{damage} \mathrm{could} \mathrm{be}$ observed in animals that received 3 to $10 \mathrm{mg} / \mathrm{kg} \mathrm{BW/}$ day. The only change seen in the monkeys that received the lowest dosage (3 mg/kg BW/day) was a slight diarrhea $[145,15]$.

In a study, a six-month oral APFO exposure of cynomolgus monkeys indicated a dose-dependent increase in liver weight in association with a proliferation of the mitochondria. No histological evidence of liver damage was observed in the low-dosage range (3 to $10 \mathrm{mg} / \mathrm{kg}$ $\mathrm{BW} /$ day). In addition, no changes were observed in clinical parameters of hormones, urine, or blood composition that could be attributed to treatment with APFO. It must be noted, however, that the groups were made up of only four to six animals, whereby one monkey from the group receiving the lowest dosage was replaced because of bacterial septicemia, and the highest dosage was lowered retroactively due to weight loss and a reduction in food uptake by the animals [146].
In a study by Seacat et al. [128], doses of 0.03, 0.15, and $0.75 \mathrm{mg}$ PFOS $/ \mathrm{kg} \mathrm{BW/day} \mathrm{were} \mathrm{applied} \mathrm{directly} \mathrm{to}$ the stomach of cynomolgus monkeys for 26 weeks. Histopathological changes were detected in the liver at the highest dosage. At the lowest dosages, changes in serum concentrations of thyroid hormones (thyroid stimulating hormone $[\mathrm{TSH}], \mathrm{T}_{3}$ ) were observed. High-density lipoprotein [HDL] and cholesterol levels were also changed. The observed effects in dependence upon dosage in male and female monkeys are shown in Table 23. The clinical changes and the effects on the liver had completely disappeared 211 days after treatment. This reversibility of the effects was accompanied by a significant reduction in PFOS concentration in the serum and in the liver [128].

In both the cynomolgus monkey and in the rat studies, a steep dose-effect relationship for PFOS was conspicuous. The dose-effect curve for PFOA in rats was less steep than that for PFOS ([17] cited Perkins et al. [141]).

Subacute toxic effects of PFC exposure were also observed in fish. Yang [147] put Japanese Girardinus guppies in sea water containing 10,50 , or $100 \mathrm{mg} / \mathrm{L}$ PFOA for 7 days. Neither survival rate nor relative liver and gonad size or growth was affected by this concentration. Peroxisomal acyl-CoA-oxidase activity was, however, increased at the highest dosage. This was accompanied by a significant increase in the peroxisome proliferator activated receptor [PPAR] $\alpha$ expression. PFOA induced a significant inhibition of catalase activity at a high dosage, without causing changes in the superoxide dismutase or glutathione peroxidase level in the liver. This suggests that PFOA causes an induction of the peroxisomal fatty acid oxidation and an increase in oxidative stress by changing the cellular oxidative homeostasis in the liver. Furthermore, PFOA increases the mRNA concentration of proinflammatory cytokines such as IL-6, TNF- $\alpha$, and IL-1 $\beta$ suggesting that inflammation and tissue damage may be involved [45].

\begin{tabular}{|c|c|c|c|c|}
\hline \multirow[t]{2}{*}{ Change } & \multicolumn{4}{|c|}{ PFOS dosage $(\mathrm{mg} / \mathrm{kg}$ BW } \\
\hline & 0 & 0.03 & 0.15 & 0.75 \\
\hline Increased mortality & & & & $x^{a}$ \\
\hline Vacuolization and hypertrophy of the liver & & & & $\times \circ$ \\
\hline TSH level increased & & & $x$ & $\times \circ$ \\
\hline$T_{3}$ level lowered & & $\circ$ & $x$ & $\times \circ$ \\
\hline HDL concentration lowered & & $x$ & $\circ$ & $\times \circ$ \\
\hline Bilirubin concentration dropping & & & & $x$ \\
\hline Cholesterol concentration dropping & & & & $\times \circ$ \\
\hline
\end{tabular}

Changes in male (cross) and female (empty circle) monkeys; ${ }^{a}$ two of six animals. Adapted from Seacat et al. [128]; BfR [17]. 
Fang et al. [148] found that a 14-day exposure of rare minnows to PFOA caused a change in the expression of apolipoproteins and upstream genes (PPAR $\alpha$, PPAR $\gamma$, HNF4 $\alpha$ ). These changes in gene expression can influence lipid metabolism or other physiological functions in fish. Results from studies on subacute and subchronic toxicities of PFCs are summarized in Table 24.

\section{Chronic toxicity and carcinogenicity}

In a study on chronic toxicity and carcinogenicity of PFOS, groups of 40 to 70 male and female rats were fed with the potassium salt of PFOS in doses of $0.5,2,5$, and $20 \mathrm{mg} / \mathrm{kg}$ mixed with their feed for 104 weeks. An additional comparison group received the maximum PFOS dose for 52 weeks, followed by 52 weeks of control diet without PFOS exposure. Hepatotoxic and carcinogenic effects were observed in the rats after PFOS exposure. Based on the hepatotoxic effects, a NOAEL of $2 \mathrm{mg} / \mathrm{kg}$ feed or $0.14 \mathrm{mg} / \mathrm{kg} \mathrm{BW} /$ day was calculated for male and female rats $([17,149]$ cited in EFSA [15]). The observed effects in rats according to dose and frequency are shown in detail in Table 25.

A study by Sibinski [150] on chronic exposure to PFOA showed an increased incidence of Leydig cell adenomas. The incidence of breast fibroadenomas was not significantly or dose-dependently increased over the control values. The 50 male and 50 female rats $^{\mathrm{e}}$ were fed 30 or $300 \mathrm{mg} / \mathrm{kg}$ APFO with their feed for a period of 2 years. A dose-dependent decrease in weight gain was observed in male rats and, to a lesser extent, in female rats. The decrease was statistically significant for both male and female animals that received the maximum dosage. Comparison of survival rates, urinalyses, and opthalmological examinations did not show any significant differences from the control animals. Additional effects observed after exposure to APFO are presented in Table 26. The biological significance of ovarian damage was questioned by the authors due to the lack of evidence of tumorigenesis. According to an evaluation by Mann and Frame [151], the effects on the ovaries were in the form of gonadal hyperplasias and/or adenomas. The NOAEL for male rats, based on increased liver weight and liver anomalies, was $1.3 \mathrm{mg} \mathrm{PFOA} / \mathrm{kg} \mathrm{BW}$. For females, the NOAEL was listed as $1.6 \mathrm{mg}$ PFOA $/ \mathrm{kg}$ $\mathrm{BW} /$ day since higher dosages led to reduced body weight and changes in blood values [15].

A pathology work group evaluated the appearance of proliferative injury to mammary glands in female rats that had been fed APFO for 2 years. Using documents

Table 24 Data from studies on subacute and subchronic toxicities of PFOS and PFOA

\begin{tabular}{|c|c|c|c|c|c|c|}
\hline Substance & $\begin{array}{l}\text { Exposure } \\
\text { period }\end{array}$ & Species & Target organ/Effect & $\begin{array}{l}\text { Effective } \\
\text { dosage }^{a}\end{array}$ & NOAEL $^{a}$ & Reference \\
\hline \multirow[t]{4}{*}{$\overline{P F O S}$} & 28 days & Rats & $\begin{array}{l}\text { Body weight } \downarrow \text {, liver mass } \uparrow \text {, and altered gene expression and fatty } \\
\text { acid metabolism in the liver, } T_{3} \text {, and } T_{4} \downarrow\end{array}$ & $\begin{array}{l}2 \text { to } 20 \\
\mathrm{mg} / \mathrm{kg} \\
\text { feed }\end{array}$ & n.r. & $\begin{array}{l}\text { Curran et } \\
\text { al. [143] }\end{array}$ \\
\hline & 14 weeks & Rats (male) & Hypertrophy and vacuolization of the liver & n.r. & 0.37 & $\begin{array}{l}\text { Seacat et } \\
\text { al. [108] }\end{array}$ \\
\hline & 26 weeks & $\begin{array}{l}\text { Cynomolgus } \\
\text { monkey }\end{array}$ & $\begin{array}{l}\text { Centrilobular vacuolization, hypertrophy of the liver, } T_{3} \downarrow, \mathrm{TSH} \uparrow, \mathrm{HDL} \\
\downarrow \text {, and bilirubin, cholesterol concentrations } \downarrow\end{array}$ & n.r. & 0.03 & $\begin{array}{l}\text { Seacat et } \\
\text { al. [128] }\end{array}$ \\
\hline & $\begin{array}{l}1 \text { and } 4 \\
\text { months }\end{array}$ & $\begin{array}{l}\text { Fresh water } \\
\text { larvae of small } \\
\text { dragonflies }\end{array}$ & $\begin{array}{l}\text { Deterioration of behavioral and activity parameters (larvae were less } \\
\text { active, less able to avoid attackers, or less efficient in foraging) }\end{array}$ & $>10 \mu \mathrm{g} /$ & $10 \mu \mathrm{g} / \mathrm{L}$ & $\begin{array}{l}\text { Van } \\
\text { Gossum et } \\
\text { al. [289] }\end{array}$ \\
\hline \multirow[t]{3}{*}{ PFOA } & 7 days & Japanese guppies & $\begin{array}{l}\text { Activity of peroxisomal acyl-CoA-oxidase } \uparrow \text { and significant inhibition } \\
\text { of catalase activity, mRNA concentration proinflammatory cytokines } \\
\text { such as IL-6, TNF- } \alpha \text { and IL-1 } \beta \uparrow\end{array}$ & $\begin{array}{l}50 \text { and } \\
100 \mathrm{mg} / \mathrm{L}\end{array}$ & n.r. & Yang [147] \\
\hline & 14 days & Minnows & $\begin{array}{l}\text { Changes in the expression of apolipoproteins and upstream genes } \\
(\text { PPAR } \alpha, \operatorname{PPAR} \gamma, \mathrm{HNF} 4 \alpha)\end{array}$ & n.r. & n.r. & $\begin{array}{l}\text { Fang et al. } \\
{[148]}\end{array}$ \\
\hline & 90 days & Rats (male) & Liver mass $\uparrow$ and hepatocellular necrosis & 1.7 & 0.6 & $\begin{array}{l}\text { Goldenthal } \\
\text { [290] }\end{array}$ \\
\hline \multirow[t]{4}{*}{ APFO } & 14 days & Rats & Body weight gain $\downarrow$, liver mass $\uparrow$, and serum enzyme activity $\uparrow$ & $84 \mathrm{mg} /$ & $1 \mathrm{mg} /$ & $\begin{array}{l}\text { Kennedy et } \\
\text { al. [100] }\end{array}$ \\
\hline & 90 days & Rats (male) & $\begin{array}{l}\text { Absolute and relative liver mass } \uparrow \text {, hepatocellular hypertrophy, and } \\
\text { effects were reversible }\end{array}$ & 0.64 & 0.06 & $\begin{array}{l}\text { Perkins et } \\
\text { al. [141] }\end{array}$ \\
\hline & 90 days & Rhesus monkey & Gastrointestinal effects and mortality & 3 to 100 & n.r. & $\begin{array}{l}\text { Goldenthal } \\
{[145]}\end{array}$ \\
\hline & 26 weeks & $\begin{array}{l}\text { Cynomolgus } \\
\text { monkey }\end{array}$ & Liver mass and mortality $\uparrow$ & 3 to 30 & n.r. & $\begin{array}{l}\text { Butenhoff } \\
\text { et al. [146] }\end{array}$ \\
\hline $\begin{array}{l}\text { PFOS/ } \\
\text { PFDA/ } \\
\text { PFOA }\end{array}$ & 3 weeks & Chicks (male) & No significant effects & n.r. & $>1$ & $\begin{array}{l}\text { Yeung et } \\
\text { al. [284] }\end{array}$ \\
\hline
\end{tabular}

${ }^{a}$ Effective dosage and NOAEL without further specifications are presented in milligrams per kilogram per body weight per day. Upward arrow, increased; downward arrow, decreased; n.r., not reported; $T_{3}$ : tri-iodo thyronine; $T_{4}$, thyroxin. 


\section{Table 25 Observed effects in a study of chronic exposure of rats to PFOS}

\begin{tabular}{|c|c|c|}
\hline Category & Effects & Occurrence, dosage, and frequency (Cases/Total number) \\
\hline Hepatotoxicity & $\begin{array}{l}\text { Increase in centrolobular hypertrophy, eosinophilic granuloma, } \\
\text { and vacuolization of liver cells }\end{array}$ & $\begin{array}{l}\text { (a) Male rats, } 2 \mathrm{mg} / \mathrm{kg} \text { of feed } \\
\text { (b) Male and female rats, } 5 \text { or } 20 \mathrm{mg} / \mathrm{kg} \text { of feed }\end{array}$ \\
\hline $\begin{array}{l}\text { Electron } \\
\text { microscopic } \\
\text { results }\end{array}$ & $\begin{array}{l}\text { Mild to moderate hyperplasia of the smooth endoplasmic } \\
\text { reticulum, minimal to mild hypertrophy of liver cells, and no } \\
\text { peroxisome proliferation }\end{array}$ & In a proportion of the animals that received $20 \mathrm{mg} / \mathrm{kg}$ of feed \\
\hline $\begin{array}{l}\text { Neoplastic } \\
\text { effects }\end{array}$ & $\begin{array}{l}\text { Significant increase in the incidence of (a) adenomas of the liver, } \\
\text { (b) follicular adenomas of the thyroid, (c) hepatocellular } \\
\text { adenomas, carcinomas, (d) follicular adenomas and carcinomas of } \\
\text { the thyroid, (e) fibrocystic breast adenomas/adenomas, and (f) } \\
\text { fibrocystic breast adenomas/adenomas/carcinomas }\end{array}$ & $\begin{array}{l}\text { (a) Male rats, } 20 \mathrm{mg} / \mathrm{kg} \text { of feed }(7 / 60) \text {, control }(0 / 60) \\
\text { (b) Comparison group (9/39), control (3/60), group with highest } \\
\text { dosage }(4 / 59) \\
\text { (c) Female rats, } 20 \mathrm{mg} / \mathrm{kg} \text { of feed } \\
\text { (d) Female rats, } 5 \mathrm{mg} / \mathrm{kg} \text { of feed (3/50), control }(0 / 60) \\
\text { (e) Female rats with the exception of the group with the highest } \\
\text { dosage } \\
\text { (f) Female rats, } 0.5 \mathrm{mg} / \mathrm{kg} \text { of feed ( } 36 / 50), 2 \mathrm{mg} / \mathrm{kg}(31 / 48) \text {, but } \\
\text { not for the group with } 5 \text { and } 20 \mathrm{mg} / \mathrm{kg} \text { of feed ( } 29 / 50 \text { and } 24 / \\
60) \text {, control ( } 29 / 60)\end{array}$ \\
\hline
\end{tabular}

Adapted from Thomford [149] cited in EFSA [15].

from the study of Sibinski [150], they came to the conclusion that the incidence of mammary gland tumors was not changed by chronic exposure to APFO. Feeding female rats (see Table 26) as much as $300 \mathrm{mg} / \mathrm{kg}$ APFO did not result in an increase in proliferative damage to breast tissue [152].

In an additional study on the carcinogenicity of APFO, rats were fed $300 \mathrm{mg} \mathrm{APFO} / \mathrm{kg}$ of food, equivalent to $\mathrm{ca}$. $14 \mathrm{mg} / \mathrm{kg} \mathrm{BW} /$ day for 2 years. The study encompassed 153 rats, and an additional 80 animals formed the control group. Hormone status, cell proliferation, and peroxisome proliferation were measured. Increases in liver weight and $\beta$-oxidation activity of the liver were statistically significant throughout the whole test period, whereas increases in weight of the testicles only occurred at 24 months. No differences were detected between the exposed rats and the control animals in regard to serum concentrations of testosterone, folliclestimulating hormone $[\mathrm{FSH}], \mathrm{LH}$, or prolactin. An increased incidence of Leydig cell adenomas was seen in the exposed group (8/76) when compared with the control group (0/80) as well as liver adenomas (10/76 vs. 2/ $80)$ and pancreas cell tumors (7/77 vs. 0/80). The numbers in brackets show the observed cases and total number of animals in the groups of exposed and control animals [153]. Further studies showed that an APFO dosage of $14.2 \mathrm{mg} / \mathrm{kg} \mathrm{BW} /$ day increases the incidence of damage to proliferating pancreas cells; however, it does not increase the incidence of adenomas or carcinomas ([17,154] cited in EFSA [15]).

Sibinski [150] and Biegel et al. [153] both showed that PFOA or PFOS induces liver-cell adenomas, Leydig cell adenomas, and hyperplasia of acinar pancreas cells. Furthermore, it could be shown that PFOA functions as promoter in liver carcinogenesis of male Wistar rats. The rats were treated with $0.02 \%$ APFO in their feed, and $200 \mathrm{mg} / \mathrm{kg} \mathrm{BW/day} \mathrm{of} \mathrm{diethylnitrosamine} \mathrm{served} \mathrm{as}$ initiator ([155,156] cited in EFSA [15]).

\section{Genotoxicity and epigenetic effects}

In various in vitro and in vivo test systems, PFOS and PFOA did not appear to be genotoxic. Therefore, it can be assumed that the carcinogenic effects are the result of an epigenetic mechanism and that the trigger is a threshold concentration, i.e., apparently a dosage exists beneath which a carcinogenic effect would not be expected [17].

Based on a number of in vitro and in vivo tests concerning gene and/or chromosome mutagenicity or the induction of unscheduled gene repair, the EFSA also assumes that PFOS is not genotoxic. PFOS does not

Table 26 Effects on rats after a 104-week application of APFO (from Sibinski [150]; EFSA [15])

\begin{tabular}{|c|c|c|}
\hline Category & Effects & $\begin{array}{l}\text { Animal, dosage, in part frequency } \\
\text { (Cases/Total number) }\end{array}$ \\
\hline $\begin{array}{l}\text { Non-neoplastic } \\
\text { effects }\end{array}$ & $\begin{array}{l}\text { (a) Slight reduction in number of erythrocytes and packed cell volume, liver mass, liver } \\
\text { nodules, Leydig cell mass } \uparrow \text {; (b) number of white blood cells } \uparrow \text { and AST, ALT, alkaline } \\
\text { phosphatase, and creatine phosphokinase } \uparrow ; \text {; (c) breast tissue mass } \uparrow \text { and tubular } \\
\text { hyperplasia of the ovarian stroma; (d) kidney mass } \uparrow \text { and changes in the liver } \\
\text { (hepatomegalocytosis, necrosis, mononuclear cell infiltration, cystoid degeneration) }\end{array}$ & $\begin{array}{l}\text { (a) Male rats, } 300 \mathrm{mg} / \mathrm{kg} \\
\text { (b) Male rats, } 30 \mathrm{mg} / \mathrm{kg} \\
\text { (c) Female rats, } 30 \mathrm{mg} / \mathrm{kg} \\
\text { (d) Female rats, } 300 \mathrm{mg} / \mathrm{kg}\end{array}$ \\
\hline Carcinogenicity & $\begin{array}{l}\text { (a) Incidences of testicular Leydig cell adenomas } \uparrow \text { and (b) fibrocystic breast adenomas } \\
\uparrow\end{array}$ & $\begin{array}{l}\text { (a) Male rats, } 0 \mathrm{mg} / \mathrm{kg}(0 / 50), 30 \mathrm{mg} / \mathrm{kg} \\
(2 / 50), 300 \mathrm{mg} / \mathrm{kg}(7 / 50) \\
\text { (b) Female rats, } 0 \mathrm{mg} / \mathrm{kg}(10 / 46), 30 \mathrm{mg} / \\
\mathrm{kg}(19 / 45), 300 \mathrm{mg} / \mathrm{kg}(21 / 44)\end{array}$ \\
\hline
\end{tabular}


induce gene mutation with or without metabolic activation in a bacterial test system, does not cause chromosome aberrations in human lymphocytes, and does not induce unscheduled DNA synthesis in rat hepatocytes. PFOS does not cause formation of micronuclei in a mouse's bone marrow cells in vivo. Various in vitro and in vivo genotoxicity tests for precursors of PFOS and $N$ ethylperfluorooctyl sulfonamide ethanol [ $N$-EtFOSE], $N$ EtFOSA, $N$-methylperfluorooctyl sulfonamide ethanol were also negative. APFO also failed to induce back mutations in tests with Salmonella typhimurium or Escherichia coli, both with or without metabolic activation. APFO did not cause chromosome aberrations in human lymphocytes or in ovary cells of Chinese hamsters, with or without metabolic activation, nor did it lead to cell transformation in mouse embryo fibroblasts. An in vivo micronuclear test on mice treated with PFOA was also negative [15].

Murli et al. [157] twice tested the potential of APFO to cause chromosome aberrations in cells of the Chinese hamster. In the first test, the results were positive, both with and without metabolic activations, i.e., chromosome damage was observed. In the second test, APFO induced chromosome aberrations and polyploidy only without activation. However, these effects were only observed at cytotoxic concentrations of APFO [15].

In the study by Yao and Zhong [158], PFOA was seen to induce not only DNA strand breaks, but also increased concentrations of reactive oxygen species and 8-hdroxydesoyguanosine [8-dG]. This result suggests that the observed genotoxic effects are induced by an oxidative damage to the DNA or by intracellular ROS. Takagi et al [159] also detected significantly increased 8dG concentrations.

\section{Reproductive and developmental toxicity}

PFOS and PFOA neither interfered with reproduction nor did they lead to any appreciable teratogenic effects. Both substances did, however, show developmental toxicity when the mother animal was exposed during pregnancy, i.e., they led to a reduced increase in body weight after birth and reduced the number of live births and the viability of the progeny in the first five days after birth $[15,17,115,134,160,161]$.

For example, in a study by Lau et al. [162], all liveborn young rats, born to a mother that was exposed to $10 \mathrm{mg}$ PFOS/kg BW/day during gestation, were pallid, inactive, became moribund within 30 to $60 \mathrm{~min}$, and died shortly thereafter. The offspring of mother animals that received $5 \mathrm{mg} \mathrm{PFOS} / \mathrm{kg} \mathrm{BW} /$ day, survived for 8 to $12 \mathrm{~h}$. This could also be observed in progeny of mother animals that received 20 or $15 \mathrm{mg} / \mathrm{kg} \mathrm{BW/day.} \mathrm{However,}$ 95\% of these progeny died within the first $24 \mathrm{~h}$ after birth. Approximately $50 \%$ of the progeny died when the mother animal received $3 \mathrm{mg}$ PFOS/kg BW/day (rat) or
$10 \mathrm{mg} / \mathrm{kg} \mathrm{BW/day} \mathrm{(mouse).} \mathrm{Wet} \mathrm{nursing} \mathrm{the} \mathrm{progeny} \mathrm{by}$ a non-exposed control animal did not improve their viability. Prenatally exposed rats and mice that did survive showed delays in growth and opening of the eyes. Exposed young mice had significantly higher liver weight and lower $\mathrm{T}_{4}$ concentrations in serum but unchanged $\mathrm{T}_{3}$ and TSH concentrations when compared with nonPFOS-exposed animals [162].

In a two-generation study on rats, Lübker et al. [163] found fertility parameters unchanged after oral application of the maximal PFOS concentration was tested (3.2 $\mathrm{mg} / \mathrm{kg} \mathrm{BW/day).}$

In another two-generation study on rats, the progeny of PFOS-exposed mother animals (LOAEL $=0.4 \mathrm{mg} / \mathrm{kg}$ $\mathrm{BW} /$ day) were found to gain body weight more slowly in the F1 generation and to have reduced birth weight in the F2 generation. The serum concentrations of the animals (F0) on the 21st day of gestation were $26.2 \mathrm{mg} /$ $\mathrm{kg}$ and of the fetuses, $34.4 \mathrm{mg} / \mathrm{kg}$ (liver- and serumpooled). The NOAEL was calculated to be $0.1 \mathrm{mg} / \mathrm{kg}$ BW/day ([164] cited in EFSA [15]).

Unaltered fertility parameters were found in yet another two-generation study of PFOA-exposed rats by Buttenhoff [165]. The highest dosage in this study was $30 \mathrm{mg} / \mathrm{kg} \mathrm{BW} /$ day. No signs of maternal toxicity were observed in the animals at exposures up to this dosage. However, compared with those in control animals, the adult body weight of the progeny was lower and liver and kidney weights were higher even at the lowest dosage tested, $1 \mathrm{mg} / \mathrm{kg} \mathrm{BW/day.} \mathrm{The} \mathrm{mortality} \mathrm{rate} \mathrm{of}$ the progeny was increased at $30 \mathrm{mg} / \mathrm{kg} \mathrm{BW} /$ day, which is the highest dosage tested [17].

Because of allusions to a correlation between PFOA serum concentrations with a reduced sperm count in young Danish adults and/or a longer period before pregnancy occurred, York et al. [166] reevaluated these twogeneration studies. Testicular and sperm structures and functions, however, were unchanged in APFO-treated rats with an average PFOA serum concentration as high as $50,000 \mu \mathrm{g} / \mathrm{L}$. Since the PFOA concentration in the Danish cohort was $5 \mu \mathrm{g} / \mathrm{L}$, the authors assume that there is no causal relationship between PFOA concentrations in serum and a reduction in sperm count in these men [166].

Lau et al. [161] carried out studies on the developmental toxicology of PFOA using mice since the excretion of PFOA in female rats is so rapid that these animals were not considered appropriate experimental subjects for these tests. Effects (increased liver weight) were observed in the mother animals exposed to a dosage of $1 \mathrm{mg} / \mathrm{kg} \mathrm{BW/day} \mathrm{or} \mathrm{higher.} \mathrm{Increased} \mathrm{resorp-}$ tion of fetuses and reduction of survival rate and body weight gain of the live-born progeny were observed when mother animals received dosages of $3 \mathrm{mg} / \mathrm{kg} \mathrm{BW/}$ 
day. These effects exhibited a steep dose-response curve. The resorption of all of the fetuses in a litter during gestation (full-litter resorption) which resulted from a dosage of $5 \mathrm{mg}$ PFOA/kg BW/day or higher was particularly striking $[17,161]$.

Grasty et al. [167] set out to determine a critical time period of gestation for effects of prenatal exposure using Sprague-Dawley rats. The authors administered $25 \mathrm{mg} /$ $\mathrm{kg} \mathrm{BW}$ of the potassium salt of PFOS on GD 2 to 5,6 to 9,10 to 13,14 to 17 , and 17 to 20 or 25 or $50 \mathrm{mg} / \mathrm{kg}$ BW on day19 to 20 . Neonatal mortality was observed for all of the time periods; however, the incidence of stillbirths increased with the PFOS exposure at later periods of gestation, reaching $100 \%$ for prenatal exposure on GD 17 to 20. Exposure to PFOS in the late phases of gestation is apparently adequate to induce effects that are toxic to reproduction. This result suggests that PFOS damages the organs that develop in the last phases of gestation. Grasty et al. [168] therefore examined the lungs of newborn rats and discovered thickening of the alveolar walls of prenatal PFOSexposed young animals. However, as a result of the normal phospholipid profile of the lungs and the fact that treatment with dexamethasone or retinylpalmitate did not ameliorate the situation, it must be concluded that the neonatal mortality is not due to the immaturity of the lungs [15]. Lau et al. [115] mentioned studies that suggest an effect of PFCs on the pulmonary surfactants, e.g., dipalmitoylphosphatidylcholine. In a study in which PFOA was exclusively applied in the late phase of gestation, it was also shown that this treatment was adequate to trigger developmental toxic effects in mice ([169] cited in BfR [17]).

In a cross-fostering study, Lübker et al. [170] observed that neonatal mortality was also high in progeny that had been exposed to PFOS in utero but which had not been exposed to any further PFOS in milk. Compared with control animals, a diminished gain in body weight was also noted in animals that were only exposed to PFOS via the milk they drank, but were not the progeny of PFOS-treated mother animals $[17,115]$.

$\mathrm{Yu}$ et al. [171], in another cross-fostering study, observed that both pre- and postnatal PFOS exposures ( $3.2 \mathrm{mg} / \mathrm{kg}$ feed) lower the $\mathrm{T}_{4}$ concentration in the prenatally exposed progeny. On days 21 and 35 after birth, the $\mathrm{T}_{4}$ concentrations were reduced by $20.3 \%$ or $19.4 \%$, and in postnatally exposed rats, by $28.6 \%$ or $35.9 \%$ compared with control animals.

Liu et al. [113] injected young mice with $50 \mathrm{mg} / \mathrm{kg}$ BW PFOS on different days after birth. They then measured, among other things, the concentration of maleic acid dialdehyde, superoxide dismutase [SOD] activity, and the total antioxidative capacity [T-AOC] as parameters of oxidative damage that might be occurring.
PFOS induced a loss of body weight in mice and an increase in the relative weight of the liver. It also suppressed SOD activity and diminished the T-AOC in the brain and liver. Younger mice were more sensitive to the effects of PFOS than older animals [113].

Abbott et al. [172] studied the influence of PPAR $\alpha$ on the PFOA-induced developmental toxicity using wildtype and PPAR $\alpha$ knockout mice. The authors administered oral dosages of $0.1,0.3,0.6,1,3,5,10$, and 20 $\mathrm{mg} / \mathrm{kg} \mathrm{BW}$ on the $1 \mathrm{st}$ to the 17th GD. (The effects are described in Table 17). Resorption of all fetuses of a mother animal through the administration of $5 \mathrm{mg}$ $\mathrm{PFOA} / \mathrm{kg} \mathrm{BW} /$ day occurred as frequently in the PPAR $\alpha$ deficient mice as in the wild-type animals. The effects of PFOA cannot therefore be attributed fully to the activation of PPAR $\alpha$. PPAR $\alpha$ does, however, seem to play a role in the delayed opening of eyes and the postnatal reduction in weight gain $[15,17,172]$. Abbott et al. [173] came to the conclusion that the developmental toxicity effects are not dependent upon the activation of PPAR $\alpha$ by PFOS. The wild-type mice were just as sensitive to the effects of neonatal lethality as were the PPAR $\alpha$ knockout mice. Furthermore, it can be seen from this publication that PPAR $\alpha, \beta$, and $\gamma$ are expressed in early developmental phases in embryos of rodents and humans. The expression patterns depend upon the developmental stage and the type of tissue, leading to the assumption that PPAR $\alpha, \beta$, and $\gamma$ play important functions in many cell types and organs during development [173].

The influences on reproduction by PFOS and PFOA are not limited to mammals but have, for example, also shown to affect chickens [174-176], quail, mallard duck [177], frogs, and fish ([178,179] cited in Lau et al. [115]). The following observations stem from studies on the developmental and reproductive toxicity of other PFCs:

The toxic effects of $N$-Et-FOSE are similar to those of PFOS. This may be explained by the transformation of $N$-Et-FOSE into PFOS; however, $N$-Et-FOSE was also seen to increase the number of stillbirths and mortality of the newborn in the F2 generation of rats $([163,164]$ cited in Lau et al. [115]). The effects of 8:2 FTOH on rats were slightly similar to those of PFOA into which FTOH can be transformed. The NOAEL for 8:2 FTOH was determined to be $200 \mathrm{mg} / \mathrm{kg} \mathrm{BW/day} \mathrm{([58]} \mathrm{cited} \mathrm{in}$ Lau et al. [115]). PFBS did not elicit a verifiable developmental effect in rats [115]. In contrast to observations on PFOS and PFOA, exposure of pregnant mice to PFBA was not found to have adverse effects on survival of newborn or their postnatal growth [180]. Although PFHxS, compared with PFBS, PFOS and PFOA, has the longest half-life in humans, no effects on reproduction or survival and growth of the progeny was observed in rats. The NOAEL for developmental toxicity of PFHxS 
was determined to be $10 \mathrm{mg} / \mathrm{kg} \mathrm{BW} /$ day ([181] cited in Lau et al. [115]). Perfluorodecanoic acid, like other PFCs, did not induce deformations and also did not elicit any other developmental toxic effects [182].

PFNA led to cell apoptosis in testicles of male rats. The animals received oral doses of 1,3 , and $5 \mathrm{mg} / \mathrm{kg} /$ day for 14 days. The results imply that the 'death receptor pathway' is the chief mediator for apoptosis in the kidneys which is a result of PFNA exposure. It is not yet known whether PFNA induces the changes in Fas and FasL expressions directly or whether the imbalance between testosterone and estradiol, which causes germ cell apoptosis, is involved in the Fas/FasL pathway [183]. Table 27 presents a survey of the studies on reproduction and developmental toxicity of PFOS, PFOA, and other PFCs.

\section{Neurotoxicity}

A study by Austin et al [107] showed that PFOS can have an influence on the neuroendocrine system in rats. The authors discovered reduced food intake and body weight, influence on the ovarian cycle, increased corticosterone concentration, and decreasing leptin concentration in serum as effects of PFOS exposure. In addition, noradrenaline concentrations in the paraventricular nucleus of the hypothalamus were elevated.

In an in vitro study, Harada et al. [184] observed that PFOS increases the negative charge density in the cell membrane of Purkinje cells, e.g., nerve cells in the cerebellum, of rats. It also reduced the membrane potential, leading to hyperpolarization and thus influencing activation and inactivation of the ion channels. This appears to indicate that PFOS has an effect on the action potential in nerve cells [185].

Slotkin et al. [186] tested the neurotoxicity of PFOS, PFOA, FOSA, and PFBS in an in vitro experiment on undifferentiated and differentiated PC12 cells. After addition of the substances, the authors examined the cells for inhibition of DNA production, deficits in cell numbers and growth, oxidative stress, reduced viability, as well as changes in the production of the neurotransmitters, dopamine and acetylcholine. They came to the conclusion that the different PFCs do not exhibit the same influence on neurons and that it is unlikely that a simple, mutual mechanism is behind all of the neurotoxic effects. FOSA exhibited the strongest effects on the cells, followed by PFOS and PFBS, and finally, PFOA. FOSA depressed DNA production, caused oxidative stress, and reduced the viability of the cells. An explanation for the stronger toxic potential of FOSA is most likely the increased hydrophobicity of this compound and the inherently enhanced access to the cell membrane [186].

In their study, Liao et al. [187] also came to the conclusion that the effects of PFCs on the neurons of the hippocampus of rats are dependent upon the length of the carbon chains and on the functional groups on the alkyl chains. The influence of PFCs on synaptic transmission, calcium current, and neurite growth were examined. Longer chain compounds or such that have a sulfonate group appeared to have stronger effects than short-chain PFCs with a carboxylate group. For example, the experiments with PFOS and PFTDA displayed the highest frequency and strongest amplitude of spontaneous miniature postsynaptic currents [187].

Ten-day old mice received a single dose of 0.75 or $11.3 \mathrm{mg}$ PFOS $/ \mathrm{kg} \mathrm{BW}, 0.58$ or $8.7 \mathrm{mg}$ PFOA $/ \mathrm{kg} \mathrm{BW}$, or 0.72 or $10.8 \mathrm{mg}$ PFDA $/ \mathrm{kg}$ BW in their stomachs. Their spontaneous behavior, defined as movement, breeding behavior, and total activity, as well as their habits were then observed at 2 and 4 months. Behavioral abnormalities were observed in the mice that were exposed to PFOS and PFOA. These appeared as a reduced or deficient adaptability and hyperactivity of the adult mice. These effects became stronger with age. An effect on the cholinergic system was examined using the nicotineinduced spontaneous behavior test on 4-month old animals. The response to nicotine was hypoactivity in exposed animals in contrast with a hyperactive response to nicotine in control animals. Based on the response to nicotine, the effects appear to be mediated by the cholinergic system. These neurotoxic changes are similar to those induced by other POPs such as PCB $[15,188]$. In a subsequent study on mice, Johansson et al. [189] also showed that PFOS and PFOA increased the concentrations of proteins that are necessary for normal brain development, the tau protein and synaptophysin. Tau proteins play a role in the pathogenesis of Alzheimer's disease, and synaptophysin is a membrane protein of synaptic vesicles [190]. Altered concentrations of these proteins could possibly explain the behavioral changes described above [189].

According to the results of Sato et al. [191], a single dose of PFOS ( $\geq 250 \mathrm{mg} / \mathrm{kg}$ in rats, $\geq 125 \mathrm{mg} / \mathrm{kg}$ in mice) caused tonic spasms; however, ultrasound stimulus was required as trigger. Even with ultrasound stimulus, PFOA was not found to cause spasms. Changes in neurotransmitter concentrations in the brain or damage to nerve cells did not occur. Therefore, it was not possible to finally elucidate the mechanism responsible for the spasms. PFOS concentrations in the brain (20 to $25 \mathrm{mg} /$ $\mathrm{kg}$ ) were always lower than those in the liver, kidneys, or serum and increased with passing time after application [191].

The developmental neurotoxic effects were studied in a further in vivo study. Rats were fed 7.2 or $14.4 \mathrm{mg}$ $\mathrm{PFOS} / \mathrm{kg}$ of feed from the beginning of gestation until 30 days after birth. The cross-fostering method was used to differentiate between pre- and postnatal 
Table 27 Studies on the reproduction and developmental toxicity of PFCs (from EFSA [15] and enhanced)

\begin{tabular}{|c|c|c|c|c|c|}
\hline Substance & $\begin{array}{l}\text { Experimental } \\
\text { animal }\end{array}$ & Tested dosage and time point & Effects & $\begin{array}{l}\text { NOAEL } \\
\text { LOAEL }^{\mathrm{a}} \\
\end{array}$ & Reference \\
\hline \multirow[t]{10}{*}{ PFOS } & Rats & $\begin{array}{l}\text { 1, 5, and } 10 \mathrm{mg} / \mathrm{kg} \text { BW/day; GD } 6 \text { to } \\
15\end{array}$ & $\begin{array}{l}\text { Body mass of the maternal animal } \downarrow \text { and lens } \\
\text { abnormalities }\end{array}$ & $\begin{array}{c}5 \\
10\end{array}$ & $\begin{array}{l}\text { Gortner } \\
{[291]}\end{array}$ \\
\hline & Rats & 5 and $10 \mathrm{mg} / \mathrm{kg} \mathrm{BW/day;} \mathrm{GD} 6$ to 15 & $\begin{array}{l}\text { Weight loss of the maternal animal and } \\
\text { developmental toxic effects: birth weight } \downarrow \text {, } \\
\text { inner organ abnormalities, delayed } \\
\text { ossification, and skeletal anomalies }\end{array}$ & $\begin{array}{l}1 \\
5\end{array}$ & Wetzel [292] \\
\hline & Rats & $\begin{array}{l}1,2,3,5 \text {, and } 10 \mathrm{mg} / \mathrm{kg} \mathrm{BW/day;} \mathrm{GD} \\
2 \text { to } 21\end{array}$ & $\begin{array}{l}\text { Weight gain of the maternal animal } \downarrow \text {; serum } \\
T_{4} \text { and } T_{3} \text { of the maternal animal } \downarrow ; \text { at the } \\
\text { highest dosage: body weight of the fetus } \downarrow \text {, } \\
\text { cleft palate, anasarca, death rate } 4 \text { to } 6 \mathrm{~h} \text { after } \\
\text { birth } \uparrow \text {; and from } 2 \mathrm{mg} / \mathrm{kg} \text { BW/day: postnatal } \\
\text { growth rate, delayed opening of eyes, } T_{4} \downarrow\end{array}$ & n.r. & $\begin{array}{l}\text { Lau et al. [162]; } \\
\text { Thiobodeaux et al. } \\
\text { [114] }\end{array}$ \\
\hline & Mice & $\begin{array}{l}\text { 1, } 5,10,15 \text {, and } 20 \mathrm{mg} / \mathrm{kg} \text { BW/day; } \\
\text { GD } 1 \text { to } 18\end{array}$ & $\begin{array}{l}\text { Delayed opening of eyes and from } 5 \mathrm{mg} / \mathrm{kg} \\
\text { BW/day: liver mass } \uparrow\end{array}$ & n.r. & $\begin{array}{l}\text { Lau et al. [162]; } \\
\text { Thiobodeaux et al. } \\
\text { [114] }\end{array}$ \\
\hline & Rats & $\begin{array}{l}0.4,0.8,1,1.2,1.6 \text {, and } 2 \mathrm{mg} / \mathrm{kg} \text { BW/ } \\
\text { day; } 6 \text { weeks before mating, during } \\
\text { gestation, and up to the fourth day } \\
\text { of nursing }\end{array}$ & $\begin{array}{l}\text { From } 0.8 \mathrm{mg} / \mathrm{kg} \text { BW/day: gestation time and } \\
\text { viability of the young animals } \downarrow\end{array}$ & n.r. & $\begin{array}{l}\text { Lübker et al. } \\
{[163,170]}\end{array}$ \\
\hline & Rats & $\begin{array}{l}0.1,0.4,1.6 \text {, and } 3.2 \mathrm{mg} / \mathrm{kg} \mathrm{BW} / \mathrm{day} ; \\
42 \text { days before mating, during } \\
\text { gestation, and nursing }\end{array}$ & $\begin{array}{l}\text { At highest dosage: gestation time, number of } \\
\text { implantation points, and litter size } \downarrow \text {; and at } \\
\text { the second-highest dosage (F1): reduced } \\
\text { viability, body weight of the newborn, } \\
\text { delayed reflexes and physical development, } \\
\text { food uptake after weaning } \downarrow \text { and dosage (F2): } \\
\text { birth weight } \downarrow\end{array}$ & $\begin{array}{l}0.1 \\
0.4\end{array}$ & $\begin{array}{l}\text { Christian et al. } \\
\text { [164] }\end{array}$ \\
\hline & Rabbits & $\begin{array}{l}0.1,1,2.5 \text {, and } 3.75 \mathrm{mg} / \mathrm{kg} \text { BW/day; } \\
\text { GD } 6 \text { to } 20\end{array}$ & $\begin{array}{l}\text { Weight gain of the maternal animal } \downarrow \text {;and at } \\
\text { the second highest dosage: birth weight } \downarrow \\
\text { and delayed ossification }\end{array}$ & $\begin{array}{c}0.1 \\
1 \\
1 \\
2.5\end{array}$ & Case et al. [293] \\
\hline & Mice & $\begin{array}{l}\text { 1, 10, and } 20 \mathrm{mg} / \mathrm{kg} \mathrm{BW} / \mathrm{day} ; \mathrm{GD} 0 \\
\text { to the end of the study }\end{array}$ & $\begin{array}{l}\text { At the highest dosage (maternal animal): } \\
\text { weight gain, feed } \downarrow \text {, water uptake } \uparrow \text {, liver } \\
\text { mass } \uparrow \text {; body weight of the fetus } \downarrow \text {, } \\
\text { enlargement of the neck, skeletal deformity; } \\
\text { and newborn weak and inactive, lung } \\
\text { atelectasis, aneurism of intracranial arteries, } \\
\text { respiratory dysfunction to death }\end{array}$ & n.r. & Yahia et al. [294] \\
\hline & $\begin{array}{l}\text { Leghorn } \\
\text { chickens }\end{array}$ & $\begin{array}{l}1,2.5 \text {, and } 5 \mathrm{mg} / \mathrm{kg} \text { egg; before } \\
\text { incubation }\end{array}$ & $\begin{array}{l}\text { No effect on hatching rate, spleen mass } \uparrow \text {, } \\
\text { right wings shorter, frequent occurrence of } \\
\text { brain asymmetry, immunoglobulin (IgM, IgY) } \\
\downarrow \text {, plasma lysozyme activity } \uparrow \text {; at the highest } \\
\text { dosage: liver mass } \uparrow \text {; and at the highest } \\
\text { dosage: body weight } \uparrow\end{array}$ & $\begin{array}{l}(1 \mathrm{mg} / \mathrm{kg} \\
\text { egg to } 154 \\
\mathrm{ng} / \mathrm{g} \text { in } \\
\text { serum) }\end{array}$ & $\begin{array}{l}\text { Peden-Adams et al. } \\
\text { [175] }\end{array}$ \\
\hline & $\begin{array}{l}\text { Mallard ducks } \\
\text { and quail }\end{array}$ & 10,50, and $150 \mathrm{mg} / \mathrm{kg}$ of feed & $\begin{array}{l}\text { Viability of the 14-day-old progeny } \downarrow \text {; at the } \\
\text { lowest dosage: slight increase in incidences of } \\
\text { small testes (length); however, } \\
\text { spermatogenesis and fertility were not } \\
\text { affected }\end{array}$ & $\begin{array}{l}\text { Quail, } 10 \\
\mathrm{mg} / \mathrm{kg} \\
\text { feed }\end{array}$ & $\begin{array}{l}\text { Newsted et al. } \\
{[177]}\end{array}$ \\
\hline \multirow[t]{4}{*}{ PFOA } & Rats & $1,3,10$, and $30 \mathrm{mg} / \mathrm{kg} B W /$ day & $\begin{array}{l}\text { Body weight } \downarrow \text {, liver and kidney mass } \uparrow \text {; and } \\
\text { at the highest dosage: birth weight } \downarrow \text {, } \\
\text { mortality after weaning } \uparrow \text {, delayed puberty }\end{array}$ & n.r. & $\begin{array}{l}\text { Butenhoff et al. } \\
{[125,165]}\end{array}$ \\
\hline & Mice & $\begin{array}{l}1,3,5,10,20 \text {, and } 40 \mathrm{mg} / \mathrm{kg} \mathrm{BW} / \\
\text { day; during gestation }\end{array}$ & $\begin{array}{l}\text { Liver enlargement; full-term gestation, viable } \\
\text { fetuses, fetus weight, postnatal viability } \downarrow \text {; and } \\
\text { growth deficit, delayed opening of eyes, } \\
\text { accelerated sexual maturity of male progeny }\end{array}$ & n.r. & Lau et al. [161] \\
\hline & Mice & 3 to $20 \mathrm{mg} / \mathrm{kg}$ BW/day & $\begin{array}{l}\text { Liver mass of the maternal animal } \uparrow \text {; body } \\
\text { weight gain } \downarrow \text {; and application during GD } 7 \\
\text { to } 17 \text { and } 10 \text { to } 17 \text { : delayed opening of eyes } \\
\text { and growth of coat }\end{array}$ & n.r. & Wolf et al. [169] \\
\hline & Mice & $\begin{array}{l}5 \mathrm{mg} / \mathrm{kg} \text { BW/day; GD } 1 \text { to } 17,8 \text { to } \\
17 \text {, and } 12 \text { to } 17\end{array}$ & $\begin{array}{l}\text { Body weight of young animals } \downarrow \text { and } \\
\text { abnormal development of the nursing } \\
\text { process to retarded growth of progeny }\end{array}$ & n.r. & White et al. [295] \\
\hline
\end{tabular}


Table 27 Studies on the reproduction and developmental toxicity of PFCs (from EFSA [15] and enhanced) (Continued)

\begin{tabular}{|c|c|c|c|c|c|}
\hline & Chickens & $\begin{array}{l}5,20,40 \mathrm{mg} / \mathrm{kg} \text { egg; before } \\
\text { incubation }\end{array}$ & $\begin{array}{l}\text { Impaired hatching rate, high prevalence of } \\
\text { splayed legs, and chicks with partial or } \\
\text { complete loss of yellow pigment in the down }\end{array}$ & n.r. & Yanai et al. [174] \\
\hline PFBS & Rats & 30 to $1,000 \mathrm{mg} / \mathrm{kg}$ & $\begin{array}{l}\text { No impairment of fertility or reproduction, no } \\
\text { developmental toxic effects aside from a } \\
\text { slight delay in onset of puberty, and weight } \\
\text { gain in male F1 rats of the group with the } \\
\text { highest dosage }\end{array}$ & n.r. & Lau et al. [115] \\
\hline PFHXS & Rats & n.r. & $\begin{array}{l}\text { No effect on fertility, reproduction, or viability } \\
\text { and growth of the progeny }\end{array}$ & 10 & $\begin{array}{l}\text { York [181] cited in } \\
\text { Lau et al. [115] }\end{array}$ \\
\hline$N$-Et-FOSE & Rats & n.r. & $\begin{array}{l}\text { Toxic effects similar to those of PFOS, still } \\
\text { birth, and mortality in the first three days } \uparrow \text {; in } \\
\text { addition, increase in the number of stillbirths } \\
\text { and mortality in the F2 generation }\end{array}$ & n.r. & $\begin{array}{l}\text { Christian et al. } \\
\text { [164]; Lübker et al. } \\
\text { [163] cited in Lau } \\
\text { et al. [115] }\end{array}$ \\
\hline PFBA & Mice & $\begin{array}{l}35,175 \text {, and } 350 \mathrm{mg} / \mathrm{kg} B W / \text { day; GD } \\
1 \text { to } 17\end{array}$ & $\begin{array}{l}\text { No adverse effects in regard to survival rate } \\
\text { of the progeny or their postnatal growth, } \\
\text { delayed opening of eyes, at the two highest } \\
\text { dosages: delayed onset of puberty, and at the } \\
\text { highest dosage: loss of complete litter }\end{array}$ & n.r. & Das et al. [180] \\
\hline PFNA & Rats & 1,3 , and $5 \mathrm{mg} / \mathrm{kg} / \mathrm{day}$; for 14 days & $\begin{array}{l}\text { Cell apoptosis in the testes and imbalance } \\
\text { between testosterone and estradiol }\end{array}$ & n.r. & Feng et al. [183] \\
\hline PFDA & Mice & $\begin{array}{l}0.25,0.5,1,2,4,8, \text { and } 16,32 \mathrm{mg} / \mathrm{kg} \\
\text { BW/day; GD } 10 \text { to } 13 \text { and } 0.03,0.3 \text {, } \\
1,3,6.4 \text {, and } 12.8 \mathrm{mg} / \mathrm{kg} \text { BW/day; } \\
\text { GD } 6 \text { to } 15\end{array}$ & $\begin{array}{l}\text { No deformities or other developmental toxic } \\
\text { effects; the applied dosages also did not } \\
\text { show toxic effects in the maternal animal }\end{array}$ & n.r. & $\begin{array}{l}\text { Harris and } \\
\text { Birnbaum [182] }\end{array}$ \\
\hline 8:2 FTOH & Rats & n.r. & $\begin{array}{l}\text { Only mild effects similar to those caused by } \\
\text { PFOA }\end{array}$ & 200 & $\begin{array}{l}\text { Mylchreest et al. } \\
\text { [58] cited in Lau et } \\
\text { al. [115] }\end{array}$ \\
\hline
\end{tabular}

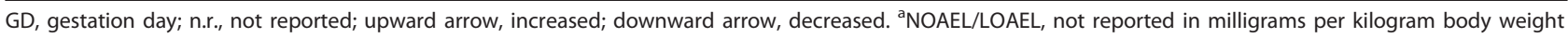
per day.

exposures. The progeny were placed in a water labyrinth, and immunohistochemical analysis was undertaken. The authors came to the conclusion that pre- and postnatal exposures to PFOS impair spatial cognition and memory. The mechanism could be related to a reduction in $N$-methyl-D-aspartate receptor 2B [NR2B] concentration in the cortex and hippocampal region of the brain [192].

In a subsequent study, the authors investigated the effects of PFOS exposure on gene expression of calcium-dependent signal molecules in the hippocampus during gestation and in the lactation period on Wistar rats. By use of the cross-foster method, rats were preand postnatally exposed to $3.2 \mathrm{mg}$ PFOS $/ \mathrm{kg}$ of feed. The expression of NR2B, calmodulin, $\mathrm{Ca}^{2+} /$ calmodulindependent kinase II $\alpha$, and cAMP-response element binding protein were examined by real-time reversetranscriptase polymerase chain reaction. Changes in gene expression of these molecules were detected at various time points during exposure to PFOS. It is therefore possible that perinatal PFOS exposure during a critical phase of brain development exerts a neurotoxic effect on the central nervous system via the molecules of the calcium signal pathway [193].

Pinkas et al. [194] also confirmed the existence of neurotoxic properties of PFOS and PFOA in developing chickens. The authors observed the impairment of cognitive performance in hatched chicks that had been exposed to PFOS or PFOA (5 or $10 \mathrm{mg} / \mathrm{kg}$ ) in ovo. Imprinting behavior was tested on the day of hatching, and impairment was observed after treatment with both of the substances. In order to learn more about the mechanism behind these effects, experiments were undertaken on protein kinase $\mathrm{C}[\mathrm{PKC}]$ isoforms $(\alpha, \beta, \gamma)$ in the intermedial part of the hyperstriatum ventrale, the region most closely associated with imprinting. Exposure to PFOA resulted in significant increases in the cytosolic PKC concentration of all three isoforms. In spite of the general increase in PKC expression, the membrane-associated PKC remained unaffected, suggesting a defect in PKC translocation. In contrast, PFOS exposure resulted in reduction of cytosolic PKC, particularly in the $\beta$ - and $\gamma$-isoforms, but again without any changes in the membrane-associated enzyme. Based on these results, PFCs do appear to be developmentally toxic. They lowered the cognitive performance after hatching. The synaptic mechanisms behind these effects seem to be different for PFOS and PFOA [194].

Effects on the endocrine system

The first reports of the effect of PFCs on thyroid hormones were from Langley and Pilcher [195] and Gutshall et al. [196]. 
Rats that had received a dose of PFDA were found to have significantly reduced $\mathrm{T}_{4}$ and $\mathrm{T}_{5}$ concentrations, lower body temperature, and a slower heartbeat than control animals. Treatment with $\mathrm{T}_{4}$ was not able to reverse the hypothermia. Other studies on rats also showed that PFOS exposure resulted in a reduction of $\mathrm{T}_{4}$ and $\mathrm{T}_{3}$ in serum. There is, however, no increase in $\mathrm{TSH}$, a hormone that enhances formation of $\mathrm{T}_{4}$ and $\mathrm{T}_{3}$. There is evidence that PFOS, similarly to PFDA, displaces the thyroid hormone from its binding protein as it circulates in the blood [115].

Weiss et al. [197] examined this subject and discovered that PFCs compete with $\mathrm{T}_{4}$ in binding to the thyroid hormone transport protein transthyretin. This may explain the decline in thyroid hormone levels after treatment with PFCs. The binding potential of PFCs to transthyretin decreases in the order of PFHxS > PFOS/ PFOA > perfluoroheptanoic acid > perfluor-1-octanoic sulfinate $>$ perfluorononanoic acid and was approximately 12.5 to 50 times lower than that of the natural ligand of $\mathrm{T}_{4}$.

When looking at the expression of the thyroid hormone-related mRNA, Yu et al. [171] only observed changes in the expression of mRNA for transthyretin. The transcription level for transthyretin was $150 \%$ higher in PFOS-exposed rats than in control animals.

Chang et al. [198] discovered that the oral application of PFOS in rats results in increased tissue availability of thyroid hormone and an increased turnover of $\mathrm{T}_{4}$ in connection with a reduction in the total amount of $\mathrm{T}_{4}$ in the serum. Under these conditions, PFOS neither induced hypothyreosis nor did it alter the activity of the hypothalamus-pituitary-thyroid axis.

Moreover, there is evidence that PFCs alter the biosynthesis of gender-specific steroid hormones. For example, application of PFOA to male rats for 14 days led to a reduction in serum and testicular testosterone and an increase in estradiol concentration in serum. Consequently, an increase took place in hormone synthesis in the liver via induction of aromatase. These hormonal changes most likely are connected to the occurrence of Leydig cell adenomas observed in chronic exposure to PFOA $[115,185]$.

Benninghoff et al. [199] described an estrogenic mechanism for PFOA that could promote carcinomas in the liver of rainbow trout. In addition, PFNA, PFDA, and PFUnA behaved like estrogens in the in vivo vitellogenin-induction-bioassay. In the meantime, there is evidence that PFCs may act as weak xenoestrogens in the environment [115].

Wei et al. [200] described effects of PFOA on estrogen responsive genes in the liver of minnows. The fish were exposed to 3,10 , or $30 \mathrm{mg} / \mathrm{L}$ PFOA for 28 days. PFOA interfered with the function of estrogen in the male fish by inducing vitellogenin and the estrogen receptor $\beta$ in the liver. It also caused a degeneration of the ovaries in female animals. Zhao et al. [201] showed that PFOA inhibits $3 \beta$-hydroxysteroid-dehydrogenase and $17 \beta$ hydroxysteroid-dehydrogenase in rat Leydig cells.

Furthermore, PFOA appears to stimulate the development of mammary glands in C57B1/6 mice by promoting steroid hormone production in the ovaries and by increasing the concentration of a number of growth factors in the mammary glands. The results of this study suggest an indirect estrogen effect of PFOA, the possible utility of progesterone biomarker for PFOA exposure of girls and women, and an independence of the PPAR $\alpha$ expression, for example, during tumorigenesis of the liver [202]. Maras et al. [203] established an estrogenic effect of 6:2 and 8:2 FTOH in vitro; however, it must be assumed that a different mechanism is responsible for this potential xenoestrogen than for the reference substance $17 \beta$-estradiol.

In a study of zebrafish (Danio rerio), Liu et al. [86] determined that 8:2 FTOH exposure interferes with sex hormone synthesis and impairs reproduction resulting in diminished hatching rates. Four-month-old zebrafish were subjected to $8: 2 \mathrm{FTOH}$ concentrations of 10,30 , 90 , or $270 \mu \mathrm{g} / \mathrm{L}$ for 4 weeks. Testosterone [T] and estradiol [E2] concentrations in the plasma of the female fish increased significantly, whereas $\mathrm{T}$ and $\mathrm{E} 2$ concentrations in males decreased or increased. Furthermore, egg numbers and sperm production were reduced; the eggshells were thinner; and the protein content and egg diameter were lower. Histological examination showed the promotion of egg-cell maturation and delayed spermiation. Gene transcription of FSH $\beta$ and LH $\beta$ in the pituitary gland was upregulated in female and downregulated in male fish. Increased gene transcription for vitellogenin and zona pellucida protein 2 in males is evidence of estrogen activity. In females, the gene transcription for these markers was reduced and was associated with reduced fertility [86].

It was shown in a study by Shi et al. [204] that PFDoA interferes with the reproductive function, testicular structure, and the genes for steroidgenesis in male rats. The rats were treated orally with 1,5 , or $10 \mathrm{mg}$ PFDoA/ $\mathrm{kg} \mathrm{BW/day.}$

Subsequent testing for chronic, oral exposure to PFDoA (over a period of 110 days) also showed inhibition of steroidgenesis in the testicles and of the expression of certain genes. Significantly lower testosterone concentrations in serum were detected in rats that received 0.2 and $0.5 \mathrm{mg} \mathrm{PFDoA} / \mathrm{kg} \mathrm{BW}$ orally per day. Many factors may play a role in inhibition of testosterone by PFDoA since these dosages of PFDoA reduced levels of the steroidogenic acute regulatory protein, cholesterol side-chain cleavage enzyme, mRNA 
concentrations for insulin-like growth factor I [IGF-I ], IGF-I-receptor, and interleukin $1 \alpha[\mathrm{IL}-1 \alpha]$ and altered genes of the hypothalamic-neurohypophysial system [205].

The EFSA assumes that thyroid tumors result secondarily due to hormone imbalances. It was not possible to draw a clear conclusion about the mammary gland tumors. Estradiol-activated growth factors may play a role in the development of Leydig cell tumors [15].

\section{Immunotoxicity}

Yang et al. [206-208] reported on the immunotoxic potential of PFOA in mice. Addition of a high dose of $0.02 \%$ PFOA to the feed for 7 to 10 days led to a loss of body weight and reduced mass of the thymus and the spleen. Thymus and spleen cells were reduced by more than $90 \%$ and by approximately $50 \%$, respectively, probably as a result of inhibition of cell proliferation. The immature $\mathrm{CD}_{4}^{+}$and $\mathrm{CD}^{+}$populations of the thymus cells were most noticeably reduced. The $\mathrm{T}$ and $\mathrm{B}$ cells were affected in the spleen. An increase in liver weight and peroxisome proliferation occurred in a similar time course as the thymus and the spleen atrophy. Exposure to PFOA (50 to $200 \mu \mathrm{M}$ ) for 24 hours in vitro, however, had no effect on the thymus and spleen cells [206].

Yang et al. [208] were also able to establish immunosuppressive properties of PFOA in in vitro and ex vivo experiments. Oral administration of PFOA in mice (10 days, $0.02 \%$ in feed) inhibited an increase in plaque formation by anti-IgM-IgG as well as an increase in serum concentration of IgM and IgG that normally occurs upon immunization with horse red blood cells. An attenuation of spleen cell proliferation by PFOA was demonstrated ex vivo. The T- and B-cell activators, lipopolysaccharide and concanavalin, serve as triggers for proliferation of spleen cells; however, no PFOA induced changes in proliferation were observed in spleen cells in vitro [208].

Fang et al. [209] discovered toxic effects of PFNA on the lymphatic organs, $\mathrm{T}$ cells, and secretion of cytokines by lymphocytes in mice. These are likely due to the activation of PPAR $\alpha$ and also PPAR $\gamma$. The hypothalamuspitutitary-adreneal axis also appears to play a role since increased serum concentrations of adrenocorticotropic hormone and cortisol were detected in exposed mice. Likewise, cell-cycle arrest and apoptosis were observed in the spleen and thymus after PFNA exposure [209].

Peden-Adams et al. [210] administered six different PFOS dosages to mice for 28 days. However, the authors reported an increase in activity of natural killer cells only in male mice, and they saw a drop in IgM concentration. Lymphocyte proliferation remained unchanged in the male and female mice. In this study, it was also shown that PFOS induces immunotoxic effects at concentrations that have also been detected in humans under special conditions of exposure (serum $91.5 \mu \mathrm{g} / \mathrm{kg}$; dose $1.66 \mu \mathrm{g} / \mathrm{kg} \mathrm{BW} /$ day). The NOAEL of suppression of the sheep red blood cell specific IgM production (plaque forming cell-response) was $0.166 \mu \mathrm{g} / \mathrm{kg} \mathrm{BW} /$ day for male animals. The PFOS serum concentration at this dosage was $17.8 \pm 4.24 \mu \mathrm{g} / \mathrm{kg}$. It can be assumed that B cells are the target location for PFOS-induced immunotoxicity [210].

Keil et al. [211] came to similar conclusions in a study of the immunotoxic effects on the developing immune system in the F1 generation of exposed mice. The immunotoxicity of PFOS resulted in functional deficits in the congenital and humoral immune systems of adult animals born to mothers that had been orally administered $0.1,1$, and $5 \mathrm{mg} P F O S / \mathrm{kg} /$ day between the $1 \mathrm{st}$ and 17th day of gestation, a significantly reduced function of the natural killer cells. A reduced production of IgM was observed in the F1 generation from the eight week of life onwards. The male progeny were significantly more sensitive to the effects triggered by PFOS than the female animals [211].

Qazi et al. [212] showed that even a comparatively short exposure over 10 days with high dosages of PFOS or PFOA $(0.02 \%$ in the feed) in mice also suppresses adaptive immunity and increases the inflammatory reactions to lipopolysaccharides.

In a subsequent study, the authors found that under the conditions mentioned above, the immune modulating effects of PFOS are in part the result of PPAR $\alpha$ activation. For example, hepatomegaly (enlargement of the liver) occurs independently of PPAR $\alpha$; the changes in the thymus are partially dependent upon PPAR $\alpha$; and the effects to the spleen are for all practical purposes eliminated in the absence of the receptors [213]. Further information on the study by Qazi et al. can be found in Table 28.

Guruge et al. [214] exposed female mice to 5 or $25 \mu \mathrm{g}$ $\mathrm{PFOS} / \mathrm{kg} \mathrm{BW/day} \mathrm{for} 21$ days and then infected them with influenza virus $\mathrm{A} / \mathrm{PR} / 8 / 34$ (H1N1). The mice were then examined for their defense against influenza A virus infection. The PFOS concentrations in the blood plasma, spleen, thymus, and lungs increased clearly after exposure to the substance (lungs $\approx$ plasma $>$ spleen $\approx$ thymus). A significant loss of weight and mortality were observed as reactions to the virus. Twenty days after infection, the survival rate of the mice was $46 \%$ (control group), 30\% (5 $\mu \mathrm{g} / \mathrm{kg} \mathrm{BW} /$ day), and 17\% (25 $\mu \mathrm{g} / \mathrm{kg} \mathrm{BW/}$ day). The average survival time was 14.1 days (control group), 13.2 days $(5 \mu \mathrm{g} / \mathrm{kg} \mathrm{BW} /$ day), and 11.4 days ( 25 $\mu \mathrm{g} / \mathrm{kg} \mathrm{BW} /$ day). Studies that dealt with immunotoxicity are presented in Table 28.

DeWitt et al. [215] wrote a summary article on the immunotoxicity of PFOS and PFOA as well as the role of PPAR $\alpha$ in the process. There is a consensus that 
Table 28 Studies on the immunotoxicity of PFOS and PFOA

\begin{tabular}{|c|c|c|c|c|c|}
\hline Substance & $\begin{array}{l}\text { Experimental } \\
\text { animal }\end{array}$ & $\begin{array}{l}\text { Dosage and length } \\
\text { of exposure }\end{array}$ & Effects/dosage & $\begin{array}{l}\text { Serum concentration } \\
\text { according to dosage }\end{array}$ & Reference \\
\hline \multirow[t]{7}{*}{ PFOS } & $\begin{array}{l}\text { Mouse } \\
\text { (C57BL/6) }\end{array}$ & $\begin{array}{l}\text { 5, 20, and } 40 \mathrm{mg} / \mathrm{kg} \\
\text { BW/day; } 7 \text { days }\end{array}$ & $\begin{array}{l}\text { Food intake, body weight } \downarrow \text {; liver mass, serum } \\
\text { corticosterone concentration } \uparrow \text {; and from } 20 \mathrm{mg} / \mathrm{kg} \text { : } \\
\text { lymphatic cells } \downarrow \text {, depression of natural killer cell activity, } \\
\text { lymphocyte proliferation, and antibody forming plasma } \\
\text { cells }\end{array}$ & 110.5 to $338 \mathrm{mg} / \mathrm{L}$ & $\begin{array}{l}\text { Zheng et } \\
\text { al. [296] }\end{array}$ \\
\hline & $\begin{array}{l}\text { Male mouse } \\
(\mathrm{C} 57 \mathrm{BL} / 6)\end{array}$ & $\begin{array}{l}8.33,83.3,416,833 \\
\text { and } 2,083 \mu \mathrm{g} / \mathrm{kg} \mathrm{BW/} \\
\text { day; } 60 \text { days }\end{array}$ & $\begin{array}{l}\text { From } 83.3 \mu \mathrm{g} / \mathrm{kg} \text { BW/day: liver mass } \uparrow \text {, altered } \\
\text { lymphocyte proliferation, and activity of natural killer } \\
\text { cells: depression of antibody forming plasma cells } \\
\text { NOAEL: } 8.33 \mu \mathrm{g} / \mathrm{kg} \text { BW/day, LOAEL: } 83.3 \mu \mathrm{g} / \mathrm{kg} \text { BW/day }\end{array}$ & $\begin{array}{l}0.674 \pm 0.166 \mathrm{mg} / \mathrm{L} \\
\text { and } 7.132 \pm 1.039 \mathrm{mg} / \\
\mathrm{L}^{\mathrm{a}}\end{array}$ & $\begin{array}{l}\text { Dong et } \\
\text { al. [297] }\end{array}$ \\
\hline & $\begin{array}{l}\text { Mouse } \\
(\mathrm{B} 6 \mathrm{C} 3 \mathrm{~F} 1)\end{array}$ & $\begin{array}{l}0.166,1.66,3.31,16.6 \\
33.1, \text { and } 166 \mu \mathrm{g} / \mathrm{kg} \\
\text { BW/day; } 28 \text { days }\end{array}$ & $\begin{array}{l}\text { At the three highest dosages: activity of the natural killer } \\
\text { cells } \uparrow \text { in male mice, altered T cells, and IgM } \downarrow \\
\text { LOAEL: } 1.66 \text { and } 16.6 \mu \mathrm{g} / \mathrm{kg} \text { BW/day for male or female } \\
\text { animals, respectively }\end{array}$ & $\begin{array}{l}0.092 \pm 0.022 \mathrm{mg} / \mathrm{kg}^{\mathrm{b}} \\
\text { and } 0.67 \pm 0.11 \mathrm{mg} / \mathrm{kg} \\
\text { respectively }\end{array}$ & $\begin{array}{l}\text { Peden- } \\
\text { Adams et } \\
\text { al. [210] }\end{array}$ \\
\hline & $\begin{array}{l}\text { Female mouse } \\
\text { (B6C3F1) }\end{array}$ & $\begin{array}{l}0.005 \text { and } 0.025 \mathrm{mg} / \\
\mathrm{kg} \mathrm{BW} / \text { day }\end{array}$ & $\begin{array}{l}\text { Body weight, immune resistance, and survival rate with } \\
\text { influenza A virus infection } \downarrow\end{array}$ & $\begin{array}{l}2.1 \pm 0.3 \mathrm{mg} / \mathrm{L} \\
\text { (control), } 189 \pm 14 \mathrm{mg} / \\
\mathrm{L}, \text { and } 670 \pm 47 \mathrm{mg} / \mathrm{L}\end{array}$ & $\begin{array}{l}\text { Guruge et } \\
\text { al. [214] }\end{array}$ \\
\hline & $\begin{array}{l}\text { Male mouse } \\
\text { (C57BL/6) }\end{array}$ & $\begin{array}{l}0.001 \% \text { to } 1 \% \text { in feed; } \\
10 \text { days }\end{array}$ & $\begin{array}{l}\text { At }>0.02 \% \text { : clinical effects; at } 0.02 \% \text { : weight } \downarrow \text {, } \\
\text { hepatomegaly, atrophy of the thymus, spleen, and fat } \\
\text { tissue, thymus and spleen cells } \downarrow \text { by } 84 \% \text { and } 43 \%\end{array}$ & $\begin{array}{l}50.8 \pm 2.5 \mathrm{mg} / \mathrm{L} \text { to } 340 \\
\pm 16 \mathrm{mg} / \mathrm{L}\end{array}$ & $\begin{array}{l}\text { Qazi et al. } \\
{[213]}\end{array}$ \\
\hline & $\begin{array}{l}\text { Mouse } \\
\text { (B6C3F1) }\end{array}$ & 7 mg/kg; 28 days & $\begin{array}{l}\text { Weight gain } \downarrow \text {, liver mass } \uparrow \text {, and no detrimental effects } \\
\text { on the adaptive immune system }\end{array}$ & $11 \mathrm{mg} / \mathrm{L}$ & $\begin{array}{l}\text { Qazi et al., } \\
{[298]}\end{array}$ \\
\hline & Rat & $\begin{array}{l}0.14 \text { to } 7.58 \mathrm{mg} / \mathrm{kg} \\
\text { BW/day; } 28 \text { days }\end{array}$ & $\begin{array}{l}\text { Body weight } \downarrow \text {, liver weight } \uparrow \text {, lymphocyte apoptosis in } \\
\text { the thymus } \uparrow, T \text { helper cells } \uparrow \text {, and B cells } \downarrow\end{array}$ & $\begin{array}{l}0.4 \text { to } 30 \mathrm{mg} / \mathrm{kg} \text { male } \\
\text { and } 1 \text { to } 43 \mathrm{mg} / \mathrm{kg} \\
\text { female rats }\end{array}$ & $\begin{array}{l}\text { Lefebvre } \\
\text { et al. [299] }\end{array}$ \\
\hline $\begin{array}{l}\text { PFOS or } \\
\text { PFOA }\end{array}$ & $\begin{array}{l}\text { Male mouse } \\
(\mathrm{C} 57 \mathrm{BL} / 6)\end{array}$ & $0.02 \%$ in feed; 10 days & $\begin{array}{l}\text { Total number of white blood cells } \downarrow \text {, lymphocyte } \\
\text { number } \downarrow \text {, neutrophilic granulocytes } \downarrow \text { (only with PFOA), } \\
\text { macrophage number in the bone marrow } \downarrow \text { (but not in } \\
\text { the spleen or abdominal cavity), and tumor necrosis } \\
\text { factor } \alpha \text { and interleukin } 6 \text { production } \uparrow \text { mildly (ex vivo) }\end{array}$ & $\begin{array}{l}340 \pm 16 \mathrm{mg} / \mathrm{L}(\mathrm{PFOS}) \\
\text { and } 152 \pm 8.6 \mathrm{mg} / \mathrm{L} \\
(\mathrm{PFOA})\end{array}$ & $\begin{array}{l}\text { Qazi et al. } \\
{[212]}\end{array}$ \\
\hline \multirow[t]{4}{*}{ PFOA } & $\begin{array}{l}\text { Male mouse } \\
(\mathrm{C} 57 \mathrm{~B} 1 / 6)\end{array}$ & $\begin{array}{l}0.02 \% \text { in feed; } 7 \text { to } 10 \\
\text { days }\end{array}$ & $\begin{array}{l}\text { Body weight } \downarrow \text {, liver mass } \uparrow \text {, spleen and thymus mass } \downarrow \text {, } \\
\text { and peroxisome proliferation } \uparrow\end{array}$ & n.r. & $\begin{array}{l}\text { Yang et al. } \\
{[206]}\end{array}$ \\
\hline & $\begin{array}{l}\text { Male mouse } \\
(\mathrm{C} 57 \mathrm{BL} / 6)\end{array}$ & $0.02 \%$ in feed; 10 days & $\begin{array}{l}\text { Immunosuppressive: plaque formation } \downarrow, \lg M \text { - and IgG } \\
\text { serum concentrations } \downarrow \text {, and proliferation of spleen } \downarrow\end{array}$ & n.r. & $\begin{array}{l}\text { Yang et al. } \\
{[208]}\end{array}$ \\
\hline & Mouse & $\begin{array}{l}3.73,7.5,15 \text {, and } 30 \\
\mathrm{mg} / \mathrm{kg} \mathrm{BW/day;} 10 \\
\text { days }\end{array}$ & $\begin{array}{l}\text { T-cell dependent antibody reaction } \downarrow \text { and no } \\
\text { consequences of a stress-induced corticosterone } \\
\text { production }\end{array}$ & n.r. & $\begin{array}{l}\text { DeWitt et } \\
\text { al. [216] }\end{array}$ \\
\hline & Mouse & $\begin{array}{l}30 \mathrm{mg} / \mathrm{kg} \mathrm{BW} / \mathrm{day} ; 10 \\
\text { to } 15 \text { days }\end{array}$ & IgM synthesis $\downarrow$ & $\begin{array}{l}74 \mathrm{mg} / \mathrm{L}^{\complement} \text { at } 3.75 \mathrm{mg} / \\
\mathrm{kg} \mathrm{BW/day}\end{array}$ & $\begin{array}{l}\text { DeWitt et } \\
\text { al. [300] }\end{array}$ \\
\hline
\end{tabular}

n.r., Not reported; upward arrow, increase; downward arrow, decrease; ${ }^{\mathrm{a}} 50$ times higher than that of a human work-related exposure; ${ }^{\mathrm{b}} 14$ times lower than that of an exposed worker; ${ }^{c} 150$ times higher than that of a heavy work exposure or environmentally contaminated human.

PFOA and PFOS influence the immune system. The immune modulation induced by PFOS and PFOA as observed in animal experiments involve changes in inflammatory response, production of cytokines and reduction in weight of the lymphatic organs, and changes in antibody synthesis. Additionally, there are indications from experimental studies that PFOA influences IgE-dependent allergic asthma. Furthermore, the role of corticosterone in PFOA-induced immunosuppression is questioned since the increased corticosterone concentration is accompanied by reduced IgM antibody titers, suggesting an immune response triggered by stress reaction. It was, however, shown by DeWitt et al. [216] that the suppression of antibody synthesis is not the result of liver toxicity nor of stress-induced corticosterone production.
In addition, it must be noted that different animal species show varying degrees of sensitivity to immunological effects. It has been shown that certain mouse strains are the most sensitive animals for immune modulatory effects of PFOA and PFOS. A few strains already showed changes at PFOA or PFOS serum concentrations that were about 100 times higher (for PFOA) or 15 times lower (for PFOS) than the concentrations that had been measured in exposed workers. This indicates that detailed studies on immunotoxicity in humans are necessary [215].

\section{Hepatotoxicity and mode of action}

Effects on the liver have often been observed in toxicological studies. For example, liver enlargement was seen in connection with hypertrophy and vacuolization of the liver cells and an increase in liver weight in studies on 
subchronic and chronic toxicity. Most generally, rodents and nonhuman primates have been exposed to PFCs. In addition, hepatocellular adenomas occurred in rats.

In particular, liver tumors have been traced to the activation of PPAR $\alpha$ [115]. PPAR $\alpha$ occurs primarily in the liver and can be activated by long-chain polyunsaturated fatty acids or fibrate. As a consequence, there is an increase in the production of enzymes for fatty acid recovery, a formation of ketone bodies, and a reduction in protein synthesis for liponeogenesis [120]. Rats have a higher susceptibility to the PPAR $\alpha$-based mechanism than humans. However, hepatocarcinogenicity can also be only partially attributed to this mechanism. This is corroborated by the fact that exposure to PFOA also caused an increase in liver weight in the PPAR $\alpha$ knockout mice comparable to that in wild-type mice $([15,207,208]$ cited in BfR [17]). In vitro studies showed the following:

In Hep G2 cells, PFOA and PFOS (50 to $200 \mu \mathrm{mol} / \mathrm{L}$ ) induced the production of reactive oxygen species [ROS], the dissipation and/or scattering of the membrane potential of the mitochondria and apoptosis. The activity of the SOD, catalase, and glutathione reductase was increased; however, the activity of glutathione-Stransferase and glutathione peroxidase was lowered. The glutathione content was reduced. A differential gene expression was observed after PFC exposure. The mechanism behind this could be an overload of antioxidative systems, stimulation of ROS formation, an influence on mitochondria, and interference of gene expression for apoptosis regulators that initiate the apoptosis program [217].

In the study by Eriksen et al. [218] on the genotoxic potential of PFCs in human HepG2 cells, an increase in intracellular ROS was only detected for PFOS, PFOA, and PFNA. However, PFOS and PFOA were not found to cause damage to DNA, and the increase in ROS was not concentration dependent. PFBS and PFHxA evoked neither ROS nor DNA damage. Only PFNA led to a weak increase in DNA damage at cytotoxic concentrations. However, this cannot be accounted for by generation of ROS [218].

Qian et al. [219] exposed human microvascular endothelial cells to PFOS. They found that PFOS induced ROS production in the cells which resulted in a reorganization of actin filaments and an increased endothelial permeability.

It must be assumed that PFOS and PFOA can function as agonists of PPAR $\alpha$. In in vitro experiments, PFOS activated PPAR $\alpha[220,221]$ and led to peroxisome proliferation, as had been previously shown only in studies on rodents $[108,222,223]$. The hepatotoxic effects of PFOA in studies on rodents may also have resulted from the activation of peroxisome proliferation
[222-224]. This mechanism is more likely to apply to PFOA than to PFOS. In a study on rats, a concentration of $0.64 \mathrm{mg} P F O A / \mathrm{kg} \mathrm{BW} /$ day and above was found to induce peroxisome proliferation, clearly illustrating the effect of PFOA as a PPAR $\alpha$ agonist ([141] cited in EFSA [15]). The activation of PPAR $\alpha$ leads to the expression of genes that are involved in lipid metabolism, energy homeostasis, cell differentiation, and peroxisome proliferation [225]. This mechanism can result in tumor induction by non-genotoxic carcinogens.

The fact that the PPAR $\alpha$ from mice, rats, and humans can be activated by PFOS and PFOA was also shown in a study by Vanden Heuvel et al. [221]. In these experiments, the respective PPAR expression plasmid was transfected with a luciferase reporter plasmid in mouse 3T3-L1 cells. The relative luciferase activity was measured after addition of increasing concentrations of possible PPAR agonists (e.g., 1 to $200 \mu \mathrm{M}$ PFOA). PFOS and PFOA had little or no influence on the induction of PPAR $\beta$ or PPAR $\gamma$. The human PPAR $\alpha$ reacted most strongly, and the rat PPAR $\alpha$, most weakly to PFOS and PFOA. Compared with the naturally occurring PPAR ligands, i.e., long-chain fatty acids such as linoleic and $\alpha$-linoleic acid, PFOS and PFOA show only a weak effect on PPAR [221].

Shipley et al. [225] were also able to show the activation of human and mouse PPAR $\alpha$ by PFOS and FOSA. The test systems used were a COS-1-cell (green monkey kidney cell)-based luciferase reporter gene transactivation test and a rat liver cell model. The mean effective concentration $\left(\mathrm{EC}_{50}\right)$ was 13 to $15 \mu \mathrm{M}$ for PFOS with a little difference between PPAR $\alpha$ from mice or humans. Maloney and Waxman [226], using a similar test system, determined the maximum activity of mouse PPAR $\alpha$ by $10 \mu \mathrm{M}$ PFOA and humans by $20 \mu \mathrm{M}$ PFOA. These results were confirmed by a more recent study using similar methods. PFOS appeared less effective than PFOA for mice or human PPAR $\alpha$. Neither PFOA nor PFOS could be shown to have a significant activating effect on PPAR $\gamma$ [227]. In studies using transgenic mice, Nakamura et al. [228] indicated that the human PPAR $\alpha$ at relatively low concentrations $(0.1$ or $0.3 \mathrm{mg} /$ $\mathrm{kg}$ ) reacts less strongly to PFOA than the mouse PPAR $\alpha$.

It is also possible that PFCs affect PPAR $\alpha$ by changes in lipid metabolism and transport. The metabolism of lipids and lipoproteins takes place in part in the liver, where PPAR $\alpha$ is also expressed. Additionally, long-chain fatty acids are the natural ligands for PPAR $\alpha$. Thus, Lübker et al. [104] were able to show in vitro that PFOS, $N$-EtFOSA, $N$-EtFOSE, and PFOA could interfere with the binding affinity of the L-FABP to endogenous ligands (fatty acids), in the same manner as a strong peroxisome proliferator. 
The connection between the activation of PPAR $\alpha$ by PFOS and the occurrence of hepatotoxic effects is, however, unclear since a number of inconsistencies appeared in regard to the dose-dependent changes. For example, liver toxicity and hepatocarcinogenicity were seen at PFOS dosages that were lower than those (200 to 500 $\mathrm{mg} / \mathrm{kg}$ ) that induced peroxisome proliferation in shortterm studies of rats. Stimulation of peroxisome proliferation was not detected in rats with high cumulative PFOS tissue concentrations. This can likely be explained by an adaptive downregulation of hepatic peroxisome proliferation that resulted from PFOS treatment in vivo [115]. This mechanism also does not seem to be responsible for the observed liver toxicity following PFOS exposure in monkey. For example, in a study using cynomolgus monkeys, hypertrophy and lipid vacuolization was observed in the group that received $0.75 \mathrm{mg}$ PFOS $/ \mathrm{kg} /$ day but without peroxisome proliferation or increase in palmitoyl-CoA-oxidase activity [128].

In addition, induction of a number of liver enzymes (carboxylesterase, cytochrome P450, acyl-CoA-oxidase and -dehydrogenase, as well as carnitine-acetyl-tranferase) was observed. Reduction of 3-hydroxy-3-methylglutaryl-Co A reductase could explain the decrease in cholesterol and triglyceride concentrations [229]. Gene expression studies on rat liver cells showed that PFOS causes changes especially in the genes that play roles in peroxisomal fatty acid metabolism, hormone regulation, and transcription of various cytochrome $\mathrm{P} 450$ forms [230].

In regard to PFOA, the correlation of hepatotoxic effects and activation of PPAR $\alpha$ is also not consistent. For example, in a study on the cynomolgus monkey, liver mass was seen to increase in association with mitochondrial proliferation at the lowest applied dosage (3 $\mathrm{mg} / \mathrm{kg} /$ day for 26 weeks). The underlying mechanism could not be explained because the peroxisomal markers remained unchanged ([146] cited in EFSA [15]). In addition, the results of another study suggest a PPAR $\alpha$-independent mechanism for induction of hepatomegaly by PFOA in mice. The increase in liver weight correlated with the exposure to PFOA or a classical peroxisome proliferator in wild-type mice. This effect did not occur in the PPAR $\alpha$ knockout mice; however, this was only true for the peroxisome proliferator, not for PFOA. The hepatomegaly observed in the PPAR $\alpha$ knockout mice could, however, also be the result of an accumulation of lipid droplets or PFOA in the liver. PFOA also interferes with lipid and lipoprotein metabolism by activating the PPAR $\alpha$. The normal lipid metabolism equilibrium in mammals is disrupted by the induction of enzymes ([230] cited in EFSA [15]). Studies on gene expression in the rat liver show that exposure to PFOA causes induction of all genes that are connected with metabolism and transport of lipids, in particular fatty acids [230-233]. For example, PPAR $\alpha$ activation upregulates a gene that is responsible for the formation of lipid droplets in many cell types. An increase in the number of lipid droplets in the liver that resulted from the changes in lipoprotein metabolism could be detected in the PPAR $\alpha$ knockout mice and might explain the rise in liver weight after exposure to PFOA [234].

In the study by Minata et al. [235], a 4-week application of APFO $(12.5,25$, and $50 \mu \mathrm{mol} / \mathrm{kg} /$ day $)$ to PPAR $\alpha$ null mice caused damage to hepatocytes and the bile duct. In wild-type mice, dosages of 25 and $50 \mu \mathrm{mol} / \mathrm{kg} /$ day resulted in more severe dose-dependent hepatocellular damage and less striking impairment of the biliary tract. PPAR $\alpha$ null mice that had been exposed to PFOA exhibited marked fat accumulation, severe damage to the biliary tract, hepatocellular damage, and apoptotic cells, most prevalently in the biliary tract. At $50 \mu \mathrm{mol} /$ $\mathrm{kg} /$ day, the oxidative stress was also increased by a factor of 4 in these animals; and at $25 \mu \mathrm{mol} / \mathrm{kg} /$ day, TNF$\alpha$ mRNA was upregulated by a factor of 3 . The bile acid/phospholipid ratio was higher in these animals than that in wild-type mice. These results suggest that PPAR $\alpha$ may actually protect against effects of PFOA and plays a critical role in xenobiotic-induced hepatobiliary damage [235].

A further study by Elcombe et al. [236] indicates that PFOA possesses the properties of a mixed enzyme inducer. It induces various cytochrome P450 types in liver microsomes. This induction profile implies a reaction of PFOA with various receptors of the super family of nuclear hormone receptors, in particular with PPAR $\alpha$, constitutive androstane receptor [CAR], and pregnane-X receptor [PXR ] [236]. Ren et al. [237] were able to show the activation of PPAR $\alpha, C A R$, and PXR by PFCs in rats, but not in chickens or fish. Furthermore, the PFOS-induced gap junctional intercellular communication [GJIC] and in vivo (GJIC) inhibition observed in vitro in the rat liver may be of importance in liver carcinogenesis [115,238]. This process is used by cells to exchange ions, secondary messengers, and other small molecules. In multicellular organisms, GJIC plays a role in tissue homeostasis, normal growth, development, and differentiation. An in vitro study by Upham et al. [239] showed a dysregulation of GJIC by PFOA that resulted from the activation of the extracellular receptor kinase and phosphatidylcholine specific phospholipase. This evidence suggests that PFOA may also have an effect on GJIC in vivo. Inhibition of GJIC appears to only be a property of PF with a chain length of 7 to 10 carbon atoms. For example, PFPeA did not exhibit inhibitory effects on GJIC and did not cause hepatomegaly [239]. The meaning of this widespread and reversible mechanism in carcinogenesis of PFOS or PFOA is, however, 
still unclear $[15,115,185]$. Experiments on the importance of the length of the carbon chain of different PFCs for liver toxicity and peroxisome proliferation in mice and rats suggest that longer chain molecules are more toxic due to their accumulation in the liver [115,240-242].

\section{Combination effects}

Wei et al. [243] studied the combined action of PFCs (PFOA, PFNA, PFDA, PFDoA, PFOS, 8:2 FTOH at a concentration of $5 \mathrm{mg} / \mathrm{L}$ each). The authors created a gene expression profile using a DNA microarray to detect changes in cultivated hepatocytes from minnows. The fish were treated with four mixtures of these substances or with each substance individually. The study showed that, in fact, certain genes were regulated by the mixture that were unaffected by the individual substances. The effected genes are involved in fatty acid metabolism and transport, in xenobiotic metabolism, in the immune response, and in the emergence of oxidative stress [243].

In another study exposure to a mixture of PFOS and PFOA (50 to $200 \mu \mathrm{mol} / \mathrm{L}$ each) induced and expedited cell apoptosis more effectively than did exposure to the individual substances. This suggests summation effects that, however, appear to be neither synergistic nor antagonistic. Therefore, the effect on the cells was stronger with the mixture than with PFOS or PFOA alone [217].

Using a micronuclear test, Jernbro et al. [244] investigated whether the presence of PFOS increased the genotoxic potential of cyclophosphamide [CPP] in hamster V79 lung cells. Up to a concentration of $12.5 \mu \mathrm{g} / \mathrm{mL}$ PFOS did not show any genotoxic effects. However, after metabolic activation, a combination of PFOS and two different dosages of CPP $(1.25$ and $2.5 \mu \mathrm{g} / \mathrm{mL})$ resulted in a greater number of micronucleus containing cells than in cells treated with CPP alone. PFOS induced changes to the cell membrane, and the ensuing changes in the uptake of toxic substances may play a role in these observations [244].

Watanabe et al. [245] examined the effect of co-exposure to 2, 3, 7, 8-tetrachlorodibenzo-p-dioxin 2, 3, 7, 8[TCDD] and PFOS or PFOA on expression of cytochrome $\mathrm{P} 450$ isoforms (monooxygenases) in a chicken embryo hepatocyte culture. PFOS or TCDD alone did not induce mRNA production of CYP4V2; however, administration of 40 to $50 \mu \mathrm{M}$ PFOS plus $0.3 \mathrm{nM}$ TCDD did. A combination of TCDD and PFOA behaved exactly the same way. PFOS caused an increase in CYP1A4 mRNA with or without TCDD co-exposure. The authors suspect a complex gene response to the combined exposure of multiple xenobiotics [245].

\section{Epidemiological studies}

Epidemiological studies have been primarily carried out on groups of people who are occupationally exposed to
PFCs. These took place, for example, in the course of medical monitoring studies of workers in the fluorochemical industry. The workers were principally from the PFC manufacturing company, 3M, in Decatur, Alabama, USA and Antwerp, Belgium. In particular, biochemical parameters for liver damage or interference with lipid metabolism were examined. Furthermore, hormonal changes and cancer death rates and/or tumor incidence were at the center of interest. Recent studies have also examined possible reproductive toxicities. The significance of these epidemiological studies is, however, limited because of the small number of participants, mostly males due to the working structure in the companies, and the problematic classification of exposure $[17,115]$.

Studies on biochemical parameters and mortality rates

An epidemiological study was carried out on 2, 083 workers in a factory in Decatur in which perfluorooctane sulfonylfluoride [POSF] is manufactured and processed. The workers had been employed for at least one year in the company and had been exposed to POSF-based materials by inhalation, skin contact, and/or ingestion. The various workplaces were categorized according to the amount of exposure as determined by analysis of serum samples of the individual workers. A total of 982 people $(47 \%)$ were subjected to a relatively high POSF exposure at their workplaces. The proportion of males in this subcohort was $84 \%$. Of a total of 145 deaths, 65 (45\%) were of these workers with high PFOS serum concentrations ( $c a .0 .6$ to $2 \mathrm{mg} / \mathrm{L}$ ). This group had a risk of urinary bladder cancer 13 times higher than did the general population of Alabama. This is based on three deaths compared to 0.23 expected cases of bladder cancer (standard mortality rate $[\mathrm{SMR}]=12.8$ ). The workers with cancer carried out maintenance work in the factory and worked in the area of the incinerator and sewage treatment plant. It is, however, possible that the workers were also exposed to other bladder cancer-producing compounds outside of the workplace. Other mortality rates in this study were below the statistically expected number of deaths. For example, there were five cases of liver cirrhosis among the total number of participants (SMR 0.85). In animal experiments, however, the liver was identified as the target organ of PFCs $[15,246]$.

In the follow-up study, 11 cases of bladder cancer were documented among the total of 1, 588 participants. Eight cases would be expected statistically. Three of the bladder cancer victims had worked for more than a year at jobs with high PFOS exposure (mean serum concentration 1.3 to $1.97 \mathrm{mg} / \mathrm{L}$ ). Nonetheless, the correlation between PFOS exposure and increased risk of bladder cancer was not significant [247].

Grice et al. [248] were unable to detect an association between occupational PFOS exposure and the 
occurrence of skin, breast, prostate, or intestinal cancer in workers at a PFC-producing company. In addition, there was no correlation between PFOS exposure and the state of health or the course of pregnancies and birth weight. This study was undertaken with the use of questionnaires and medical reports and, as in the study by Alexander et al. [246], encompassed 2, 083 workers of a POSF-processing factory in Decatur [248].

The first retrospective cohort study on mortality of employees of the PFOA-producing factory of $3 \mathrm{M}$ was carried out by Gilliland and Mandel [249]. Participants in the study (2, 788 men and 749 women) were required to have worked for at least 6 months in the factory between 1947 and 1983. In this time period, 398 workers died (348 men and 50 women). Eleven and 148 of the deceased women and men, respectively, had been exposed to APFO. The SMR for prostate cancer (2.03) was increased, based on four deaths out of 148 cases of APFO-exposed workers. The expected frequency would have been 1.97. The relative prostate cancer risk for a one year longer period of employments was 1.13 and rose to 3.3 for workers who had been employed there for over 10 years. The SMR value for other causes of death was not significantly increased [249].

An update of this study was undertaken by Alexander [250] in order to record the deaths that occurred by 1997. The 3, 992 employees were divided into three exposure categories: definite exposure, possible exposure, and exposure not expected. The 607 deaths were allocated to these three categories $(46,267,294)$. Regarding all workers, the highest SMR (1.31) was for bladder cancer. A few of the SMR values were elevated in the group that was definitely exposed. For example, two deaths resulted from colon cancer (SMR 1.67), one from pancreatic cancer (SMR 1.34), and one from prostate cancer (SMR 1.3). In the group with possible exposure, elevated SMR values were obtained for cancers of male sexual organs (2.75), pancreas (1.24), and skin (1.42). The results are difficult to interpret because of the changing, more specific exposure categories. The previously determined significant association between prostate cancer and time of employment could not be confirmed in this study [15].

A recent epidemiological study was undertaken by Lundin et al. [251]. The authors examined the correlation between the APFO exposure of 3, 993 workers in the $3 \mathrm{M}$ factory in Minnesota and the rates of mortality. This study differed from that of Gilliland and Mandel [249] because of newer data and increased exclusion of workers with only short times of exposure. The workers were divided into three exposure categories: definite exposure, possible exposure, and workplace without exposure. APFO exposure was not associated with liver, pancreas, or testicular cancer but presumably with prostate cancer, cerebral vascular disease, and diabetes mellitus [251].

Studies by DuPont [252] provide little information about correlations of PFOA exposure at the workplace and death rates or incidence of cancer since data on exposure, contact with other substances, and lifestyle were missing. Significant differences regarding exposure were shown for bladder and kidney cancer [15,115]. A subsequent study indicated increased SMR values for kidney, liver, and bladder cancers; however, the only significant increase in rate of death was from diabetes mellitus ([253] cited in Lau et al. [115]). No significant liver toxicity was found in a further study by Gilliland and Mandel [254] of 115 males, occupationally PFOAexposed study participants with PFOA serum concentrations of ( 0 to $26 \mathrm{mg} / \mathrm{L}$; mean $3.3 \mathrm{mg} / \mathrm{L}$ ), although hepatotoxic effects often occurred in studies of rats. Total fluorine values were measured since $90 \%$ of those in serum are made up of PFOA. The enzymes of the liver (serum glutamate oxaloacetate transaminase, serum glutamate pyruvate transaminase, gamma glutamyltransferase), the lipoproteins (LDL, HDL), and the cholesterol values were within the normal zone of fluctuation. Possible disturbance variables such as body mass index [BMI] and tobacco and alcohol consumption were taken into account. Based on the enzyme profiles, the authors suspected that PFOA possibly modulates the reaction of the liver to obesity and xenobiotics [254].

Olsen et al. [68] examined similar parameters in connection with the PFOS serum concentrations in workers involved in the production of fluororganic compounds at $3 \mathrm{M}$. In 1995, the PFOS mean concentration for 178 male workers was $2.19 \mathrm{mg} / \mathrm{L}$, and in 1997 , the concentration for 149 workers was $1.75 \mathrm{mg} / \mathrm{L}$. No explicit changes in liver enzymes, cholesterol, or lipoproteins in serum could be detected in the serum of workers with PFOS concentrations below $6 \mathrm{mg} / \mathrm{L}$ [68].

One year later, a study was published by Olsen et al. [255] on workers in the production of APFO. The mean PFOA serum concentration was $5 \mathrm{mg} / \mathrm{L}$ (1993), $6.8 \mathrm{mg} /$ $\mathrm{L}$ (1995), and 6.4 mg/L (1997). Cholecystokinin concentration in plasma was also determined. It was assumed that pancreatic adenomas of the acinar cells observed in animal studies were caused by a steady increase in cholecystokinin that resulted from hepatic cholestasis (bile congestion). However, the cholecystokinin values (average $28.5 \mathrm{ng} / \mathrm{L}$ ) were within the reference range and were negatively coordinated with increasing PFOA concentrations. The measured PFOA concentrations, therefore, did not appear to cause a hepatotoxic effect. The previous suspicion that PFOA modulates the reaction of the liver to obesity and alcohol consumption could not be confirmed. The weak points in the study were the small number of workers (17), the relevant experimental 
data for whom encompassed only three years, the low rate of participation in the study (50\% to $70 \%)$, and the low number of participants with serum concentrations over $10 \mathrm{mg} / \mathrm{L}$ [255].

Olsen et al. [69] then linked PFOS and PFOA serum concentrations with data from medical examinations of workers in one plant. The mean serum concentrations of PFOS and PFOA of the 263 workers in Decatur were found to be $1.32 \mathrm{mg} / \mathrm{L}$ and $1.78 \mathrm{mg} / \mathrm{L}$, respectively. The serum concentrations of the 255 workers at the plant in Antwerp were approximately 50\% lower. After taking into consideration possible disturbance variables (age, BMI, cigarette, and alcohol consumption per day) no conspicuous changes in the blood, lipid, liver, thyroid, or urine parameters were noted [69].

Possible weak points in the study of Olsen et al. [69] were taken into consideration in a following study by Olsen and Zobel [256]. Since the intention was to measure cholesterol levels, persons who took cholesterollowering drugs were excluded. The calculations of LDL were not coupled to triglyceride values, and data on PFOA were also gathered both in Antwerp and Decatur. The study comprised 506 workers at $3 \mathrm{M}$ factories in Antwerp, Minnesota and Alabama who took part in a 'fluorochemical medical surveillance program.' PFOA serum concentrations were between 0.007 and $92.0 \mathrm{mg} /$ L. The total cholesterol or LDL concentrations were not significantly altered with increasing PFOA concentrations in the serum after removal of the disturbance variables such as age, BMI, and alcohol consumption $(P>$ 0.05). HDL was negatively correlated with PFOA in the workers at all three locations, but not in employees at each individual location. This may be explained by demographic differences between the locations. The positive correlation of triglyceride values with PFOA serum concentrations of the workers appeared similar. There was no statistically significant correlation between the concentrations of PFOA and liver enzyme activities. Only for the employees at one of the locations was a weak positive association apparent. Results were inconsistent for thyroid hormones. TSH and $\mathrm{T}_{4}$ concentrations showed no correlation to PFOA levels. Free $\mathrm{T}_{4}$ was negatively associated to PFOA, whereby increases in $\mathrm{T}_{3}$ concentrations were correlated with increased PFOA values. Nonetheless, thyroid hormone levels were within the range of reference values [132].

Olsen et al. [257] looked for potential correlations between PFOA exposure and changes in hormone levels in male PFOA production workers. The focus of the study was on a drop in $\mathrm{T}_{3}$ and $\mathrm{T}_{4}$ levels and estrogenlike effects. The study showed an increase in mean estradiol concentration of approximately $10 \%$ at the highest PFOA serum concentrations $(>0.03 \mathrm{mg} / \mathrm{L})$ in the 191 workers. This relationship, however, could have been influenced by the BMI. No PFOA concentration relationships were found for other hormones. The weak points in this study were the cross-sectional design that led to the low number of participants with high blood PFOA concentrations [257].

In regard to blood lipids, liver enzymes, and occupational exposure to APFO, Sakr et al. [258] detected an increase in total cholesterol $(10.6 \mathrm{mg} / \mathrm{L}$ per $1 \mathrm{mg} / \mathrm{L}$ PFOA) and aspartate aminotransferase (0.35 U per 1 $\mathrm{mg} / \mathrm{L}$ PFOA) in serum. After adjusting for possible influencing factors, an association of PFOA concentrations and triglyceride or lipoprotein levels was no longer recognizable. Total bilirubin was reduced by $0.08 \mathrm{mg} / \mathrm{L}$ per $1 \mathrm{mg}$ PFOA/L serum in exposed persons.

Because of the correlation between APFO exposure and increased lipid concentrations in serum, Sakr et al. [259] examined the association of APFO exposure and incidence of ischemic heart disease. The study cohort comprised 4, 747 workers from the DuPont Washington Works. However, no evidence was found of an increased mortality risk for ischemic heart disease in the exposed workers [259].

Costa et al. [260] evaluated medical surveillance reports for the years 1978 to 2007 from workers who had been employed in the PFOA-producing industry. The study population comprised 53 male workers who had received a medical examination each year and for whom blood tests for various parameters and for PFOA concentrations were available. In the most recent study from 2007, the PFOA concentrations of workers presently employed were 0.2 to $47 \mathrm{mg} / \mathrm{L}$ (mean value 5.71 $\mathrm{mg} / \mathrm{L}$ ), and for previously exposed workers, 0.53 to 18.7 $\mathrm{mg} / \mathrm{L}$ (mean value $4.43 \mathrm{mg} / \mathrm{L}$ ). No clinical evidence was found to indicate a correlation between PFOA concentrations and illness in the 30 years of observation. Biochemical parameters for liver, kidneys, and hormonal functionality were also within the reference range. However, significant correlations between the PFOA serum concentration and the total cholesterol and uric acid levels were detected, as had also been previously reported by Sakr et al. [258]. This is suggestive of an effect of PFOA on purine metabolism in the liver [260].

Very few epidemiological studies exist with data from the general population. In a study by Bloom et al. [261], they compared concentrations of various PFCs (PFDA, PFNA, PFHpA, PFHxS, PFOA, PFOS, FOSA, PFUnA) as well as free $\mathrm{T}_{4}\left[\mathrm{FT}_{4}\right]$ in the blood of 31 fishermen from New York. The background of this study is the crucial role played by the thyroid hormones in the neuronal development of human beings. A statistically significant correlation was not found between any of the PFCs examined or the sum of all the substances and TSH or $\mathrm{FT}_{4}$ concentration. There is a possibility, however, that a weakly positive correlation exists between $\mathrm{FT}_{4}$, PFDA, 
and PFUnA, detected in low concentrations (0.21 and $0.2 \mu \mathrm{g} / \mathrm{L}$ ) in the blood of the fishermen.

Based on possible effects of PFCs on the thyroid, Pirali et al. [262] examined PFOS and PFOA in surgical thyroid samples from patients with diseases of the thyroid. The substances were detected in all samples. The mean concentration for PFOS was $5.3 \mu \mathrm{g} / \mathrm{kg}$, and for PFOA, $2.0 \mu \mathrm{g} / \mathrm{kg}$. There was no correlation between the intrathyroidal PFC concentrations and the occurrence of thyroid diseases. For PFOS, a correlation between the tissue and serum concentrations was established. The serum concentrations were always higher than the respective surgical tissue samples.

Melzer et al. [263] also investigated a correlation between the occurrence of thyroid diseases and PFOS and PFOA in 3, 974 adults from the NHANES. The authors came to the conclusion that higher PFOA and PFOS serum concentrations were associated with a thyroid disease in adults of the general US population. More women with blood concentrations of $\geq 5.7 \mu \mathrm{g}$ PFOA/L were found to have currently treated thyroid disease than women with $\leq 4.0 \mathrm{~g} / \mathrm{L}$ of blood levels. More men with blood concentrations of PFOS $\geq 36.8 \mu \mathrm{g} / \mathrm{L}$ also had diseases of the thyroid than men with concentrations $\leq$ $25.5 \mu \mathrm{g} / \mathrm{L}$. The correlation with PFOS in women was not significant [263].

Test persons from the general public that had been contaminated with higher concentrations of $\mathrm{PFOA}^{\mathrm{f}}$ in drinking water had distinctly higher serum values (mean $354 \mu \mathrm{g} / \mathrm{L}$ ) than the average population in the US (mean 4 to $5 \mu \mathrm{g} / \mathrm{L}$ ). A blood count was made; biochemical parameters were recorded; and the subjects were interviewed. No statistically significant correlations could be found between the PFOA serum concentration and the values from liver and kidney tests, or with cholesterol or TSH concentrations in serum or with the blood count in regard to red or white blood cells or thrombocytes when compared to standard reference values from the general population. PFOA concentrations were not elevated in persons with liver or thyroid illnesses ([264] cited in BfR [17]).

Nelson et al. [265] established a positive association between PFOS, PFOA, and PFNA and total cholesterol, LDL, and very LDL [VLDL] levels. The participants from the highest PFOS quartile $(44.8 \pm 28.0 \mu \mathrm{g} / \mathrm{L})$ had $13.4 \mathrm{mg} / \mathrm{dL}$ higher total cholesterol concentrations than the participants from the lowest quartile $(9.6 \pm 2.9 \mu \mathrm{g} /$ $\mathrm{L})$. The differences were $9.8,13.9$, and $-7.0 \mathrm{mg} / \mathrm{dL}$ for PFOA, PFNA, and PFHxA. Thus, an opposite result was detected for PFHxS. The authors did not find any correlations between PFC concentrations and BMI, hip measurent, or insulin resistance.

Steenland et al. [266] also detected increased bloodlipid levels in connection with elevated PFOA and PFOS concentrations in the blood. HDL was the only exception to this.

The study comprised 46, 294 persons who had been residents for more than 18 years and who drank water contaminated with PFOA by a chemical factory in West Virginia. The mean PFOA and PFOS serum concentrations were found to be $80 \mu \mathrm{g} / \mathrm{L}$ and $22 \mu \mathrm{g} / \mathrm{L}$. The cholesterol level increased from 11 to $12 \mathrm{mg} / \mathrm{dL}$, from the lowest to the highest decile for both substances.

Elevated PFOA serum concentrations were also associated with a higher prevalence of hyperuricemia. The uric acid level increased by 0.2 to $0.3 \mathrm{mg} / \mathrm{dL}$, from the lowest to the highest decile of PFOA or PFOS concentration [267].

Anderson-Mahoney et al. [268] examined 566 persons who also had been exposed to PFOA via drinking water ${ }^{\mathrm{g}}$. In a questionnaire, the participants were asked about their medical anamnesis. There was evidence that exposed persons more often suffered from angina, myocardial infarctions, chronic bronchitis, shortness of breath, and asthma. Further studies will be necessary to determine whether PFOA is the cause of the increased prevalence of these effects in PFOA-exposed persons [268].

Additionally, Lin et al. [269] showed a correlation between PFCs and glucose homeostasis, as well as other indicators of metabolic syndrome. In the general population, elevated PFNA serum concentrations were associated with hyperglycemia, correlated positively with HDL levels in serum, and correlated inversely with the prevalence of metabolic syndrome. Increasing PFOA serum concentrations increased the $\beta$-cell function. Elevated PFOS serum concentrations increased the insulin level in the blood, insulin resistance, and $\beta$-cell function and was negatively correlated with serum HDL cholesterol values [269].

McNeil et al. [270] pursued the results of a study that established an increased diabetes mortality rate in PFOA-exposed workers. Based on 22 diabetes deaths, employees of the Washington Works exhibited twice the mortality rate over other non-exposed workers [271]. The study population $(n=54,468)$ comprised participants in the $\mathrm{C} 8$ health project. A total of 1,055 people had type II diabetes and before diagnosis, had lived in the area of elevated PFOA contamination, most likely the result of contaminated drinking water. The PFOA serum concentration for these individuals was found to be $0.028 \mathrm{mg} / \mathrm{L}$ (mean) in contrast to $0.004 \mathrm{mg} /$ $\mathrm{L}$ for the general population of the USA. Table 29 lists the PFOA serum concentrations of the participants in this study.

Diabetes prevalence amounted to $7.8 \%$. A decreasing risk of diabetes was found for the highest PFOA serum concentration compared with the lower values, but 
Table 29 PFOA serum concentrations ( $\mathrm{mg} / \mathrm{L}$ ) in relation to type II diabetes (from McNeil et al. [270])

\begin{tabular}{|c|c|c|c|c|}
\hline $\begin{array}{l}\text { PFOA serum } \\
\text { concentration }(\mathrm{mg} / \\
\text { L) }\end{array}$ & $\begin{array}{l}\text { All participants } \\
(n=54,468)\end{array}$ & $\begin{array}{l}\text { Self-reported type II } \\
\text { diabetes }(n=4,278)\end{array}$ & $\begin{array}{l}\text { Diagnosed type II } \\
\text { diabetes }(n=3,539)\end{array}$ & $\begin{array}{l}\text { Long-standing a resident with type II diabetes } \\
\text { diagnosed in the last } 10 \text { years }(n=1,055)\end{array}$ \\
\hline Mean & 0.087 & 0.093 & 0.091 & 0.123 \\
\hline Median & 0.028 & 0.030 & 0.033 & 0.049 \\
\hline Geometric mean & 0.033 & 0.034 & 0.036 & 0.052 \\
\hline
\end{tabular}

${ }^{\mathrm{a}}$ At least 10 years in a region with elevated PFOA contamination.

without showing a consistent negative correlation. Taking age into account, however, this correlation could be reversed. A consistent pattern was not apparent for fasting serum glucose levels in connection with PFOA serum concentrations. Consequently, an unambiguous trend for diabetes risk in connection with PFOA serum concentrations did not emerge. However, a correlation cannot be dismissed on the basis of the results of this study since the data was limited due to the cross-sectional design, and a causal relationship cannot be excluded. For these reasons, the authors are planning further studies with an improved design [270]. The studies listed in the 'Studies on biochemical parameters and mortality rates' section are summarized in Table 30.

The US EPA also discussed existing epidemiological studies in 2005. Nevertheless, a consistent correlation between PFOS, PFOA, or APFO serum concentrations in humans and adverse health effects could not be observed.

According to the German BfR [17], only a few individual studies have shown statistically significant relationships between the concentration of liver enzymes, cholesterol level, HDL concentration, and triglyceride concentration or concentration of individual hormones in the human blood and the exposure to PFCs. In addition, the correlations could generally not be confirmed in subsequent studies and even contradicted the effects of the compounds observed in animal experiments [17]. More recent studies indicate correlations between PFC concentrations and diabetes and thyroid disease, as well as blood lipid and uric acid levels; however, these cannot be considered proven and will need to be confirmed in further studies.

\section{Studies on reproductive and developmental toxicity}

Grice et al. [248], in a written survey on exposure and the course of pregnancy, comprising 421 women who had been occupationally exposed to PFOS, did not find a correlation between the degree of PFOS exposure and birth weight of the children. One of the first studies published that analyzed the PFC concentration in the maternal blood and cord blood as parameters for the exposure of the fetus and/or newborn stemmed from Inoue et al. [54]. The authors examined 15 mother/child pairs in Japan and did not find a correlation between PFOS in the cord blood and birth weight or concentration of thyroid hormones in the blood of the newborn. This may well be the consequence of the concentrations to be expected in cord blood and the relatively high limit of detection, $0.5 \mu \mathrm{g} / \mathrm{L}$ [54].

In the study by Fei et al. [57], 1, 400 selected mother/ child pairs from the Danish 'National Birth Cohort' were examined in an attempt to find possible correlations between the concentration of PFOS and PFOA in the maternal blood during the first and second trimesters of pregnancy and the birth weight and risk of premature birth. A correlation between PFC concentration in the maternal plasma and birth weight of children from mothers of normal weight could only be shown for PFOA. The length of gestation was unrelated to PFOS or PFOA concentrations in the maternal blood [57].

Monroy et al. [56] also measured the PFC concentration in the blood of pregnant women in the 24th to the 28 th week, at birth, and in the cord blood. PFOS and PFOA were detected in all samples. Also in this study, the PFOS serum concentrations were higher during gestation $(18 \pm 11 \mu \mathrm{g} / \mathrm{L})$ than at the time of birth $(16 \pm$ $10 \mu \mathrm{g} / \mathrm{L})$ and higher than in the cord blood $(7.3 \pm 5.8$ $\mu \mathrm{g} / \mathrm{L}$ ). The differences were smaller for PFOA (24th to the 28th week of gestation $2.5 \pm 1.7 \mu \mathrm{g} / \mathrm{L}$; birth $2.2 \pm$ $1.6 \mu \mathrm{g} / \mathrm{L}$; cord blood $1.9 \pm 1.5 \mu \mathrm{g} / \mathrm{L}$ ). PFHxS was detected in $45.5 \%$ of the maternal samples and in $20 \%$ of the cord blood samples [56].

On the other hand, in a cross-sectional study, Apelberg et al. [55] found a weak inverse correlation between the concentration of PFOS and PFOA in the cord blood and birth weight, the ponderal index, and head circumference of 293 newborns. No correlation was found between the concentration of the substances and the birth length or gestation time. The results for birth weight were statistically corrected for influence factors such as the mother's smoking habits, diabetes, and hypertension. The authors recommend exercising caution when interpreting these results since the association of head circumference was only for vaginal births; the newborns were all healthy, and the variations in head circumference and birth weight were within the normal range [55]. Washino et al. [272] could also see a negative correlation between the in utero PFOS exposure and the birth weight of baby girls. A correlation between the PFOA concentration and the birth weight was not 
Table 30 Epidemiological studies on biochemical parameters and mortality rates of humans related to PFC exposure

\begin{tabular}{|c|c|c|c|c|}
\hline Effects & Study population & Results & $\begin{array}{l}\text { Serum concentration } \\
\text { (mg/L) }\end{array}$ & Referenc \\
\hline $\begin{array}{l}\text { Death rates } \\
\text { and } \\
\text { incidence of }\end{array}$ & $\begin{array}{l}\text { 2, } 083 \text { Workers in POSF production (USA); } \\
\text { minimal time of employment is one year }\end{array}$ & $\begin{array}{l}\text { Heavy-exposure group: deaths resulting from } \\
\text { bladder cancer, 3; SMR, 12.8; and no increase in } \\
\text { liver disease }\end{array}$ & PFOS, ca. 0.6 to 2 (GM) & $\begin{array}{l}\text { Alexander } \\
\text { et al. [246 }\end{array}$ \\
\hline
\end{tabular}

cancer

Workers in POSF production (USA), 1, 400 questionnaires, and 188 death certificates

Workers in POSF production (USA); 1, 400 questionnaires

3, 537 Workers in POSF production (USA)

3, 992 Workers

4, 747 Workers

3, 993 Workers of the $3 \mathrm{M}$ plant (USA)

Endocrine effects

191 Workers, 111 in 1993 and 80 in 1995 (USA)

Biochemical 115 male workers (USA) parameters
11 Cases of bladder cancer and 8 expected

No association between PFOS and various forms of PFOS, ca. 0.1 to 1.97 cancer, and no correlation between PFOS contamination and state of health, course of pregnancy, or birth weight

Elevated SMR for prostate cancer (2.03) and no significant correlation with other cancer or heart diseases

All workers: elevated SMR for bladder cancer, 1.31; n.r. group with certain exposure: elevated SMR for colon, pancreas, and prostate cancers

No clear evidence of increased risk of death that resulted from ischemic heart disease

No association with liver, pancreas, and testicular cancer and liver cirrhosis; elevated SMR for prostate cancer, cerebrovascular diseases, and diabetes

Increase (10\%) in estradiol level at $>0.03 \mu \mathrm{g} / \mathrm{mL}$ PFOA (BMI as cofactor); for other hormones: no association with PFOA serum concentration

As related to enzymes in the liver, lipoproteins, and cholesterol, no significant indication of liver toxicity or dysfunction

No dramatic changes in liver enzymes, cholesterol, or lipoproteins in serum

178 Male workers in 1995 and 149 workers in 1997

111 Male workers (1993), 80 male workers (1995), and 74 male workers (1997) in APFO-production

263 Workers of the $3 \mathrm{M}$ factory in Decatur (USA) and 255 workers from the plant in Antwerp (Belgium)

506 Workers in the three $3 \mathrm{M}$ factories in Antwerp, Minnesota, and Alabama

454 Workers with APFO exposure (USA)

53 Male workers, from 1978 to 2007

371 Persons of the general public that were exposed to PFOA via drinking water

Participants in the NHANES study 2003/ 2004 between 12 to 80 years of age
No changes in hepatic enzymes, cholesterol, or liporotein levels

No conspicuous changes in blood, liver, thyroid, or urinary parameters after correcting for possible interfering factors

No significant correlation of PFOA with total cholesterol or LDL concentrations, liver enzymes, TSH, and $\mathrm{T}_{4}$; inconsistent results for $\mathrm{HDL}$ and triglyceride values; $\mathrm{FT}_{4}$ was negatively correlated with PFOA; and $\mathrm{T}_{3}$ elevation with increasing PFOA concentrations $\rightarrow$ within reference values

Elevation of total cholesterol and AST levels; no correlation with triglycerides or lipoproteins

No clinical evidence of dysfunction or disease; biochemical parameters for liver, kidneys, and hormonal functionality within reference values; and significant correlation between PFOA serum concentration and total cholesterol and uric acid levels

No significant correlation of PFOA concentration with liver or kidney function tests, cholesterol levels, TSH hormone level, or values for various blood cells

Positive association between PFOS, PFOA, and PFNA and total cholesterol, LDL, and VLDL levels for PFHxS, a negative correlation
PFOS, ca. 1.3 to 1.97

n.r.

n.r.

n.r.

Certain APFO exposure

is 2.5 to 5.2 ; possible

APFO exposure is 0.3 to

1.5

PFOA, 0 to 26; mean, 3.27

Alexander and Olsen [247]

Grice et al. [248]

Total fluorine concentration is 0 to 26; and

mean is 3.3

\section{Gilliland \\ and Mandel \\ [249]}

Alexander [250]

Sakr et al. [259]

Lundin et al. [251]

PFOS, $<6$

PFOA 5 (1993), 6.8

(1995), and 6.4 (1997)

Olsen et

al. [257]

Gilliland and Mandel [254] Olsen et al. [68] Olsen et al. [255]

Decatur: PFOS, 1.32 and PFOA, 1.78; Antwerp ca. 50\% lower

PFOA is 0.007 to 92.03 ; mean is 2.21

Olsen et al. [69]

Olsen and Zobel [256]

n.r.

Skar et al. [258]

PFOA is 0.2 to $47.04 \quad$ Costa et

(2007); median value is al. [260] 5.71

PFOA median value is 0.354

Emmet et al. [264]

PFOA, 0.007; PFOS, 0.038; Nelson et PFNA, 0.002; PFHXS, al. [265] 0.005 (median) 
Table 30 Epidemiological studies on biochemical parameters and mortality rates of humans related to PFC exposure (Continued)

\begin{tabular}{|c|c|c|c|c|}
\hline & $\begin{array}{l}\text { 46, } 294 \text { Residents for more than } 18 \text { years } \\
\text { that drank water contaminated with } \\
\text { PFOA by a chemical factory in West } \\
\text { Virginia }\end{array}$ & $\begin{array}{l}\text { Rising blood lipid values with increasing PFOA and } \\
\text { PFOS concentrations in the blood }\end{array}$ & PFOA, 0.080; PFOS, 0.022 & $\begin{array}{l}\text { Steenland } \\
\text { et al. [266] }\end{array}$ \\
\hline & $\begin{array}{l}\text { 54, } 951 \text { Adult residents from Ohio and } \\
\text { West Virginia exposed via drinking water }\end{array}$ & $\begin{array}{l}\text { Elevated uric acid concentrations in the highest } \\
\text { decile of PFOA or PFOS concentrations compared } \\
\text { with the lowest }\end{array}$ & PFOA, 0.189; PFOS, 0.041 & $\begin{array}{l}\text { Steenland } \\
\text { et al. [267] }\end{array}$ \\
\hline \multirow[t]{5}{*}{ Disease } & $\begin{array}{l}566 \text { Persons exposed to PFOA via } \\
\text { drinking water }\end{array}$ & $\begin{array}{l}\text { Increased occurrence of angina, myocardial } \\
\text { infarction, chronic bronchitis, shortness of breath, } \\
\text { and asthma }\end{array}$ & n.r. & $\begin{array}{l}\text { Anderson- } \\
\text { Mahoney } \\
\text { et al. [268] }\end{array}$ \\
\hline & $\begin{array}{l}\text { General public comprising } 474 \text { adults and } \\
969 \text { juveniles in Taiwan }\end{array}$ & $\begin{array}{l}\text { Correlation of PFCs with glucose homeostasis and } \\
\text { other indicators of the metabolic syndrome }\end{array}$ & n.r. & $\begin{array}{l}\text { Lin et al. } \\
{[269]}\end{array}$ \\
\hline & $\begin{array}{l}\text { 54, } 468 \text { Persons exposed to PFOA via } \\
\text { drinking water, 1, } 055 \text { with type II } \\
\text { diabetes }\end{array}$ & $\begin{array}{l}\text { Reduced risk of diabetes mortality at high PFOA } \\
\text { values; not consistent }\end{array}$ & PFOA, 0.028 & $\begin{array}{l}\text { McNeil et } \\
\text { al. [270] }\end{array}$ \\
\hline & $\begin{array}{l}28 \text { Patients who had had thyroid } \\
\text { operations }\end{array}$ & $\begin{array}{l}\text { No correlation between intrathyroidal PFC } \\
\text { concentrations and occurrence of thyroid disease }\end{array}$ & n.r. & $\begin{array}{l}\text { Pirali et al. } \\
{[262]}\end{array}$ \\
\hline & 3, 974 Adults of the NHANES study & $\begin{array}{l}\text { High PFOA and PFOS serum concentrations } \\
\text { associated with thyroid disease }\end{array}$ & $\begin{array}{l}\text { PFOA, } \geq 0.0057 \text { (women); } \\
\text { PFOS, } \geq 0.0368 \text { (men) }\end{array}$ & $\begin{array}{l}\text { Melzer et } \\
\text { al. [263] }\end{array}$ \\
\hline
\end{tabular}

n.r., Not reported; GM, geometric mean.

found. Hamm et al. [273] were unable to establish an association between the birth weight or gestation time and the maternal serum concentrations (mean values: PFOA $1.5 \mu \mathrm{g} / \mathrm{L}$, PFHxS $0.97 \mu \mathrm{g} / \mathrm{L}$, PFOS $7.8 \mu \mathrm{g} / \mathrm{L})$. Nolan et al. [274] investigated the relationship between a PFOA-contaminated drinking water supply and the birth weight and gestation time. They did not find any indication for low birth weight or premature birth related to the water supply. The risk group comprised mothers from Washington County, Ohio. The drinking water there had a PFOA concentration 80 times higher $(6.8 \mu \mathrm{g} / \mathrm{L})$ than can be assumed for the general US population [274]. More recent studies by the authors, also dealing with the connections between the PFOA contamination of drinking water (customers of the Little Hocking Water Association) and the pregnancy complications, indicate an association of PFOA exposure, the incidence of anemia, and dysfunction of labor contractions [275].

Stein et al. [276] also described a connection between PFOA and PFOS serum concentrations of residents of the Mid-Ohio Valley (200 to 2, 006) who were exposed to PFOA in drinking water with self-reported coursesof-pregnancy descriptions. PFOA measurements for 1 , 845 pregnant women and PFOS values for 5, 262 pregnant women were available. The mean PFOA concentration in serum was $49 \mu \mathrm{g} / \mathrm{L}$, and the mean PFOS concentration was $15 \mu \mathrm{g} / \mathrm{L}$. Neither the PFOS nor PFOA serum concentrations could be statistically correlated with miscarriage or premature birth. However, a weak association of PFOA with the development of preeclampsia and congenital defects ${ }^{\mathrm{h}}$ was noted. A weak connection was also shown for PFOS and development of preeclampsia. Mean PFOS concentrations exceeding $12.8 \mu \mathrm{g} / \mathrm{L}$ were seen to increase the risk of reduced birth weight of newborns. It must be noted, however, that these associations were weak and imprecise and were based solely on reports made by the pregnant women [276].

Fei et al. [277] investigated the development of infants with the help of questionnaires that the mothers were to fill out when their children were between 6 and 18 months of age. These data were examined in connection with prenatal exposure to PFOA and PFOS. The authors could not find any differences in the development of the infants from mothers with high PFOA and PFOS blood concentrations (PFOA 7 to $42 \mu \mathrm{g} / \mathrm{L}$; PFOS 43 to $107 \mu \mathrm{g} / \mathrm{L}$ ) and children of mothers with low PFOA and PFOS blood concentrations (PFOA < 1 to $4 \mu \mathrm{g} / \mathrm{L}$; PFOS 6 to $26 \mu \mathrm{g} / \mathrm{L}$ ). The Apgar scores and point in time of developmental progress were similar for children of mothers with high PFOS and PFOA concentrations in blood as for children of mothers with low PFOS and PFOA blood concentrations. There was only a weak indication that children of mothers with high blood concentrations of PFOS began to sit without support at a later time point [277].

A further study by Fei et al. [278] suggests a possible impairment of fertility as seen in the PFOS and PFOA blood concentrations measured in the general population. The mean PFOS and PFOA plasma concentrations of women who planned to get pregnant were $33.7 \mu \mathrm{g} / \mathrm{L}$ and $5.3 \mu \mathrm{g} / \mathrm{L}$, respectively. The time until pregnancy was longer in the proband group with higher PFOA and PFOS contaminations [278].

Since PFOA was seen to cause impairment of lactation in mice, Fei et al. [279] examined PFOS and PFOA 
concentrations in connection with duration of nursing in 1 , 400 nursing women. They discovered a decrease in duration of nursing in correlation with increasing PFC concentrations by women who had had repeated births. Whether PFOS or PFOA really reduces the ability to nurse or whether the correlation is reversed remains questionable.

Hoffman et al. [280] discovered an increasing risk of attention deficit hyperactivity disorder [ADHD] in children with elevated PFC serum concentrations. Data from the NHANES study from 1999 to 2000 and from 2003 to 2004 on ADHD and PFC blood concentrations from 571 children between the ages of 12 and 17 were evaluated in this study. Forty eight children were reported to suffer from ADHD. The corrected odds ratios for an increase of $1 \mu \mathrm{g} / \mathrm{L}$ serum concentration of PFOS, PFOA, PFHxA, and PFNA were 1.03, 1.12, 1.06, and 1.32, respectively. The results of epidemiological studies on the correlation between PFC blood concentration and reproduction and developmental toxic effects are summarized in Table 31.

Olsen et al. [281] published a review article on epidemiological studies that dealt with the influence of PFCs

Table 31 Results of studies on reproduction toxicological effects of PFCs on humans

\begin{tabular}{|c|c|c|c|}
\hline Effects & Study population & Results & Reference \\
\hline \multirow[t]{9}{*}{ Birth weight } & Occupationally exposed women, USA & No correlation between extent of PFOS exposure and birth weight & $\begin{array}{l}\text { Grice et } \\
\text { al. [248] }\end{array}$ \\
\hline & General population, Japan & $\begin{array}{l}\text { No correlation between PFOS concentration in cord blood and } \\
\text { birth weight }\end{array}$ & $\begin{array}{l}\text { Inoue et } \\
\text { al. [54] }\end{array}$ \\
\hline & General population, Danish National Cohort & $\begin{array}{l}\text { Correlation between the PFOA concentration in mother's plasma } \\
\text { and birth weight; not detectable for PFOS }\end{array}$ & $\begin{array}{l}\text { Fei et al. } \\
{[57]}\end{array}$ \\
\hline & General population, USA & $\begin{array}{l}\text { Weak inverse correlation between concentrations of PFOS and } \\
\text { PFOA in cord blood and birth weight }\end{array}$ & $\begin{array}{l}\text { Apelberg } \\
\text { et al. [55] }\end{array}$ \\
\hline & General population, Canada & No correlation of PFC serum concentrations and birth weight & $\begin{array}{l}\text { Monroy et } \\
\text { al. [56] }\end{array}$ \\
\hline & General population, Japan, 2002 to 2005 & $\begin{array}{l}\text { Negative correlation of in utero exposure to PFOS birth weight; } \\
\text { not detectable for PFOA }\end{array}$ & $\begin{array}{l}\text { Washino } \\
\text { et al. [272] }\end{array}$ \\
\hline & General population, USA & $\begin{array}{l}\text { No indication of a connection between low birth weight and } \\
\text { PFOA-contaminated drinking water }\end{array}$ & $\begin{array}{l}\text { Nolan et } \\
\text { al. [274] }\end{array}$ \\
\hline & General population, USA, 2000 to 2006 & $\begin{array}{l}\text { Correlation between PFOS contamination and the risk of reduced } \\
\text { birth weight }\end{array}$ & $\begin{array}{l}\text { Stein et al. } \\
{[276]}\end{array}$ \\
\hline & General population, Canada & $\begin{array}{l}\text { No correlation between PFOA, PFHxS, PFOS serum concentrations } \\
\text { and birth weight }\end{array}$ & $\begin{array}{l}\text { Hamm et } \\
\text { al. [273] }\end{array}$ \\
\hline \multirow[t]{4}{*}{$\begin{array}{l}\text { Gestation } \\
\text { time }\end{array}$} & General population, Danish National Cohort & $\begin{array}{l}\text { No correlation of PFOA and PFOS concentrations in mother's } \\
\text { plasma with time of gestation }\end{array}$ & $\begin{array}{l}\text { Fei et al. } \\
{[57]}\end{array}$ \\
\hline & General population, USA & $\begin{array}{l}\text { No indication of premature birth as a result of PFOA } \\
\text { contamination via drinking water }\end{array}$ & $\begin{array}{l}\text { Nolan et } \\
\text { al. [274] }\end{array}$ \\
\hline & General population, USA, 2000 to 2006 & $\begin{array}{l}\text { No connection of PFOS or PFOA serum concentration with } \\
\text { miscarriage or premature birth }\end{array}$ & $\begin{array}{l}\text { Stein et al. } \\
{[276]}\end{array}$ \\
\hline & General population, Canada & $\begin{array}{l}\text { No correlation between PFOA, PFHxS, PFOS serum concentrations } \\
\text { and gestation time }\end{array}$ & $\begin{array}{l}\text { Hamm et } \\
\text { al. [273] }\end{array}$ \\
\hline Development & General population, Danish National Cohort & $\begin{array}{l}\text { No difference in the development of newborns from mothers } \\
\text { with high PFOA and PFOS concentrations and children of mothers } \\
\text { with low PFOA and PFOS concentrations; sitting without support } \\
\text { possibly delayed in children of mothers with high PFOS } \\
\text { concentrations }\end{array}$ & $\begin{array}{l}\text { Fei et al. } \\
{[277]}\end{array}$ \\
\hline \multirow[t]{5}{*}{$\begin{array}{l}\text { Other } \\
\text { aspects }\end{array}$} & General population, USA & $\begin{array}{l}\text { Weak inverse correlation between concentrations of PFOS and } \\
\text { PFOA in cord blood and the ponderal index or head } \\
\text { circumference }\end{array}$ & $\begin{array}{l}\text { Apelberg } \\
\text { et al. [55] }\end{array}$ \\
\hline & General population, Japan & $\begin{array}{l}\text { No correlation between PFOS concentration in cord blood and } \\
\text { concentration of thyroid hormones }\end{array}$ & $\begin{array}{l}\text { Inoue et } \\
\text { al. [54] }\end{array}$ \\
\hline & General population, USA, 2000 to 2006 & $\begin{array}{l}\text { Weak correlation of PFOA concentrations and occurrence of } \\
\text { miscarriages }\end{array}$ & $\begin{array}{l}\text { Stein et al. } \\
{[276]}\end{array}$ \\
\hline & General population, USA, 2000 to 2006 & $\begin{array}{l}\text { Weak association of PFOA and PFOS serum concentrations with } \\
\text { the occurrence of preeclampsia }\end{array}$ & $\begin{array}{l}\text { Stein et al. } \\
{[276]}\end{array}$ \\
\hline & $\begin{array}{l}\text { General population, } 571 \text { children between } 12 \text { to } 15 \\
\text { years from the NHANES study, } 1999 \text { to } 2000 \text { and } \\
2003 \text { to } 2004\end{array}$ & $\begin{array}{l}\text { Increased risk of ADHD for children with elevated PFOS, PFOA, } \\
\text { PFHXA, and PFNA serum concentrations }\end{array}$ & $\begin{array}{l}\text { Hoffman } \\
\text { et al. [280] }\end{array}$ \\
\hline Fertility & $\begin{array}{l}\text { General population, Danish National Birth Cohort, } \\
1996 \text { to } 2002\end{array}$ & $\begin{array}{l}\text { Fertility disorders related to elevated PFOA and PFOS plasma } \\
\text { concentrations }\end{array}$ & $\begin{array}{l}\text { Fei et al. } \\
{[278]}\end{array}$ \\
\hline
\end{tabular}


on human fetal development. The authors compared the published results, listed the strengths and weaknesses, listed alternative possible explanations for published results, and suggested future studies. They came to the conclusion that future research activities on this subject will need to consider more carefully the physiology of pregnant mothers and the increased maternal plasma volume during pregnancy. In addition, participants from the general population with the highest PFOS and PFOA concentrations should be included in order to better recognize possible toxic effects [281].

Steenland et al. [282] also published a review of epidemiological studies on PFOA. The authors concluded that available studies provide consistent evidence of a weakly positive association of the PFOA concentration in serum with cholesterol and the uric acid levels, whereby the magnitude of the effect on cholesterol level is not correlated with the extent of exposure.

Apart from that, there are a few but inconsistent indications of a weakly positive correlation with the activities of liver enzymes. A majority of the results stem from cross-sectional analyses from which it is not possible to draw conclusions of causality. Two cohort studies of occupationally exposed workers do not provide unequivocal evidence of chronic disease; however, as a result of the small numbers of participants, the information they provide is limited.

There is a recent upturn in the number of publications on reproductive effects. The results from these studies are, however, inconsistent, and the observed adverse effects are weak. It is therefore concluded that the information provided by the results from previous epidemiological studies is limited and the data is inadequate to allow unambiguous conclusions to be drawn about the role of PFOA in the development of particular diseases [282].

\section{Summary}

The present general opinion is that the main route of PFC uptake is dietary with contaminated fish and game, constituting a majority of the exposure. Nonetheless, the representative data that would allow an estimation of dietary exposure is not available. Therefore, in 2009, the EU launched the research project, PERFOOD, with the aim of improving the level of awareness about PFCs in foods. Among other things, the migration of PFCs from packaging material into foodstuffs is also to be studied. Additionally, other less studied pathways such as skin contact with PFC-treated utensils and inhalation of indoor air in particular should also be further studied. Comparatively, little data is, however, presently available on these paths of exposure. According to previous studies, the total daily PFC uptake is in the range of 2 to $200 \mathrm{ng} / \mathrm{kg} \mathrm{BW} /$ day for PFOS and 3 to $14 \mathrm{ng} / \mathrm{kg} \mathrm{BW/day}$ for PFOA. Admittedly, other PFCs such as FTOH or FOSE/FOSA may contribute to the internal contamination of humans. As a result of their lower body mass and increased hand-to-mouth contact, it may be assumed that the internal PFC contamination per kilogram body mass of children is greater than that of adults. In addition, PFOS and PFOA can cross the placental barrier and can pass into breast milk.

The quantitatively dominant component of PFCs in the human blood is PFOS. The PFOA concentrations are generally somewhat lower in the blood than PFOS concentrations. The linear forms of both so-called reference components are most commonly identifiable in blood samples. Geographic differences have been found for PFC serum concentrations in humans. Individual studies show a possible influence of diet on the degree of contamination with PFCs. An unequivocal correlation between age and blood PFC concentration is not evident. Gender-dependent differences are, however, probable. Men generally show a higher contamination with PFCs than women. The serum concentrations of these compounds appear to have risen over the last decades. Whether this trend will continue is presently unknown.

Animal experiments suggest that PFCs are relatively well taken up by the organism both orally and by inhalation. They accumulate primarily in the liver, and after increasing exposure, also in the blood, and other organs such as the kidneys. An explanation of the mechanism by which this distribution takes place involves the preferred binding of PFCs to serum albumin, L-FABP, and membrane structures in the liver. There is presently no evidence for metabolism of PFOS or PFOA. In contrast, there is increasing evidence for metabolism of FTOH. Differences in the excretion of PFCs have been found for different compounds and different species. PFOS is excreted more slowly than PFOA so that the latter has a shorter elimination half-life and higher rate of excretion. It can be assumed that branched chain molecules are more rapidly excreted than the linear isomers, which therefore tend to accumulate more. According to current knowledge, short-chain PFCs such as PFBS are also excreted more rapidly than long-chain PFCs. An active and sex-hormone-regulated mechanism for renal excretion of PFOA has been demonstrated in rats. Enterohepatic circulation appears to reduce the excretion rate of PFOS and PFOA as also shown in an experiment on rats.

Based on the results of animal experiments, the acute toxicity is considered modest. Diverse toxic effects were observed in longer-term animal tests. Hepatotoxic effects have often been described. In addition, lipid metabolism was often affected in experimental animals. Epidemiological studies have indicated effects of PFCs on glucose, urea, and/or uric acid metabolism; therefore, 
it would seem that further studies on PFCs and metabolic processes are necessary. Tumor growth has been observed in experimental animals after chronic exposure. Most commonly the liver, Leydig cells, and mammary gland tissue have been involved. Evidence of the occurrence of particular cancer diseases, most often urinary bladder and prostrate cancers, have been observed in individual epidemiological studies. The target organs of animals and humans appear to differ, aside from the pancreas that was seen to be prone to cancerous growth both in humans and in animals. In regard to carcinogenesis, a genotoxic mechanism cannot be assumed for PFOS and PFOA, but rather a tumor promoting effect and/or epigenetic process come into question. Animal studies show unmistakable reproductive and developmental toxic effects that were only partially found in epidemiological studies. There is presently no evidence of teratogenic effects. To more thoroughly understand the influence on human fertility and the development of newborn children, the results on reproductive toxicity from animal studies should be taken into consideration. Considering the results of animal experiments, neuro- and immunotoxic effects will have to be examined in future epidemiological studies. The trigger for hepato- and immuno-reproductive, reproductive, and developmental effects as well as carcinogenesis of PFCs may be partially or completely attributed to the activation of the PPAR $\alpha$. Correspondingly, a change in expression of the genes that control lipid metabolism, energy homeostasis, cell differentiation, and peroxisome proliferation might be involved.

Apparently, different PFCs exhibit different toxicities. PFOS and linear isomers appear to be more toxic than PFOA and branched chain compounds, i.e., in comparison, PFOS and linear isomers exhibit a longer half-life than do PFOA and branched chain compounds and cause adverse effects at lower dosages. The data presently available regarding toxicology of PFCs other than PFOS and PFOA is in comparison meager, inhomogeneous, and fragmentary, particularly in light of the diversity of PFCs occurring in biological matrices.

\section{Conclusions}

There are a number of pathways by which PFC contamination of humans can take place including diet, food contact materials, non-food personal items, and indoor and outdoor air. Although a number of authors have attempted to calculate the contribution of these individual pathways to total contamination, the available data records are not presently adequate to allow sound conclusions to be drawn. In addition, the various authors have, to some extent, taken diverse approaches to the subject of dietary contamination. Some have assumed that consumption of fish and seafood are the main source of PFC contamination in humans, whereas others have postulated that, particularly in regions in which only small amounts of fish are eaten, meat and vegetables are the primary source. There is, however, a general consensus that dietary uptake represents the largest contribution. Nonetheless, it will be necessary to establish the contribution of various foodstuffs to total exposure by comparing the data from studies that systematically determine PFC contamination of a large number of edible products. Studies that are limited to local or regional products are not adequate to describe the global exposure scenario. Toxicokinetic and toxicodynamic data of PFCs, aside from those for the socalled reference substances, PFOA and PFOS, are not consistent enough to allow a conclusive toxicological evaluation.

In recent years, numerous publications have appeared in which biological properties of PFCs are described; however, these are generally limited to PFOA and PFOS. These two substances are, to the best of our knowledge, the only PFCs that have been toxicologically examined in animal studies that would allow conclusions to be drawn about potential human toxicity. Data on short-chain PFCs that are apparently being substituted for longer chain molecules in industrial processes are, if available at all, only of a fragmentary nature. Because of their solubility in water and the increasingly wide spectrum and volume of their use, these short-chain PFCs deserve considerable study. This is particularly evident since they appear to be ubiquitously distributed throughout the water pathway and can thus lead to an increased background contamination of the environment. Additionally, PFCs are being used in mixtures with varying compositions, making toxicological evaluations much more difficult. For this reason, standardized in vitro and in vivo methods should be used and further developed in order to allow reliable conclusions to be drawn concerning the toxicity of the individual substances as well as of various PFC mixtures. Consequently, an adequate toxicological evaluation of the total situation is presently not possible.

\section{Endnotes}

${ }^{a}$ The LOD was not specified in the publication. ${ }^{\mathrm{b}}$ The type of average was not specified. ${ }^{\mathrm{c}}$ Whether the dose was based on a kg BW is not evident from the description of the study. ${ }^{\mathrm{d}}$ Calculated according to the following formula: bile clearance $(\mathrm{mL} / \mathrm{hr} / \mathrm{kg} \mathrm{BW})=$ PFOA in the bile-300 min $_{\text {(nmol)/AUC }}$ 0-300 min $(\mathrm{nmol} \cdot \mathrm{hr} / \mathrm{mL}) / \mathrm{kg} \mathrm{BW}$. ${ }^{\mathrm{e}}$ The age of the animals was not listed. ${ }^{\mathrm{f}}$ Concentrations and locations were not listed. ${ }^{\mathrm{g}}$ More details were not presented. ${ }^{\mathrm{h}}$ The types of congenital defects were not described. 


\section{Abbreviations}

8-dG: 8-hydroxydesoxyguanosine; AFC: EFSA Panel on food additives: flavourings: processing aids and materials in contact with food; ALT: alanine aminotransferase; APFO: ammonium perfluorooctanoate; AST: aspartate aminotransferase; BfR: Bundesinstitut für Risikobewertung (Federal Institute for Risk Assessment); BMI: body mass index; BW: body weight; CAR: constitutive androstane receptor; COT: Committee on Toxicity of Chemicals in Food: Consumer Products and the Environment; ECF: electrochemical fluorination; EFSA: European Food Safety Authority; FDA: US Food and Drug Administration; FOSA: perfluorooctyl sulfonamide; FOSE:

perfluorooctanesulfonamide ethanol; $\mathrm{FT}_{4}$ free thyroxine; $\mathrm{FTOH}$ : fluorotelomer alcohol; GD: gestational day; GIC: gap junction intercellular communication; HDL: high density lipoprotein; LADD: lifetime average daily dose; $\mathrm{LC}_{50}$ : lethal concentration with $50 \%$ lethality; $L_{50}$ : lethal dose with $50 \%$ lethality; LFABP: liver type fatty acid binding protein; LH: luteinizing hormone; LOAEL: lowest observed adverse effect level; L-PFOA: linear PFOA; L-PFOS linear PFOS; MTE: more typical exposure; $N$ (or n): number (of samples); n.a.: not analyzed; n.d.: not detected; n.r.: not reported; N-EtFOSA: N-

ethylperfluorooctyl sulfonamide; N-EtFOSE: N-ethylperfluorooctyl sulfonamide ethanol; NHANES: National Health and Nutrition Examination Survey; NOAEL: no observed adverse effect level; OAT: organic anion transporter; OECD: Organisation for Economic Co-operation and Development; PCB: polychlorinated biphenyls; PFBA: perfluorobutanoic acid; PFBS: perfluorobutanesulfonic acid; PFCs: perfluorinated compounds/ polyfluorinated compounds; PFCA: perfluorinated carboxylic acids; PFDA: perfluorodecanoic acid; PFDoA: perfluorododecanoic acid; PFHpA: perfluoroheptanoic acid; PFHXA: perfluorohexanoic acid; PFHXS: perfluorohexanesulfonic acid; PFNA: perfluorononanoic acid; PFO: deprotonated PFOA; PFOA: perfluorooctanoic acid; PFOS: perfluorooctanesulfonic acid; PFPA: perfluorinated phosphonic acid; PFPeA: perfluoropentanoic acid; PFTDA: perfluorotetradecanoic acid; PFUnA: perfluoroundecanoic acid; POP: persistent organic pollutants; POSF: perfluorooctane sulfonyl fluoride; PPAR: peroxisome proliferator activated receptor; PTFE: polytetrafluoroethene; PXR: pregnane $\times$ receptor; RME: reasonable maximum exposure; ROS: reactive oxygen species; SMR: standard mortality ratio; SOD: superoxide dismutase; $T_{3}$ : tri-odo thyronine; $T_{4}$ : thyroxine; T-AOC: total antioxidant capacity; TDI: tolerable daily intake; TSH: thyroid stimulating hormone; UBA: Umweltbundesamt (German Environmental Protection Agency); US EPA: United States Environmental Protection Agency.

\section{Acknowledgements}

We wish to thank Dr. Roy Ackmann and Ms. Barbara Gamb of Hessian State Laboratory for their assistance in the extensive literature search.

\section{Author details}

${ }^{1}$ Hessian State Laboratory, Glarusstr. 6, Wiesbaden, D-65203, Germany

${ }^{2}$ Hessian State Laboratory, Schuberstr. 60, Giessen, D-35392, Germany

\section{Authors' contributions}

TS had the idea to write such a review and drafted the manuscript. DM evaluated the original literature and participated in drafting the manuscript. HB structured this complex review in chapters and subchapters and participated in drafting the manuscript. All authors read and approved the final manuscript.

\section{Competing interests}

The authors declare that they have no competing interests.

Received: 15 July 2011 Accepted: 6 December 2011

Published: 6 December 2011

\section{References}

1. Fricke M, Lahl U: Risikobewertung von Perfluortensiden als Beitrag zur aktuellen Diskussion zum REACH-Dossier der EU-Kommission. UWSF-Z Umweltchem Ökotox 2005, 17:36-49.

2. Fromme H, Schlumer M, Ungewiss J, Roscher E: Materialien zur Umweltmedizin-Umweltmedizinische Bedeutung perfluorierter Kohlenwasserstoffe (PFC), Bayerisches Landesamt für Gesundheit und Lebensmittelsicherheit (Hrsg.), Band 16 der Schriftenreihe. 2006, ISBN 3939652-12-1.
3. Umweltbundesamt (UBA): Perfluorierte Verbindungen: Falscher Alarm oder berechtigte Sorge? Februar 2007, Dessau 2007.

4. Umweltbundesamt (UBA): Per- und Polyfluorierte Chemikalien. Einträge vermeiden-Umwelt schützen. Juli 2009, Dessau-Roßlau 2009.

5. Weinfurtner K, Kördel W, Bücking M: Untersuchungen zum Übergang von PFT aus belasteten Böden in Pflanzen. Bodenschutz. Ausgabe 032008.

6. Stahl T, Heyn J, Thiele H, Hüther J, Failing K, Georgii S, Brunn H: Carryover of perfluorooctanoic acid (PFOA) and perfluorooctane sulfonate (PFOS) from soil to plants. Arch Environ Contam Toxicol 2009, 57:289-298.

7. Trudel D, Horowitz L, Wormuth M, Scheringer M, Cousins IT, Hungerbühler K: Estimating consumer exposure to PFOS and PFOA. Risk Anal 2008, 28:251-269.

8. Tittlemier SA, Pepper K, Seymour C, Moisey J, Bronson R, Cao XL, Dabeka RW: Dietary exposure of Canadians to perfluorinated carboxylates and perfluorooctane sulfonate via consumption of meat, fish, fast foods, and food items prepared in their packaging. J Agric Food Chem 2007, 55:3203-3210.

9. Haug LS, Huber S, Schlabach M, Becher G, Thomsen C: Investigation on per- and polyfluorinated compounds in paired samples of house dust and indoor air from Norwegian homes. Environ Sci Technol 2011, 45:7991-7998.

10. Haug LS, Huber S, Becher G, Thomsen C: Characterisation of human exposure pathways to perfluorinated compounds-comparing exposure estimates with biomarkers of exposure. Environ Int 2011, 37:687-693.

11. Scheringer M, Trudel D, Horowitz L, Wormuth M, Cousins IT, Hungenbühler K: Konsumentenexposition gegenüber PFOS und PFOA. Mitt Umweltchem Ökotox 2007, 14:32-36.

12. Vestergren $R$, Cousins IT: Tracking the pathways of human exposure to perfluorocarboxylates. Environ Sci Technol 2009, 43:5565-5575.

13. Fromme H, Midasch O, Twardella D, Angerer J, Boehmer S, Liebl B: Occurrence of perfluorinated substances in an adult German population in southern Bavaria. Int Arch Occup Environ Health 2007, 80:313-319.

14. UK Food Standards Agency: Fluorinated chemicals: UK dietary intakes. [http://www.food.gov.uk/multimedia/pdfs/fsis1106.pdf].

15. European Food Safety Authority: Perfluorooctane sulfonate (PFOS), perfluorooctanoic acid (PFOA) and their salts. Scientific opinion of the panel on contaminants in the food chain. EFSA J 2008, 653:1-131.

16. Ostertag SK, Tague BA, Humphries MM, Tittlemier SA, Chan HM: Estimated dietary exposure to fluorinated compounds from traditional foods among Inuit in Nunavut, Canada. Chemosphere 2009, 75:1165-1172.

17. Bundesinstitut für Risikobewertung (BfR): Gesundheiltiche Risiken durch PFOS und PFOA in Lebensmitteln sind nach dem derzeitigen wissenschaftlichen Kenntnisstand unwahrscheinlich. Stellungnahme Nr. 004/2009 2008.

18. Skutlarek D, Exner $M$, Färber H: Perfluorierte Tenside (PFT) in der aquatischen Umwelt und im Trinkwasser. UWSF Z Umweltchem Ökotox 2006, 18:151-154.

19. Hölzer J, Midasch O, Rauchfuss K, Kraft M, Reupert R, Angerer J, Kleeschulte P, Marschall N, Wilhelm M: Biomonitoring of perfluorinated compounds in children and adults exposed to perfluorooctanoatecontaminated drinking water. Environ Health Perspect 2008, 5:651-657.

20. Hölzer J, Goeen T, Rauchfuss K, Kraft M, Angerer J, Kleeschulte P, Wilhelm M: One-year follow-up of perfluorinated compounds in plasma of German residents from Arnsberg formerly exposed to PFOAcontaminated drinking water. Int J Hyg Environ Health 2009, 212:499-504.

21. Wilhelm M, Hölzer J, Dobler L, Rauchfuss K, Midasch O, Kraft M, Angerer J, Wiesmüller G: Preliminary observations on perfluorinated compounds in plasma samples (1977-2004) of young German adults from an area with perfluorooctanoate-contaminated drinking water. Int I Hyg Environ Health 2009, 212:142-145.

22. Wilhelm M, Bergmann S, Dieter HH: Occurrence of perfluorinated compounds (PFCs) in drinking water of North Rhine-Westphalia, Germany and new approach to assess drinking water contamination by shorter-chained C4-C7 PFCs. Int J Hyg Environ Health 2010, 13:224-232.

23. Mak YL, Taniyasu S, Yeung LW, Lu G, Jin L, Yang Y, Lam PK, Kannan K, Yamashita N: perfluorinated compounds in tap water from China and several other countries. Environ Sci Technol 2009, 43:4824-4829.

24. Rumsby PC, McLaughlin CL, Hall T: Perfluorooctane sulphonate and perfluorooctanoic acid in drinking and environmental waters. Philos Transact A Math Phys Eng Sci 2009, 367:4119-4136. 
25. D'Eon JC, Crozier PW, Furdui VI, Reiner EJ, Libelo EL, Mabury SA Perfluorinated phosphonic acids in Canadian surface waters and wastewater treatment plant effluent: discovery of a new class of perfluorinated acids. Environ Toxicol Chem 2009, 28:2101-2107.

26. Stahl T, Ackmann R, Georgii S, Wohlfarth R, Brunn H: Perfluorierte Tenside. Verwendung, Vorkommen und Aufnahme mit Trinkwasser und Nahrung. Ernährung 2007, 1:27-35

27. Schuetze A, Heberer T, Effkemann S, Juergensen S: Occurrence and assessment of perfluorinated chemicals in wild fish from Northern Germany. Chemosphere 2010, 78:647-652.

28. Berger U, Glynn A, Holmström KE, Berglund M, Ankarberg EH, Törnkvist A: Fish consumption as a source of human exposure to perfluorinated alkyl substances in Sweden-analysis of edible fish from Lake Vättern and the Baltic Sea. Chemosphere 2009, 76:799-804.

29. Ericson I, Martí-Cid R, Nadal M, Van Bavel B, Lindström G, Domingo JL: Human exposure to perfluorinated chemicals through the diet: intake of perfluorinated compounds in foods from the Catalan (Spain) market. $J$ Agric Food Chem 2008, 56:1787-1794.

30. European Food Safety Authority: Results of the monitoring of perfluoroalkylated substances in food in the period 2000-2009. EFSA J 2011, 9:2016.

31. Martin JW, Mabury SA, O'Brien PJ: Metabolic products and pathways of fluorotelomer alcohols in isolated rat hepatocytes. Chem Biol Interact 2005, 155:165-180

32. Kudo N, Iwase $Y$, Okayachi H, Yamakawa Y, Kawashima Y: Induction of hepatic peroxisome proliferation by $8-2$ telomer alcohol feeding in mice: Formation of perfluorooctanoic acid in the liver. Toxicol Sci 2005, 86:231-238.

33. Bundesinstitut für Risikobewertung: Perfluorchemikalien in Papieren und Kartons für Lebensmittelverpackungen. Gesundheitliche Bewertung Nr. 049/ 20052005.

34. Powley CR, Michalczyk MJ, Kaiser MA, Buxton W: Determination of perfluorooctanoic acid (PFOA) extractable from the surface of commercial cookware under simulated cooking conditions by LC/MS/ MS. Analyst 2005, 130:1299-1302.

35. Begley TH, White K, Honigfort P, Twaroski ML, Neches R, Walker RA: Perfluorochemicals: potential sources of and migration from food packing. Food Addit Contam 2005, 22:1023-1031.

36. Sinclair E, Kim SK, Akinleye HB, Kannan K: Quantitation of gas-phase perfluoroalkyl surfactants and fluorotelomer alcohols released from nonstick cookware and microwave popcorn bags. Environ Sci Technol 2007, 41:1180-1185.

37. Tittlemier SA, Pepper K, Edwards L: Concentrations of perfluorooctanesulfonamides in Canadian total diet study composite food samples collected between 1992 and 2004. J Agric Food Chem 2006, 54:8385-8389.

38. Fromme H, Tittlemier SA, Völkel W, Wilhelm M, Twardella D: Perfluorinated compounds-exposure assessment for the general population in western countries. Int J Hyg Environ Health 2009, 212:239-270.

39. Ericson Jogsten I, Perelló G, Llebaria X, Bigas E, Martí-Cid R, Kärrman A, Domingo JL: Exposure to perfluorinated compounds in Catalonia, Spain through consumption of various raw and cooked foodstuffs, including packaged food. Food Chem Toxicol 2009, 47:1577-1583.

40. D'Eon JC, Simpson AJ, Kumar R, Baer AJ, Mabury SA: Determining the molecular interactions of perfluorinated carboxylic acids with human sera and isolated human serum albumin using nuclear magnetic resonance spectroscopy. Environ Toxicol Chem 2010, 29:1678-1688.

41. Renner R: PFOA in people. Environ Sci Technol 2007, 41:4497-4500.

42. Begley TH, Hsu W, Noonan G, Diachenko G: Food migration of fluorochemical paper additives from food-contact paper into foods and food simulants. Addit Contam 2008, 25:384-390.

43. LV G, Wang L, Liu S, Li S: Determination of perfluorinated compounds in packaging materials and textiles using pressurized liquid extraction with gas chromatography-mass spectrometry. Analytical Sciences 2009, 25:425-429.

44. Goosey E, Harrad S: Perfluoroalkyl compounds in dust from Asian, Australian, European, and North American homes and UK cars, classrooms, and offices. Environ Int 2011, 37:86-92.

45. Langer V, Dreyer A, Ebinghaus R: Polyfluorinated compounds in residential and nonresidential indoor air. Environ Sci Technol 2011, 44:8075-8081.
46. Huber S, Haug LS, Schlabach M: Per- and polyfluorinated compounds in house dust and indoor air from northern Norway-a pilot study. Chemosphere 2011, 84:1686-1693.

47. Washburn ST, Bingman TS, Braithwaite SK, Buck RC, Buxton LW, Clewell HJ, Haroun LA, Kester JE, Rickard RW, Shipp AM: Exposure assessment and risk characterization for perfluorooctanoate in selected consumer articles. Environ Sci Technol 2005, 39:3904-3910.

48. Moriwaki H, Takata Y, Arakawa R: Concentrations of perfluorooctane sulfonate (PFOS) and perfluorooctanoic acid (PFOA) in vacuum cleaner dust collected in Japanese homes. J Environ Monit 2003, 5:753-757.

49. Kubwabo C, Stewart B, Zhu J, Marro L: Occurrence of perfluorosulfonates and other perfluorochemicals in dust from selected homes in the city of Ottawa, Canada. J Environ Monit 2005, 7:1074-1078.

50. Kato K, Calafat AM, Needham LL: Polyfluoroalkyl chemicals in house dust. Environ Res 2009, 109:518-523.

51. Fromme $H$, Schlummer M, Möller A, Gruber L, Wolz G, Ungewiss J, Böhmer S, Dekant W, Mayer R, Liebl B, Twardella D: Exposure of an adult population to perfluorinated substances using duplicate diet portions and biomonitoring data. Environ Sci Technol 2007, 41:7928-7933.

52. Zhang T, Wu Q, Sun HW, Zhang XZ, Yun SH, Kannan K: Perfluorinated compounds in whole blood samples from infants, children, and adults in China. Environ Sci Technol 2010, 44:4341-4347.

53. Midasch O, Drexler H, Hart N, Beckmann MW, Angerer J: Transplacental exposure of neonates to perfluorooctanesulfonate and perfluorooctanoate: a pilot study. Int Arch Occup Environ Health 2007, 80:643-648.

54. Inoue K, Okada F, Ito R, Kato S, Sasaki S, Nakajima S, Uno A, Saijo Y, Sata F, Yoshimura Y, Kishi R, Nakazara H: Perfluorooctane sulfonate (PFOS) and related perfluorinated compounds in human blood and cord blood samples: assessment of PFOS exposure in a susceptible population during pregnancy. Environ Health Perspect 2004, 112:1204-1207.

55. Apelberg BJ, Witter FR, Herbstman JB, Calafat AM, Halden RU, Needham LL, Goldman LR: Cord serum concentrations of perfluorooctane sulfonate (PFOS) and perfluorooctanoate (PFOA) in relation to weight and size at birth. Environ Health Perspect 2007, 115:1670-1676.

56. Monroy R, Morrison K, Teo K, Atkinson S, Kubwabo C, Stewart B, Foster WG: Serum levels of perfluoroalkyl compounds in human maternal and umbilical cord blood samples. Environ Res 2008, 108:56-62.

57. Fei C, McLaughlin JK, Tarone RE, Olsen J: Perfluorinated chemicals and fetal growth: a study within the Danish National Birth Cohort. Environ Health Perspect 2007, 115:1677-1682.

58. Hinderliter PM, Mylchreest E, Gannon SA, Butenhoff JL, Kennedy GL: Perfluorooctane: placental and lactational transport pharmacokinetics in rats. Toxicology 2005, 211:139-148.

59. Kärrman A, Ericson I, van Bavel B, Darnerud PO, Aune M, Glynn A, Lignell S, Lindstrom G: Exposure of perfluorinated chemicals through lactation: levels of matched human milk and serum and a temporal trend, 19962004, in Sweden. Environ Health Perspect 2007, 115:226-230.

60. So MK, Yamashita N, Taniyasu S, Jiang Q, Giesy JP, Chen K, Lam PKS: Health risks in infants associated with exposure to perfluorinated compounds in human breast milk from Zhoushan, China. Environ Sci Technol 2006, 40:2924-2929.

61. Völkel W, Genzel-Broviczeny O, Demmelmair H, Gebauer C, Koletzko B, Twardella D, Raab U, Fromme H: Perfluoroctane sulfonate (PFOS) and perfluoroctanoic acid (PFOA) in human breast milk: results of a pilot study. Int J Hyg Envirnon Health 2007, 211:440-446.

62. Liu J, Li J, Zhao Y, Wang Y, Zhang L, Wu Y: The occurrence of perfluorinated alkyl compounds in human milk from different regions of China. Environ Int 2010, 36:433-438.

63. Tao L, Ma J, Kunisue T, Libelo EL, Tanabe S, Kannan K: Perfluorinated compounds in human breast milk from several Asian countries, and in infant formula and dairy milk from the United States. Environ Sci Technol 2008, 42:8597-8602.

64. Llorca M, Farré M, Picó Y, Teijón ML, Alvarez JG, Barceló D: Infant exposure of perfluorinated compounds: levels in breast milk and commercial baby food. Environ Int 2010, 36:584-592.

65. Jones PD, Hu W, de Coen W, Newsted JL, Giesy JP: Binding of perfluorinated fatty acids to serum proteins. Environ Toxicol Chem 2003, 22:2639-2649.

66. Taves DR: Electrophoretic mobility of serum fluoride. Nature 1968, 119:582-583 
67. Shen YW, Taves DR: Fluoride concentrations in the human placenta and maternal and cord blood. An J Obstet Gynecol 1974, 119:205-207.

68. Olsen GW, Burris JM, Mandel JH, Zobel LR: Serum perfluorooctane and hepatic and lipid clinical chemistry tests in fluorochemical production employees. J Occup Environ Med 1999, 41:799-806.

69. Olsen GW, Hansen KJ, Stevenson LA, Burris JM, Mandel JH: Human donor liver and serum concentrations of perfluorooctanesulfonate and other perfluorochemicals. Environ Sci Technol 2003, 37:888-891.

70. Ehresman DJ, Chang S, Bjork JA, Hart JA, Lieder PH, Wallace KB, Butenhoff JL: Increased acyl CoA oxidase activity in rats after five consecutive daily doses of perfluorobutanesulfonate, perfluorohexanesulfonate, and perfluorooctanesulfonate. Toxicologist 2007, 96:179.

71. Kannan K, Corsolini S, Falandysz J, Fillmann G, Kumar KS, Loganathan BG, Mohd MA, Olivero J, Van Wouwe N, Yang JH, Aldous KM: Perfluorooctanesulfonate and related fluorochemicals in human blood from several countries. Environ Sci Technol 2004, 38:4489-4495.

72. Kärrman A, Langlois I, van Bavel B, Lindström G, Oehme M: Identification and pattern of perfluorooctane sulfonate (PFOS) isomers in human serum and plasma. Environ Int 2007, 33:782-788.

73. Ericson I, Gomez M, Nadal M, van Bavel B, Lindstrom G, Domingo JL: Perfluorinated chemicals in blood of residents in Catalonia (Spain) in relation to age and gender: a pilot study. Environ Int 2007, 33:616-623.

74. Calafat AM, Kuklenyik Z, Reidy JA, Caudill SP, Tully JS, Needham LL: Serum concentrations of 11 polyfluoroalkyl compounds in the U.S. population: data from the national health and nutrition examination survey (NHANES) 1999-2000. Environ Sci Technol 2007, 41:2237-2242.

75. Wilhelm M, Angerer J, Fromme H, Hölzer J: Contribution to the evaluation of reference values for PFOA and PFOS in plasma of children and adults from Germany. Int J Hyg Environ Health 2009, 212:56-60.

76. Midasch O, Schettgen T, Angerer J: Pilot study on the perfluorooctanesulfonate and perfluorooctanoate exposure of the German general population. Int J Hyg Environ Health 2006, 209:489-496.

77. Fromme H, Albrecht M, Angerer J, Drexler H, Gruber L, Schlummer M, Parlar H, Korner W, Wanner A, Heitmann D, Roscher E, Bolte G: Integrated Exposure Assessment Survey (INES): exposure to persistent and bioaccumulative chemicals in Bavaria, Germany. Int J Hyg Environ Health 2007, 210:345-349

78. Kärrman A, van Bavel B, Jarnberg U, Hardell L, Lindstrom G: Perfluorinated chemicals in relation to other persistent organic pollutants in human blood. Chemosphere 2006, 64:1582-1591.

79. Bischel HN, Macmanus-Spencer LA, Luthy RG: Noncovalent interactions of long-chain perfluoroalkyl acids with serum albumin. Environ Sci Technol 2010, 44:5263-5269.

80. Chen YM, Guo LH: Fluorescence study on site-specific binding of perfluoroalkyl acids to human serum albumin. Arch Toxicol 2009, 83:255-261.

81. Calafat AM, Needham LL, Kuklenyik Z, Reidy JA, Tully JS, AguilarVillalobos M, Naeher LP: Perfluorinated chemicals in selected residents of the American continent. Chemosphere 2006, 63:490-496.

82. Harada K, Saito N, Inoue K, Yoshinaga T, Watanabe T, Sasaki S, Kamiyama S, Koizumi A: The influence of time, sex and geographic factors on levels of perfluorooctane sulfonate and perfluorooctanoate in human serum over the last 25 years. J Occup Health 2004, 46:141-147.

83. Kärrman A, Mueller JF, van Bavel B, Harden F, Toms LM, Lindstrom G: Levels of 12 perfluorinated chemicals in pooled australian serum, collected 2002-2003, in relation to age, gender, and region. Environ Sci Technol 2006, 40:3742-3748.

84. Rylander C, Brustad M, Falk H, Sandanger TM: Dietary predictors and plasma concentrations of perfluorinated compounds in a coastal population from Northern Norway. J Environ Public Health 2010.

85. Olsen GW, Huang H-Y, Helzlsouer KJ, Hansen KJ, Butenhoff JL, Mandel JH: Historical comparison of perfluorooctanesulfonate, perfluorooctanoate, and other fluorochemicals in human blood. Environ Health Perspect 2005, 113:539-545.

86. Liu C, Deng J, Yu L, Ramesh M, Zhou B: Endocrine disruption and reproductive impairment in zebrafish by exposure to $8: 2$ fluorotelomer alcohol. Aquat Toxicol 2010, 96:70-76.

87. Liu W, Li X, Xu L, Liu L, Jin Y, Sato I, Tsuda S: Influence of gestation, regular bleeding and intermittent exposure on blood perfluorooctane sulfonate levels in mice: potential factors inducing sex difference and affecting exposure evaluation. J Toxicol Sci 2010, 35:309-316.

88. Rylander C, Sandanger TM, Frøyland L, Lund E: Dietary patterns and plasma concentrations of perfluorinated compounds in 315 Norwegian women: the NOWAC postgenome study. Environ Sci Technol 2010, 44:5225-5232.

89. Hanssen L, Röllin H, Odland JØ, Moe MK, Sandanger TM: Perfluorinated compounds in maternal serum and cord blood from selected areas of South Africa: results of a pilot study. J Environ Monit 2010, 12:1355-1361.

90. Hemat H, Wilhelm M, Völkel W, Mosch C, Fromme H, Wittsiepe J: Low serum levels of perfluorooctanoic acid (PFOA), perfluorooctane sulfonate (PFOS) and perfluorohexane sulfonate (PFHXS) in children and adults from Afghanistan. Sci Total Environ 2010, 408:3493-3495.

91. Calafat A, Kuklenyik Z, Reidy JA, Tully JS, Needham LL: Perfluorochemicals in residents of the United States in 2001 through 2002. "Fluoros" 9th International Symposium on Fluorinated Alkyl Organics in the Environment: August 19-20 2005; Toronto Toronto; University of Toronto; 2005.

92. Holmström KE, Berglund $M$, Järnberg U: Exposure to perfluorinated acids in 108 Swedish women in relation to methylmercury and fish consumption. Fluoros 9th International Symposium on Fluorinated Alkyl Organics in the Environment August 19-20 2005; Toronto Toronto; University of Toronto; 2005.

93. Falandysz J, Taniyasu S, Gulkowska A, Yamada N, Schulte-Oehlmann U: Is fish a major source of fluorinated surfactants and repellents in humans living on the Baltic coast? Environ Sci Technol 2006, 40:748-751.

94. Jin Y, Saito N, Harada KH, Inoue K, Koizumi A: Historical trends in human serum levels of perfluorooctanoate and perfluorooctane sulfonate in Shenyang, China. Tohoku J Exp Med 2007, 212:63-70.

95. Calafat AM, Wong L-Y, Kuklenyik Z, Reidy JA, Needham LL: Polyfluoroalky Chemicals in the U.S. Population: Data from the National Health and Nutrition Examination Survey (NHANES) 2003-2004 and comparisons with NHANES 1999-2000. Environ Health Perspect 2007, 115:1596-1602.

96. De Silva AO, Mabury SA: Isomer distribution of perfluorocarboxylates in humanblood: potential correlation to source. Environ Sci Technol 2006, 40:2903-2909.

97. Gibson SJ, Johnson JD: Absorption of FC-143-14C in Rats After a Single Oral Dose. Riker Laboratories, Inc., Subsidiary of 3M, St. Paul MN, U.S. EPA Public Docket AR-226-0455, Washington, DC; 1979.

98. Johnson JD, Gibson SJ, Ober RF: Absorption of FC-95-14C in rats after a single oral dose Project No. 890310200. Riker Laboratories, Inc., Subsidiary of 3 M, St. Paul MN. (U.S. EPA Docket No. 8(e)HQ-1180-00374); 1979.

99. Kennedy GL Jr: Dermal toxicity of ammonium perfluorooctanoate. Toxicol Appl Pharmacol 1985, 81:348-355.

100. Kennedy GL Jr, Hall GT, Brittelli MR, Barnes JR, Chen HC: Inhalation toxicity of ammonium perfluorooctanoate. Food Chem Toxicol 1986, 24:1325-1329.

101. Kudo N, Kawashima Y: Toxicity and toxicokinetics of perfluorooctanoic acid in humans and animals. J Toxicol Sci 2003, 28:49-57.

102. Fasano WJ, Carpenter SC, Gannon SA, Snow TA, Stadler JC, Kennedy GL, Buck RC, Korzeniowski SH, Hinderliter PM, Kemper RA: Absorption, distribution, metabolism and elimination of 8-2 fluorotelomer alcohol in the rat. Toxicol Sci 2006, 91:341-355.

103. Han X, Snow TA, Kemper RA, Jepson GW: Binding of perfluorooctanoic acid to rat and human plasma proteins. Chem Res Toxicol 2003, 16:775-781.

104. Lübker DJ, Hansen KJ, Bass NM, Butenhoff JL, Seacat AM: Interactions of fluorochemicals with rat liver fatty acid-binding protein. Toxicology 2002, 176:175-185

105. Ylinen M, Auriola S: Tissue distribution and elimination of perfluorodecanoic acid in the rat after single intraperitoneal administration. Pharmacol Toxicol 1990, 66:45-48.

106. Qin $P$, Liu R, Pan X, Fang X, Mou Y: Impact of carbon chain length on binding of perfluoroalkyl acids to bovine serum albumin determined by spectroscopic methods. J Agric Food Chem 2010, 58:5561-5567.

107. Austin ME, Kasturi BS, Barber M, Kannan K, Mohan-Kumar PS, MohanKumar SMJ: Neuroendocrine effects of perfluorooctane sulfonate in rats. Environ Health Perspect 2003, 111:1485-1489.

108. Seacat AM, Thomford PJ, Hansen KJ, Clemen LA, Eldridge SR, Elcombe CR, Butenhoff JL: Sub-chronic dietary toxicity of potassium perfluorooctanesulfonate in rats. Toxicology 2003, 183:117-131.

109. Yoo H, Guruge KS, Yamanaka N, Sato C, Mikami O, Miyazaki S, Yamashita N, Giesy JP: Depuration kinetics and tissue disposition of PFOA and PFOS in 
white leghorn chickens (Gallus gallus) administered by subcutaneous implantation. Ecotoxicol Environ Saf 2009, 72:26-36.

110. Han X, Yang C-H, Snajdr SI, Nabb DL, Mingoia RT: Uptake of perflurooctanoate in freshly isolated hepatocytes from male and female rats. Toxicol Lett 2008, 181:81-86.

111. Kudo N, Sakai A, Mitsumoto A, Hibino Y, Tsuda T, Kawashima Y: Tissue distribution and hepatic subcellular distribution of perfluorooctanoic acid at low dose are different from those at high dose in rats. Biol Pharm Bull 2007, 30:1535-1540.

112. Tan YM, Clewell HJ III, Andersen ME: Time dependencies in perfluorooctylacids disposition in rat and monkeys: a kinetic analysis. Toxicol Lett 2008, 177:38-47.

113. Liu L, Jin YH, Wang L, Yu HY, Liu W, Yu QL, Wang K, Liu B, Wang J: Effects of perfluorooctane sulfonate on learning and memory of rat pups. Zhonghua Yu Fang Yi Xue Za Zhi 2009, 43:622-627.

114. Thibodeaux JR, Hanson RG, Rogers JM, Grey BE, Barbee BD, Richards JH, Butenhoff JL, Stevenson LA, Lau C: Exposure to perfluorooctane sulfonate during pregnancy in rat and mouse I. Maternal and prenatal evaluations. Toxicol Sci 2003, 74:369-381.

115. Lau C, Anitole K, Hodes C, Lai D, Pfahles-Hutchens A, Seed J: Perfluoroalkyl acids: a review of monitoring and toxicological findings. Toxicol Sci 2007, 99:366-394.

116. Peng H, Wei Q, Wan Y, Giesy JP, Li L, Hu J: Tissue distribution and maternal transfer of poly- and perfluorinated compounds in Chinese sturgeon (Acipenser sinensis): implications for reproductive risk. Environ Sci Technol 2010, 44:1868-1874.

117. Henderson WM, Smith MA: Perfluorooctanoic acid and perfluorononanoic acid in fetal and neonatal mice following in utero exposure to 8-2 fluorotelomer alcohol. Toxicol Sci 2007, 95:452-461.

118. Butt CM, Muir DC, Mabury SA: Elucidating the pathways of poly- and perfluorinated Acid formation in rainbow trout. Environ Sci Technol 2010, 44:4973-4980

119. Martin JW, Chan K, Mabury SA, O'Brien PJ: Bioactivation of fluorotelomer alcohols in isolated rat hepatocytes. Chem Biol Interact 2009, 177:196-203.

120. Kudo N, Katakura M, Sato Y, Kawashima Y: Sex hormone-regulated renal transport of perfluorooctanoic acid. Chem Biol Interact 2002, 139:301-316.

121. Van den Heuvel JP, Kuslikis BI, van Rafelghem MJ, Peterson RE: Tissue distribution, metabolism and elimination of perfluorooctanoic acid in male and female rats. J Biochem Toxicol 1991, 6:83-92.

122. Weaver YM, Ehresman DJ, Butenhoff JL, Hagenbuch B: Roles of rat renal organic anion transporters in transporting perfluorinated carboxylates with different chain lengths. Toxicol Sci 2010, 113:305-314.

123. Johnson JD, Gibson SJ, Ober RE: Cholestyramine-enhanced fecal elimination of carbon-14 in rats after administration of ammonium [14C] perfluorooctanoate or potassium [14C]perfluorooctansulfonate. Fundam Appl Toxicol 1984, 4:972-976.

124. Cui L, Liao CY, Zhou QF, Xia TM, Yun ZJ, Jiang GB: Excretion of PFOA and PFOS in male rats during a subchronic exposure. Arch Environ Contam Toxicol 2010, 58:205-213.

125. Butenhoff JL, Kennedy GL, Frame SR, O'Connor JC, York RG: The reproductive toxicology of ammonium perfluorooctanoate (APFO) in the rat. Toxicology 2004, 196:95-116.

126. Harada K, Inoue K, Morikawa A, Yoshinaga T, Saito N, Koizumi A: Renal clearance of perfluorooctane sulfonate and perfluorooctanoate in humans and their species-specific excretion. Environ Res 2005, 99:253-261.

127. Committee on Toxicity of Chemicals in Food, Consumer Products and the Environment (COT): COT Statement on the Tolerable Daily Intake for Perfluorooctane Sulfonate. COT Statement 2006/9 2006.

128. Seacat AM, Thomford PJ, Hansen KJ, Olsen GW, Case MT, Butenhoff JL: Subchronic toxicity studies on perfluorooctanesulfonate potassium salt in cynomolgus monkeys. Toxicol Sci 2002, 68:249-264.

129. Benskin JP, De Silva AO, Martin LJ, Arsenault G, McCrindle R, Riddell N, Mabury SA, Martin JW: Disposition of perfluorinated acid isomers in Sprague-Dawley rats; part 1: single dose. Environ Toxicol Chem 2008, 28:542-554.

130. De Silva AO, Benskin JP, Martin LJ, Arsenault G, McCrindle R, Riddell N, Martin JW, Mabury SA: Disposition of perfluorinated acid isomers in sprague-dawley rats; part 2: subchronic dose. Environ Tox Chem 2008, 28:555-567.
131. Olsen GW, Butenhoff JL, Zobel LR: Perfluoroalkyl chemicals and human fetal development: an epidemiologic review with clinical and toxicological perspectives. Reprod Toxicol 2009, 27:212-230.

132. Olsen GW, Burris JM, Ehresman DJ, Froehlich JW, Seacat AM, Butenhoff JL, Zobel LR: Half-life of serum elimination of perfluorooctanesulfonate, perfluorohexanesulfonate, and perfluorooctanoate in retired fluorochemical production workers. Environ Health Perspect 2007, 115:1298-1305.

133. Hundley SG, Sarrif AM, Kennedy GL: Absorption, distribution and excretion of ammonium perfluorooctanoate (APFO) after oral administration to various species. Drug Chem Toxicol 2006, 29:137-145.

134. Organisation for Economic Cooperation and Development: Hazard assessment of perfluorooctane sulfonate (PFOS) and its salts. November 21, ENV/JM/RD 17/Final 2002.

135. Glaza S: Acute Dermal Toxicity Study of T-6342 in Rabbits. Coming Hazelton Inc., Madison WI., 3 M Company, St Paul. US EPA AR226-0427 1995.

136. Biesemeier JA, Harris DL: Eye and Skin Irritation Report on Sample T-1117. Report. Project No. 4102871, WARF Institute Inc 1974

137. Ji K, Kim Y, Oh S, Ahn B, Jo H, Choi K: Toxicity of perfluorooctane sulfonic acid and perfluorooctanoic acid on freshwater macroinvertebrates (Daphnia magna and Moina macrocopa) and fish (Oryzias latipes). Environ Toxicol Chem 2008, 27:2159-2168.

138. Christopher B, Martin JW: 28-Day Oral Toxicity Study with FC-143 in Albino Mice 8532-10655, T-1742CoC. Industrial Bio-Test Laboratories, Inc; 1977.

139. Metrick M, Marias AJ: 28-Day oral toxicity study with FC-143 in albino rats 8532-10654, T-1742CoC. Industrial Bio-Test Laboratories, Inc; 1977.

140. So MK, Miyake Y, Yeung WY, Ho YM, Taniyasu S, Rostkowski P, Yamashita N, Zhou BS, Shi XJ, Wang JX, Giesy JP, Yu H, Lam PK: Perfluorinated compounds in the Pearl River and Yangtze River of China. Chemosphere 2007, 68:2085-2095.

141. Perkins RG, Butenhoff JL, Kennedy GL Jr, Palazzolo MJ: 13-week dietary toxicity study of ammonium perfluorooctanoate (APFO) in male rats. Drug Chem Toxicol 2004, 27:361-378.

142. Loveless SE, Finlay C, Everds NE, Frame SR, Gillies PJ, O'Connor JC, Powley CR, Kennedy GL: Comparative responses of rats and mice exposed to linear/branched, linear, or branched ammonium perfluorooctanoate (APFO). Toxicology 2006, 220:203-217.

143. Curran I, Hierlihy SL, Liston V, Pantazopoulos P, Nunnikhoven A, Tittlemier S, Barker M, Trick K, Bondy G: Altered fatty acid homeostasis and related toxicologic sequelae in rats exposed to dietary potassium perfluorooctanesulfonate (PFOS). J Toxicol Environ Health A 2008, 71:1526-1541.

144. Cui L, Zhou QF, Liao CY, Fu JJ, Jiang GB: Studies on the toxicological effects of PFOA and PFOS on rats using histological observation and chemical analysis. Arch Environ Contam Toxicol 2009, 56:338-349.

145. Goldenthal El, Jessup DC, Geil RG, Mehring JS: Ninety-Day Subacute Rhesus Monkey Toxicity Study 137-092. Internation Research and Development Corporation; 1978

146. Butenhoff J, Costa G, Elcombe C, Farrar D, Hansen K, Iwai H, Jung R, Kennedy G Jr, Lieder P, Olsen G, Thomford P: Toxicity of ammonium perfluorooctanoate in male cynomolgus monkeys after oral dosing for 6 months. Toxicol Sci 2002, 69:244-257.

147. Yang JH: Perfluorooctanoic acid induces peroxisomal fatty acid oxidation and cytokine expression in the liver of male Japanese medaka (Oryzias latipes). Chemosphere 2010, 81:548-552.

148. Fang $X$, Wei $Y$, Liu Y, Wang J, Dai J: The identification of apolipoprotein genes in rare minnow (Gobiocypris rarus) and their expression following perfluorooctanoic acid exposure. Comp Biochem Physiol C Toxicol Pharmacol 2010, 151:152-159.

149. Thomford PJ: 104-week dietary chronic toxicity and carcinogenicity study with perfluorooctane sulfonic acid potassium salt (PFOS; T-6295) in rats Covance Laboratories Inc; 2002, 6329-183.

150. Sibinski LJ: Final report of a two-year oral (diet) toxicity and carcinogenicity study of fluorochemical FC-143 (perfluorooctanane ammonium carboxylate) in rats 1987, Vol. 1-4, 3 M Company/RIKER, Exp. No. 0281CR0012; 8 EHQ-10870394, October 16.

151. Mann PC, Frame SR: FC-143: Two-year oral toxicity-oncogenicity study in rats: Peer review of ovaries 2004, DuPont Project ID 15621, June 25, 2004. US. EPA AR226.

152. Hardisty JF, Willson GA, Brown WR, McConnell EE, Frame SR, Gaylor DW, Kennedy GL, Butenhoff JL: Pathology Working Group review and 
evaluation of proliferative lesions of mammary gland tissues in female rats fed ammonium perfluorooctanoate (APFO) in the diet for 2 years. Drug Chem Toxicol 2010, 33:131-137.

153. Biegel LB, Hurtt ME, Frame SR, O'Conner JC, Cook JC: Mechanisms of extrahepatic tumour induction by peroxisome proliferators in male CD rats. Toxicol Sci 2001, 60:44-55.

154. Frame SR, McConnell EE: Review of the proliferative lesions of the exocrine pancreas in two chronic studies in rats with ammonium perfluorooctanoate. DuPont-13788 2003.

155. Abdellatif AG, Preat $V$, Taper HS, Roberfroid M: The modulation of rat liver carcinogenesis by perfluorooctanoic acid, a peroxisome proliferator. Toxicol Appl Pharmacol 1991, 111:530-537.

156. Nilsson R, Beije B, Preat V, Erixon K, Ramel C: On the mechanism of the hepatocarcinogenicity of peroxisome proliferators. Chem-Biol Interact 1991, 78:235-250.

157. Murli H: In Mutagenicity test on T-6564 measuring chromosomal aberrations in Chinese Hamster Ovary (CHO) cells with a confirmatory assay with multiple harvests. Edited by: Vienna VA. Corning Hazleton Inc; 1996:, Study Number: 17750-0-437CO, September 16, 1996. US EPA. AR226-0433.

158. Yao X, Zhong L: Genotoxic risk and oxidative DNA damage in HepG2 cells exposed to perfluorooctanic acid. Mutat Res 2005, 587:38-44.

159. Takagi A, Umemura T, Hasegawa R, Kurokawa Y: Short-term exposure to the peroxisome proliferators perfluorooctanoic acid and perfluorodecanoic acid causes significant increase of 8hydroxydeoxyguanosine in liver DNA of rats. Cancer Lett 1991, 57:55-60.

160. Lau C, Butenhoff JL, Rogers JM: The developmental toxicity of perfluoroalkyl acids and their derivatives. Toxicol Appl Pharmacol 2004, 198:231-241.

161. Lau C, Thibodeaux JR, Hanson RG, Narotsky MG, Rogers JM, Lindstrom AB, Strynar MJ: Effects of perfluorooctanoic acid exposure during pregnancy in the mouse. Toxicol Sci 2006, 90:510-518.

162. Lau C, Thibodeaux JR, Hanson RG, Rogers JM, Grey BE, Stanton ME, Butenhoff JL, Stevenson LA: Exposure to perfluorooctane sulfonate during pregnancy in rat and mouse. II: postnatal evaluation. Toxicol Sci 2003, 74:382-392.

163. Lübker DJ, Case MT, York RG, Moore JA, Hansen KJ, Butenhoff JL: Twogeneration reproduction and cross-foster studies of perfluorooctanesulfonate (PFOS) in rats. Toxicology 2005, 215:126-148.

164. Christian MS, Hoberman AM, York RG: In Combined oral (gavage) fertility, developmental and perinatal/postnatal reproduction toxicity study of N-EtFOSE in rats. Edited by: Horsham PA. Argus Research Laboratories, Inc; 1999:, US EPA Administrative Record, AR-226-0552.

165. Butenhoff JL, Kennedy GL, Hinderliter PM, Lieder PH, Jung R, Hansen K, Gorman GS, Noker PE, Thomford PJ: Pharmacokinetics of perfluorooctanoate in cynomolgus monkeys. Toxicol Sci 2004, 82:394-406.

166. York RG, Kennedy GL Jr, Olsen GW, Butenhoff JL: Male reproductive system parameters in a two-generation reproduction study of ammonium perfluorooctanoate in rats and human relevance. Toxicology 2010, 271:64-72.

167. Grasty RC, Wolf DC, Grey BE, Lau CS, Rogers JM: Prenatal window of susceptibility to perfluorooctane sulfonate-induced neonatal mortality in the Sprague-Dawley rat. Birth Defects Res B Dev Reprod Toxicol 2003, 68:465-471.

168. Grasty RC, Bjork JA, Wallace KB, Lau CS, Rogers JM: Effects of prenatal perfluorooctane sulfo-nate (PFOS) exposure on lung maturation in the perinatal rat. Birth Defects Res B Dev Reprod Toxicol 2005, 74:405-416.

169. Wolf CJ, Fenton SE, Schmid JE, Calafat AM, Kuklenyik Z, Bryant XA, Thibodeaux J, Das KP, White SS, Lau CS, Abbott BD: Developmental toxicity of per-fluorooctanoic acid in the CD-1 mouse after cross-foster and restricted gestational exposures. Toxicol Sci 2007, 95:462-473.

170. Lübker DJ, York RG, Hansen KJ, Moore JA, Butenhoff JL: Neonatal mortality from in utero exposure to perfluorooctanesulfonate (PFOS) in SpragueDawley rats: dose-response, and biochemical and pharamacokinetic parameters. Toxicology 2005, 215:149-169.

171. Yu WG, Liu W, Jin YH, Liu XH, Wang FQ, Liu L, Nakayama SF: Prenatal and postnatal impact of perfluorooctane sulfonate (PFOS) on rat development: a cross-foster study on chemical burden and thyroid hormone system. Environ Sci Technol 2009, 43:8416-8422.

172. Abbott BD, Wolf CJ, Schmid JE, Das KP, Zehr RD, Helfant L, Nakayama S, Lindstrom AB, Strynar MJ, Lau C: Perfluorooctanoic acid induced developmental toxicity in the mouse is dependent on expression of peroxisome proliferator activated receptor-alpha. Toxicol Sci 2007, 98:571-581.

173. Abbott BD: Review of the expression of peroxisome proliferator-activated receptors alpha (PPAR alpha), beta (PPAR beta) and gamma (PPAR gamma) in rodent and human development. Reprod Toxicol 2009, 27:246-257.

174. Yanai J, Dotan S, Goz R, Pinkas A, Seidler FJ, Slotkin TA, Zimmerman F: Exposure of developing chicks to perfluorooctanoic acid induces defects in prehatch and early posthatch development. J Toxicol Environ Health $\mathrm{A}$ 2008, 71:131-133.

175. Peden-Adams MM, Stuckey JE, Gaworecki KM, Berger-Ritchie J, Bryant K, Jodice PG, Scott TR, Ferrario JB, Guan B, Vigo C, Boone JS, McGuinn WD DeWitt JC, Keil DE: Developmental toxicity in white leghorn chickens following in ovo exposure to perfluorooctane sulfonate (PFOS). Reprod Toxicol 2009, 27:307-318.

176. Molina ED, Balander R, Fitzgerald SD, Giesy JP, Kannan K, Mitchell R, Bursian SJ: Effects of air cell injection of perfluorooctane sulfonate before incubation on development of the white Leghorn chicken (Gallus domesticus) embryo. Environ Toxicol Chem 2006, 25:227-232.

177. Newsted JL, Coady KK, Beach SA, Butenhoff JL, Gallagher S, Giesy JP: Effects of perfluorooctane sulfonate on mallard and northern bobwhite quail exposed chronically via the diet. Environ Toxicol Pharmacol 2007, 23:1-9.

178. Ankley GT, Kuehl DW, Kahl MD, Jensen KM, Butterworth BC, Nichols JW: Partial life-cycle toxicity and bioconcentration modeling of perfluorooctanesulfonate in the Northern leopard frog (Rana pipiens). Environ Toxicol Chem 2004, 23:2745-2755.

179. Ankley GT, Kuehl DW, Kahl MD, Jensen KM, Linnum A, Leino RL, Villeneuve DA: Reproductive and developmental toxicity and bioconcentration of perfluorooctanesulfonate in a partial lifecycle test with the fathead minnow (Pimephales promelas). Environ Toxicol Chem 2005, 24:2316-2324.

180. Das KP, Grey BE, Zehr RD, Wood CR, Butenhoff JL, Chang SC, Ehresman DJ, Tan YM, Lau C: Effects of perfluorobutyrate exposure during pregnancy in the mouse. Toxicol Sci 2008, 105:173-181.

181. York RG: Oral (gavage) combined repeated dose toxicity study of T-7706 with the reproduction/developmental toxicity screening test 2003, 3 M Sponsor Study Number T-7706.1. US EPA Administrative Record, AR-226-1523.

182. Harris MW, Birnbaum LS: Developmental toxicity of perfluorodecanoic acid in C57BL/6N mice. Fundam Appl Toxicol 1989, 12:442-448.

183. Feng $Y$, Shi Z, Fang X, Xu M, Dai J: Perfluorononanoic acid induces apoptosis involving the Fas death receptor signaling pathway in rat testis. Toxicol Lett 2009, 190:224-230.

184. Harada KH, Ishii TM, Takatsuka K, Koizumi A, Ohmori H: Effects of perfluorooctane sulfonate on action potentials and currents in cultured rat cerebellar Purkinje cells. Biochem Biophys Res Commun 2006, 351:240-245.

185. Kovarova J, Svobodova Z: Perfluorinated compounds: occurrence and risk profile. Neuro Endocrinol Lett 2008, 29:599-608.

186. Slotkin TA, Mackillop EA, Melnick RL, Thayer KA, Seidler FJ: Developmental neurotoxicity of perfluorinated chemicals modeled in vitro. Environ Health Perspect 2008, 116:716-722.

187. Liao C, Wang T, Cui L, Zhou Q, Duan S, Jiang G: Changes in synaptic transmission, calcium current, and neurite growth by perfluorinated compounds are dependent on the chain length and functional group. Environ Sci Technol 2009, 43:2099-2104.

188. Johansson N, Fredriksson A, Eriksson P: Neonatal exposure to perfluorooctane sulfonate (PFOS) and perfluorooctanoic acid (PFOA) causes neurobehavioural defects in adult mice. Neurotoxicology 2008, 29:160-169.

189. Johansson N, Eriksson P, Viberg H: Neonatal exposure to PFOS and PFOA in mice results in changes in proteins which are important for neuronal growth and synaptogenesis in the developing brain. Toxicol Sci 2009, 108:412-418.

190. Löffler G, Petrides P, Heinrich P: Biochemie \& Pathobiochemie. 8. Auflage Heidelberg: Springer Medizin Verlag; 2007.

191. Sato I, Kawamoto K, Nishikawa Y, Tsuda S, Yoshida M, Yaegashi K, Saito N, Liu W, Jin Y: Neurotoxicity of perfluorooctane sulfonate (PFOS) in rats and mice after single oral exposure. J Toxicol Sci 2009, 34:569-574.

192. Liu L, Liu W, Song J, Yu H, Jin Y, Oami K, Sato I, Saito N, Tsuda S: A comparative study on oxidative damage and distributions of 
perfluorooctane sulfonate (PFOS) in mice at different postnatal developmental stages. Toxicol Sci 2009, 34:245-254.

193. Liu X, Liu W, Jin Y, Yu W, Wang F, Liu L: Effect of gestational and lactational exposure to perfluorooctanesulfonate on calcium-dependent signaling molecules gene expression in rats' hippocampus. Arch Toxicol 2010, 84:71-79.

194. Pinkas A, Slotkin TA, Brick-Turin Y, Van der Zee EA, Yanai J: Neurobehavioral teratogenicity of perfluorinated alkyls in an avian model. Neurotoxicol Teratol 2010, 32:182-186.

195. Langley AE, Pilcher GD: Thyroid, bradycardic and hypothermic effects of perfluoro-n-decanoic acid in rats. J Toxicol Environ Health 1985, 15:485-491.

196. Gutshall DM, Pilcher GD, Langley AE: Effect of thyroxine supplementation on the response to perfluoro-n-decanoic acid (PFDA) in rats. $J$ Toxicol Environ Health 1988, 24:491-498.

197. Weiss JM, Andersson PL, Lamoree MH, Leonards PE, van Leeuwen SP, Hamers T: Competitive binding of poly- and perfluorinated compounds to the thyroid hormone transport protein transthyretin. Toxicol Sci 2009, 109:206-216.

198. Chang SC, Thibodeaux JR, Eastvold ML, Ehresman DJ, Bjork JA, Froehlich JW, Lau C, Singh RJ, Wallace KB, Butenhoff JL: Thyroid hormone status and pituitary function in adult rats given oral doses of perfluorooctanesulfonate (PFOS). Toxicology 2008, 243:330-339.

199. Benninghoff AD, Field JA, Williams DE: Assessment of the estrogen activity of perfluorooctanoic acid (PFOA), perfluorooctane sulfonate (PFOS) and other structurally diverse perfluorinated chemicals in rainbow trout. Toxicologist CD 2007, 96:110.

200. Wei Y, Dai J, Liu M, Wang J, Xu M, Zha J, Wang Z: Estrogen-like properties of perfluorooctanic acid as revealed by expressing hepatic estrogenresponsive genes in rare minnows (Gobiocypris rarus). Environ Toxicol Chem 26:2440-2447.

201. Zhao B, Chu Y, Hardy DO, Li XK, Ge RS: Inhibition of 3beta- and 17betahydroxysteroid dehydrogenase activities in rat Leydig cells by perfluorooctane acid. J Steroid Biochem Mol Biol 2010, 118:13-17.

202. Zhao Y, Tan YS, Haslam SZ, Yang C: Perfluorooctanoic acid effects on steroid hormone and growth factor levels mediate stimulation of peripubertal mammary gland development in C57BL/6 mice. Toxicol SC 2010, 115:214-224

203. Maras M, Vanparys C, Muylle F, Robbens J, Berger U, Barber IL, Blust R, De Coen W: Estrogen-like properties of fluorotelomer alcohols as revealed by MCF-7 breast cancer cell proliferation. Environ Health Perspect 2006, 114:100-105.

204. Shi Z, Zhang H, Liu Y, Xu M, Dai J: Alterations in gene expression and testosterone synthesis in the testes of male rats exposed to perfluorododecanoic acid. Toxicol Sci 2007, 98:206-215.

205. Shi Z, Ding L, Zhang H, Feng Y, Xu M, Dai J: Chronic exposure to perfluorododecanoic acid disrupts testicular steroidogenesis and the expression of related genes in male rats. Toxicol Lett 2009, 188:192-200.

206. Yang Q, Xie Y, Depierre JW: Effects of peroxisome proliferators on the thymus and spleen of mice. Clin Exp Immunol 2000, 122:219-226.

207. Yang Q, Abedi-Valugerdi M, Xie Y, Zhao X, Moller G, Nelson BD, DePierre JW: Potent suppression of the adaptive immune response in mice upon dietary exposure to the potent peroxisome proliferator, perfluorooctanoic acid. Int Immunopharmacol 2002, 2:289-397.

208. Yang Q, Xie Y, Alexson SEH, Nelson BD, DePierre JW: Involvement of the peroxisome proliferator-activated receptor alpha in the immunomodilation caused by peroxisome proliferators in mice. Biochem Pharmacol 2002, 63:1893-1900.

209. Fang $X$, Zhang L, Feng Y, Zhao Y, Dai J: Immunotoxic effects of perfluorononanoic acid on BALB/c mice. Toxicol Sci 2008, 105:312-321.

210. Peden-Adams MM, Keller JM, Eudaly JG, Berger J, Gilkeson GS, Keil DE: Suppression of humoral immunity in mice following exposure to perfluorooctane sulfonate. Toxicol Sci 2008, 104:144-154.

211. Keil DE, Mehlmann T, Butterworth L, Peden-Adams MM: Gestational exposure to perfluorooctane sulfonate suppresses immune function in B6C3F1 mice. Toxicol Sci 2008, 103:77-85.

212. Qazi MR, Bogdanska J, Butenhoff JL, Nelson BD, DePierre JW, AbediValugerdi M: High-dose, short-term exposure of mice to perfluorooctanesulfonate (PFOS) or perfluorooctanoate (PFOA) affects the number of circulating neutrophils differently, but enhances the inflammatory responses of macrophages to lipopolysaccharide (LPS) in a similar fashion. Toxicology 2009, 262:207-214.
213. Qazi MR, Nelson BD, Depierre JW, Abedi-Valugerdi M: 28-Day dietary exposure of mice to a low total dose $(7 \mathrm{mg} / \mathrm{kg})$ of perfluorooctanesulfonate (PFOS) alters neither the cellular compositions of the thymus and spleen nor humoral immune responses: Does the route of administration play a pivotal role in PFOS-induced immunotoxicity? [abstract]. Toxicology 2009, 267:132-139.

214. Guruge KS, Hikono H, Shimada N, Murakami K, Hasegawa J, Yeung LW, Yamanaka N, Yamashita N: Effect of perfluorooctane sulfonate (PFOS) on influenza A virus-induced mortality in female B6C3F1 mice. J Toxicol Sci 2009, 3:687-691.

215. DeWitt JC, Copeland CB, Luebke RW: Suppression of humoral immunity by perfluorooctanoic acid is independent of elevated serum corticosterone concentration in mice. Toxicol Sci 2009, 109:106-112.

216. DeWitt JC, Shnyra A, Badr MZ, Loveless SE, Hoban D, Frame SR, Cunard R, Anderson SE, Meade BJ, Peden-Adams MM, Luebke RW, Luster MI: Immunotoxicity of perfluorooctanoic acid and perfluorooctane sulfonate and the role of peroxisome proliferator-activated receptor alpha. Crit Rev Toxicol 2009, 39:76-94.

217. Hu XZ, Hu DC: Effects of perfluorooctanoate and perfluorooctane sulfonate exposure on hepatoma Hep G2 cells. Arch Toxicol 2009, 83:851-861.

218. Eriksen KT, Raaschou-Nielsen O, Sørensen M, Roursgaard M, Loft S, Møller P: Genotoxic potential of the perfluorinated chemicals PFOA, PFOS, PFBS, PFNA and PFHxA in human HepG2 cells. Mutat Res 2010, 700:39-43.

219. Qian Y, Ducatman A, Ward R, Leonard S, Bukowski V, Lan Guo N, Shi X, Vallyathan V, Castranova V: Perfluorooctane sulfonate (PFOS) induces reactive oxygen species (ROS) production in human microvascular endothelial cells: role in endothelial permeability. J Toxicol Environ Health A 2010, 73:819-836.

220. Sohlenius AK, Eriksson AM, Hogstrom C, Kimland M, DePierre JW: Perfluorooctane sulfonic acid is a potent inducer of peroxisomal fatty acid $\beta$-oxidation and other activities known to be affected by peroxisome proliferators in mouse liver. Pharmacol Toxicol 1993, 72:90-93.

221. Vanden Heuvel JP, Thompson JT, Frame SR, Gillies PJ: Differential activation of nuclear receptors by perfluorinated fatty acid analogs and natural fatty acids: a comparison of human, mouse, and rat peroxisome proliferator-activated receptor-alpha, -beta, and -gamma, liver $\times$ receptor-beta, and retinoid $\times$ receptor-alpha. Toxicol Sci 2006, 92:476-489.

222. Ikeda T, Aiba K, Fukuda K, Tanaka M: The induction of peroxisome proliferation in rat liver by perfluorinated fatty acids, metabolically inert derivatives of fatty acids. J Biochem 1985, 98:475-482.

223. Sohlenius AK, Andersson K, DePierre JW: The effects of perfluorooctanoic acid on hepatic peroxisome proliferation and related parameters show no sex-related differences in mice. Biochem J 1992, 285:779-783.

224. Pastoor TP, Lee KP, Perri M, Gillies PJ: Biochemical and morphologica studies of ammonium perfluorooctanoate-induced hepatomegaly and peroxisome proliferation. Exp Mol Pathol 1987, 47:98-109.

225. Shipley JM, Hurst CH, Tanaka SS, DeRoos FL, Butenhoff JL, Seacat AM, Waxman DJ: Trans-activation of PPARa and induction of PPARa target genes by perfluorooctane-based chemicals. Toxicol Sci 2004, 80:151-160.

226. Maloney EK, Waxman DJ: Trans-activation of PPARa and PPARc by structurally diverse environmental chemicals. Toxicol Appl Pharmacol 1999, 161:209-218.

227. Takacs ML, Abbott BD: Activation of mouse and human peroxisome proliferator-activated receptors (alpha, beta/delta, gamma) by perfluorooctanoic acid and perfluorooctane sulfonate. Toxicol Sci 2007, 95:108-117.

228. Nakamura $T$, Ito $Y$, Yanagiba $Y$, Ramdhan $D H$, Kono $Y$, Naito $H$, Hayashi $Y$, Li Y, Aoyama T, Gonzalez FJ, Nakajima T: Microgram-order ammonium perfluorooctanoate may activate mouse peroxisome proliferatoractivated receptor alpha, but not human PPARalpha. Toxicology 2009, 265:27-33

229. Haughom B, Spydevold $\varnothing$ : The mechanism underlying the hypolipemic effect of perfluorooctanoic acid (PFOA), perfluorooctane sulphonic acid (PFOSA) and clofibric acid. Biochim Biophys Acta 1992, 1128:65-72.

230. Martin MT, Brennan RJ, Hu W, Ayanoglu E, Lau C, Ren H, Wood CR, Corton JC, Kavlock RJ, Dix DJ: Toxicogenomic study of triazole fungicides and perfluoroalkyl acids in rat livers predicts toxicity and categorizes chemicals based on mechanisms of toxicity. Toxicol Sci 2007, 97:595-613,

231. Yin Yeung W, Guruge KS, Yamanaka N, Miyazaki S, Lam PKS, Yamashita N, Geisy JP: Gene expression profiles in rat liver treated with 
pentadecafluorooctanic acid (PFOA). 9th "Fluoros" International Symposium on Fluorinated Alkyl Organics in the Environment August 19-20 2005; Toronto Toronto; University of Toronto; 2005.

232. Guruge KS, Yeung LWY, Yamanaka N, Miyazaki S, Lam PKS, Giesy JP, Jones PD, Yamashita N: Gene expression profiles in rat liver treated with perfluorooctaonic acid (PFOA). Toxicol Sci 2006, 89:93-107.

233. Rosen MB, Thibodeaux JR, Wood CR, Zehr RD, Schmid JE, Lau C: Gene expression profiling in the lung and liver of PFOAexposed mouse fetuses. Toxicology 2007.

234. Peters JM, Hennuyer N, Staels B, Fruchart JC, Fievet C, Gonzalez FJ: Alterations in lipoprotein metabolism in peroxisome proliferatorsactivated receptor alpha-deficient mice. J Biol Chem 1997, 272:27307-27312.

235. Minata M, Harada KH, Kärrman A, Hitomi T, Hirosawa M, Murata M, Gonzalez FJ, Koizumi A: Role of peroxisome proliferator-activated receptor-alpha in hepatobiliary injury induced by ammonium perfluorooctanoate in mouse liver. Ind Health 2010, 48:96-107.

236. Elcombe CR, Elcombe BM, Farrar DG, Foster JR: Characterization of ammonium perfluorooctanic acid (APFO) induced hepatomegaly in rats. Toxicology 2007, 240:172-173

237. Ren H, Vallanat B, Nelson DM, Yeung LW, Guruge KS, Lam PK, LehmanMcKeeman LD, Corton JC: Evidence for the involvement of xenobioticresponsive nuclear receptors in transcriptional effects upon perfluoroalkyl acid exposure in diverse species. Reprod Toxicol 2009, 27:266-277.

238. Hu W, Jones PD, Upham BL, Trosko JE, Lau C, Giesy JP: Inhibition of gap junctional intercellular communication by perfluorinated compounds in rat liver and dolphin kidney epithelial cell lines in vitro and SpragueDawley rats in vivo. Toxicol Sci 2002, 68:429-436.

239. Upham BL, Park JS, Babica P, Sovadinova I, Rummel AM, Trosko JE, Hirose A, Hasegawa R, Kanno J, Sai K: Structure-activity-dependent regulation of cell communication by perfluorinated fatty acids using in vivo and in vitro model systems. Environ Health Perspect 2009, 117:545-551.

240. Ehresman DJ, Froehlich JW, Olsen GW, Chang SC, Butenhoff JL: Comparison of human whole blood, plasma, and serum matrices for the determination of perfluorooctanesulfonate (PFOS), perfluorooctanoate (PFOA), and other fluorochemicals. Environ Res 2007, 103:176-184.

241. Kudo N, Suzuki-Nakajima E, Mitsumoto A, Kawashima Y: Responses of the liver to perfluorinated fatty acids with different carbon chain length in male and female mice: in relation to induction of hepatomegaly, peroxisomal b-oxidation and microsomal 1-acylglycerophosphocholine acyltransferase. Biol Pharm Bull 2006, 29:1952-1957.

242. Permadi H, Lundgren B, Andesson K, Sundberg C, DePierre JW: Effects of perfluoro fatty acids on peroxisome proliferation on mitochondrial size in mouse liver: dose and time factors and effect of chain length. Xenobiotic 1993, 23:761-770.

243. Wei Y, Shi X, Zhang H, Wang J, Zhou B, Dai J: Combined effects of polyfluorinated and perfluorinated compounds on primary cultured hepatocytes from rare minnow (Gobiocypris rarus) using toxicogenomic analysis. Aquat Toxicol 2009, 95:27-36.

244. Jernbro S, Rocha PS, Keiter S, Skutlarek D, Färber H, Jones PD, Giesy JP, Hollert $\mathrm{H}$, Engwall M: Perfluorooctane sulfonate increases the genotoxicity of cyclophosphamide in the micronucleus assay with V79 cells-further proof of alterations in cell membrane properties caused by PFOS. Env Sci Pollut Res 2007, 14:85-87.

245. Watanabe MX, Jones SP, Iwata H, Kim EY, Kennedy SW: Effects of coexposure to 2, 3, 7, 8-tetrachlorodibenzo-p-dioxin and perfluorooctane sulfonate or perfluorooctanoic acid on expression of cytochrome P450 isoforms in chicken (Gallus gallus) embryo hepatocyte cultures. Comp Biochem Physiol C Toxicol Pharmacol 2009, 149:605-612.

246. Alexander BH, Olsen GW, Burris JM, Mandel JH, Mandel JS: Mortality of employees of a perfluorooctanesulphonyl fluoride manufacturing facility. Occup Environ Med 2003, 60:722-729.

247. Alexander BH, Olsen GW: Bladder cancer in perfluorooctanesulfonyl fluoride manufacturing workers. Ann Epidemiol 2007, 17:471-478.

248. Grice MM, Alexander BH, Hoffbeck R, Kampa DM: Self-reported medical conditions in perfluorooctanesulfonyl fluoride manufacturing workers. $J$ Occup Environ Med 2007, 49:722-729.

249. Gilliland FD, Mandel JS: Mortality among employes of a perfluorooctanoic acid production plant. J Occup Med 1993, 35:950-954.
250. Alexander BH: Mortality Study of Workers Employed at the 3 M Cottage Grove Facility. Final Report Division of Environmental and Occupational Health, School of Public Health, University of Minnesota, 2001 EPA AR226-1030a018; 2001.

251. Lundin Jl, Alexander BH, Olsen GW, Church TR: Ammonium perfluorooctanoate production and occupational mortality. Epidemiology 2009, 20:921-928.

252. DuPont 2003: Epidemiology surveillance report: cancer incidence for Washington Works site 1959-2001. US EPA Administrative Record , AR-2261307-7.

253. DuPont 2006: Ammonium perfluorooctanoate: phase II. Retrospective cohort analysis related to a serum biomarker of exposure in polymer production plant. US EPA Administrative Record, 8EHQ-0381-0394.

254. Gilliland FD, Mandel JS: Serum perfluorooctanoic acid and hepatic enzymes, lipoproteins and cholesterol: a study of occupationally exposed men. Am J Ind Med 1996, 29:560-568.

255. Olsen GW, Burris JM, Burlew MM, Mandel JH: Plasma cholecystokinin and hepatic enzymes, cholesterol and lipoproteins in ammonium perfluorooctanoate production workers. Drug Chem Toxicol 2000, 23:603-620.

256. Olsen GW, Zobel LR: Assessment of lipid, hepatic, and thyroid parameters with serum perfluorooctanoate (PFOA) concentrations in fluorochemical production workers. Int Arch Occup Environ Health 2007, 81:231-246.

257. Olsen GW, Gilliland FD, Burlew MM, Burris JM, Mandel JS, Mandel JH: An epidemiological investigation of reproductive hormones in men with occupational exposure to perfluorooctanoic acid. J Occ Env Med 1998, 40:614-622.

258. Sakr CJ, Leonard RC, Kreckmann KH, Slade MD, Cullen MR: Longitudinal study of serum lipids and liver enzymes in workers with occupational exposure to ammonium perfluorooctanoate. J Occup Environ Med 2007, 49:872-879.

259. Sakr CJ, Symons JM, Kreckmann KH, Leonard RC: Ischaemic heart disease mortality study among workers with occupational exposure to ammonium perfluorooctanoate. Occup Environ Med 2009, 66:699-703.

260. Costa G, Sartori S, Consonni D: Thirty years of medical surveillance in perfluooctanoic acid production workers. J Occup Environ Med 2009, 51:364-372.

261. Bloom MS, Kannan K, Spliethoff HM, Tao L, Aldous KM, Vena JE: Exploratory assessment of perfluorinated compounds and human thyroid function. Physiol Behav 2010, 99:240-245.

262. Pirali B, Negri S, Chytiris S, Perissi A, Villani L, La Manna L, Cottica D, Ferrari M, Imbriani M, Rotondi M, Chiovato L: Perfluorooctane sulfonate and perfluorooctanoic acid in surgical thyroid specimens of patients with thyroid diseases. Thyroid 2009, 19:1407-1412.

263. Melzer D, Rice N, Depledge MH, Henley WE, Galloway TS: Association between serum perfluorooctanoic acid (PFOA) and thyroid disease in the U.S. National Health and Nutrition Examination Survey. Environ Health Perspect 2010, 118:686-692.

264. Emmett EA, Zhang H, Shofer FS, Freeman D, Rodway NV, Desai C, Shaw LM Community exposure to perfluorooctanoate: relationships beween serum levels and certain health parameters. J Occup Environ Med 2006, 48:771-779.

265. Nelson JW, Hatch EE, Webster TF: Exposure to polyfluoroalkyl chemicals and cholesterol, body weight, and insulin resistance in the general U.S population. Environ Health Perspect 2010, 118:197-202.

266. Steenland K, Tinker S, Frisbee S, Ducatman A, Vaccarino V: Association of perfluorooctanoic acid and perfluorooctane sulfonate with serum lipids among adults living near a chemical plant. Am J Epidemiol 2009, 170:1268-1278.

267. Steenland K, Fletcher T, Savitz DA: Epidemiologic evidence on the health effects of perfluorooctanoic acid (PFOA). Environ Health Perspect 2010, 118:1100-1108.

268. Anderson-Mahoney P, Kotlerman J, Takhar H, Gray D, Dahlgren J: Selfreported health effects among community residents exposed to perfluorooctanoate. New Solut 2008, 18:129-143.

269. Lin CY, Chen PC, Lin YC, Lin LY: Association among serum perfluoroalkyl chemicals, glucose homeostasis, and metabolic syndrome in adolescents and adults. Diabetes Care 2009, 32:702-707.

270. MacNeil J, Steenland NK, Shankar A, Ducatman A: A cross-sectional analysis of type II diabetes in a community with exposure to perfluorooctanoic acid (PFOA). Environ Res 2009, 109:997-1003. 
271. Leonard RC, Kreckmann KH, Sakr CJ, Symons JM: Retrospective cohort mortality study of workers in a polymer production plant including a reference population of regional workers. Ann Epidemiol 2008, 18:15-22.

272. Washino N, Saijo Y, Sasaki S, Kato S, Ban S, Konishi K, Ito R, Nakata A, Iwasaki Y, Saito K, Nakazawa H, Kishi R: Correlations between prenatal exposure to perfluorinated chemicals and reduced fetal growth. Environ Health Perspect 2009, 117:660-667.

273. Hamm MP, Cherry NM, Martin JW, Bamforth F, Burstyn I: The impact of isolated maternal hypothyroxinemia on perinatal morbidity. J Obstet Gynecol Can 2009, 31:1015-1021.

274. Nolan LA, Nolan JM, Shofer FS, Rodway NV, Emmett EA: The relationship between birth weight, gestational age and perfluorooctanoic acid (PFOA)-contaminated public drinking water. Reprod Toxicol 2009, 27:231-238.

275. Nolan LA, Nolan JM, Shofer FS, Rodway NV, Emmett EA: Congenital anomalies, labor/delivery complications, maternal risk factors and their relationship with perfluorooctanoic acid (PFOA)-contaminated public drinking water [abstract]. Reprod Toxicol 2010, 29:147-155.

276. Stein CR, Savitz DA, Dougan M: Serum levels of perfluorooctanoic acid and perfluorooctane sulfonate and pregnancy outcome. Am J Epidemiol 2009, 170:837-846

277. Fei C, McLaughlin JK, Lipworth L, Olsen J: Prenatal exposure to perfluorooctanoate (PFOA) and perfluorooctanesulfonate (PFOS) and maternally reported developmental milestones in infancy. Environ Health Perspect 2008, 116:1391-1395.

278. Fei C, McLaughlin JK, Lipworth L, Olsen J: Maternal levels of perfluorinated chemicals and subfecundity. Hum Reprod 2009, 24:1200-1205.

279. Fei C, McLaughlin JK, Lipworth L, Olsen J: Maternal concentrations of perfluorooctanesulfonate (PFOS) and perfluorooctanoate (PFOA) and duration of breastfeeding. Scand J Work Environ Health 2010, 36:413-421.

280. Hoffman K, Webster TF, Weisskopf MG, Weinberg J, Vieira VM: Exposure to polyfluoroalkyl chemicals and attention deficit hyperactivity disorder in U.S. children aged 12-15 years. Environ Health Perspect 2010, 118:1762-1767.

281. Olsen GW, Chang SC, Noker PE, Gorman GS, Ehresman DJ, Lieder PH, Butenhoff JL: A comparison of the pharmacokinetics of perfluorobutanesulfonate (PFBS) in rats, monkeys and humans. Toxicology 2009, 256:65-74

282. Steenland K, Tinker S, Shankar A, Ducatman A: Association of perfluorooctanoic acid (PFOA) and perfluorooctane sulfonate (PFOS) with uric acid among adults with elevated community exposure to PFOA. Environ Health Perspect 2010, 118:229-233.

283. Butenhoff JL, Kennedy GL, Hinderliter PM, Lieder PH, Jung R, Hansen KJ, Gorman GS, Noker PE, Thomford PJ: Pharmacokinetics of perfluorooctanoate in cynomolgus monkeys. Toxicol Sci 2004, 82:394-406.

284. Yeung LW, Loi El, Wong VY, Guruge KS, Yamanaka N, Tanimura N, Hasegawa J, Yamashita N, Miyazaki S, Lam PK: Biochemical responses and accumulation properties of long-chain perfluorinated compounds (PFOS/PFDA/PFOA) in juvenile chickens (Gallus gallus). Arch Environ Contam Toxicol 2009, 57:377-386.

285. Chang SC, Thibodeaux JR, Eastvold ML, Ehresman DJ, Bjork JA, Froehlich JW, Lau C, Singh RJ, Wallace KB, Butenhoff JL: Thyroid hormone status and pituitary function in adult rats given oral doses of perfluorooctanesulfonate (PFOS). Toxicology 2008, 243:330-339.

286. Hanhijärvi $H$, Ophaug RH, Singer L: The sex-related difference in perfluorooctanoate excretion in the rat. Proc Soc Exp Biol Med 1982, 171:50-5.

287. Dean WP, Jessup AC: Acute oral toxicity (LD50) study in rats. International research and development corporation, Study 137-091 1978, US EPA AR2260419.

288. Li MH: Toxicity of perfluorooctane sulfonate and perfluorooctanoic acid to plants and aquatic invertebrates. Environ Toxicol 2009, 24:95-100.

289. Van Gossum H, Bots J, Snijkers T, Meyer J, Van Wassenbergh S, De Coen W, De Bruyn L: Behaviour of damselfly larvae (Enallagma cyathigerum) (Insecta, Odonata) after long-term exposure to PFOS. Environ Pollut 2009, 157:1332-1336.

290. Goldenthal El, Jessup DC, Geil RG, Mehring JS: Ninety-Day Subacute Rat Toxicity Study 137-085 International Research and Development Corporation; 1978.
291. Gortner EG: Oral Teratology Study of FC-95 in Rats. Riker Laboratories, Inc Experiment Number: 0680TR0008, December, 1980. AR-226 226-0016 US Environmental Protection Agency, Washington, DC, USA; 1980.

292. Wetzel LT: Rat teratology study, T-3351, final report. Hazelton Laboratories America, Inc. Project Number: 154-160, December 19, 1983. US EPA AR-226 226-0014 1983.

293. Case MT, York RG, Christian MS: Rat and rabbit oral developmental toxicology studies with two perfluorinated compounds. Int J Toxicol 2001, 20:101-109.

294. Yahia D, Tsukuba C, Yoshida M, Sato I, Tsuda S: Neonatal death of mice treated with perfluorooctane sulfonate. J Toxicol Sci 2008, 33:219-226.

295. White SS, Calafat AM, Kuklenyik Z, Villaneuva LT, Zehr RD, Helfant L, Strynar MJ, Lindstrom AB, Thibodeaux JR, Wood C, Fenton SE: Gestational PFOA exposure of mice is associated with altered mammary gland development in dams and female offspring. Toxicol Sci 2007, 96:133-144.

296. Zheng L, Dong GH, Jin YH, He QC: Immunotoxic changes associated with a 7-day oral exposure to perfluorooctanesulfonate (PFOS) in adult male C57BL/6 mice. Arch Toxicol 2009, 83:679-689.

297. Dong GH, Zhang YH, Zheng L, Liu W, Jin YH, He QC: Chronic effects of perfluorooctanesulfonate exposure on immunotoxicity in adult male C57BL/6 mice. Arch Toxicol 2009, 83:805-815.

298. Qazi MR, Xia Z, Bogdanska J, Chang SC, Ehresman DJ, Butenhoff JL, Nelson BD, DePierre JW, Abedi-Valugerdi M: The atrophy and changes in the cellular compositions of the thymus and spleen observed in mice subjected to short-term exposure to perfluorooctanesulfonate are highdose phenomena mediated in part by peroxisome proliferator-activated receptor-alpha (PPAR alpha). Toxicology 2009, 260:68-76.

299. Lefebvre DE, Curran I, Armstrong C, Coady L, Parenteau M, Liston V, Barker M, Aziz S, Rutherford K, Bellon-Gagnon P, Shenton J, Mehta R, Bondy G: Immunomodulatory effects of dietary potassium perfluorooctane sulfonate (PFOS) exposure in adult Sprague-Dawley rats. J Toxicol Environ Health A 2008, 71:1516-1525.

300. DeWitt JC, Copeland CB, Strynar MJ, Luebke RW: Perfluorooctanoic acidinduced immunomodulation in adult $\mathrm{C} 57 \mathrm{BL} / 6 \mathrm{~J}$ or $\mathrm{C} 57 \mathrm{BL} / 6 \mathrm{~N}$ female mice. Environ Health Perspect 2008, 116:644-650.

doi:10.1186/2190-4715-23-38

Cite this article as: Stahl et al:: Toxicology of perfluorinated compounds. Environmental Sciences Europe 2011 23:38.

\section{Submit your manuscript to a SpringerOpen ${ }^{\circ}$ journal and benefit from:}

- Convenient online submission

- Rigorous peer review

- Immediate publication on acceptance

- Open access: articles freely available online

- High visibility within the field

- Retaining the copyright to your article

Submit your next manuscript at $>$ springeropen.com 